\title{
Effects of Chronic Prenatal Adversities on the Adult Response to a Social Stressor
}

\author{
by
}

Angela Paric

A thesis submitted to the Faculty of Graduate and Postdoctoral Affairs in partial fulfillment of the requirements for the degree of

Master of Science

in

Neuroscience

Carleton University

Ottawa, Ontario

(C) 2014, Angela Paric 


\begin{abstract}
It was hypothesized that prenatal stressor effects persist into adulthood and would be particularly notable following re-exposure to an adult stressor. Pregnant mice were stressed for 12 days and adult offspring underwent a social stressor. Following the adult treatment, exploratory and social behaviour, and plasma corticosterone (CORT) levels were observed in addition to cytokine, corticotropin releasing hormone (CRH), and CRH receptor messenger RNA (mRNA) expression in the prefrontal cortex (PFC). Increased and decreased anxiety-like behaviour was observed in males and females, respectively. Also, elevated CORT was detected in prenatally stressed males and females while increased pro-inflammatory cytokines, $\mathrm{CRH}$, and $\mathrm{CRH}$ receptor 1 (CRHR1) in the PFC were mainly observed in prenatally stressed females. These findings suggest gender dimorphic effects of maternal stress on behaviour and PFC cytokine, CRH, and CRHR1 expression that may impair stress and emotional regulation in the offspring.
\end{abstract}




\section{Acknowledgements}

First and foremost, I would like to thank my supervisor Dr. Hymie Anisman. His trust, guidance, and patience have enabled me to progress through my degree and incorporate my own ideas and interests into my work. I would also like to thank Dr. Shlomit Jacobson-Pick for all her support, Dr. Marie-Claude Audet for helping me design my

research, Marzena Sieczkos for her assistance and encouragement, and Jerzy Kulczycki for his help. Furthermore, I am incredibly grateful to all my friends for their care and motivation, and especially to my family, for their love and support. 


\section{Table of Contents}

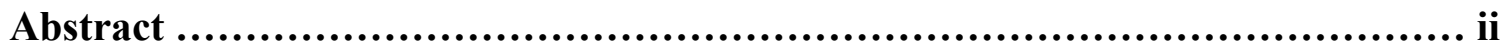

Acknowledgements ............................................................... iii

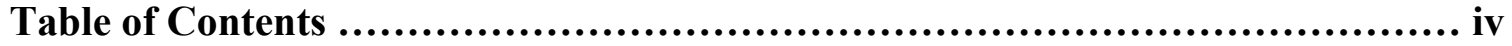

List of Figures ........................................................................ vi

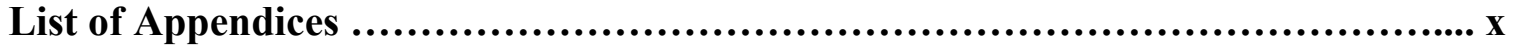

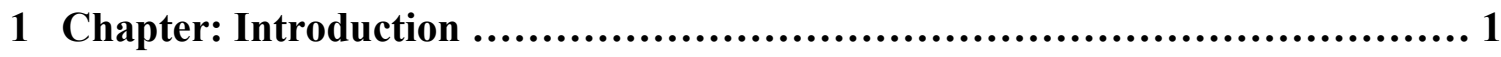

1.1 Impact of the maternal stress response on the fetus $\ldots \ldots \ldots \ldots \ldots \ldots \ldots \ldots . \ldots 2$

1.2 The effects of prenatal stress on immune functioning ..................... 5

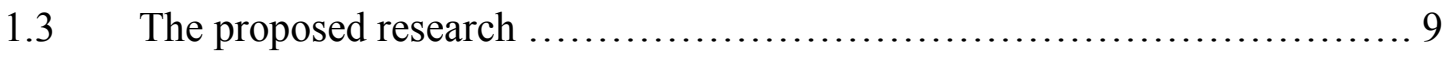

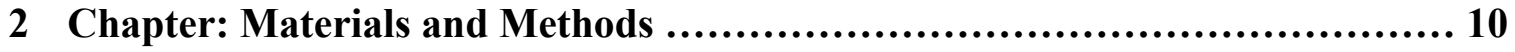

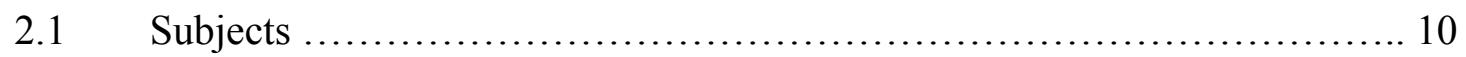

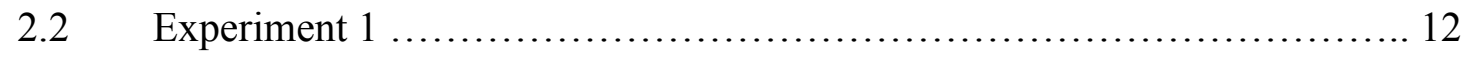

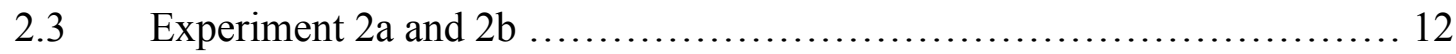

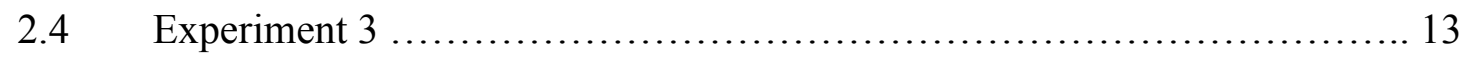

2.5 Blood Collection and Corticosterone Analysis ......................... 14

2.6 Brain Removal ................................................ 14

2.7 Reverse Transcription-Quantitative polymerase chain reaction analysis (RT-

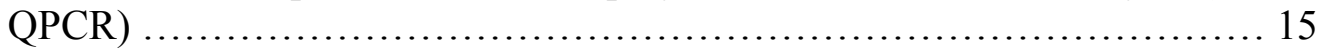

2.8 Data Analysis ................................................ 17

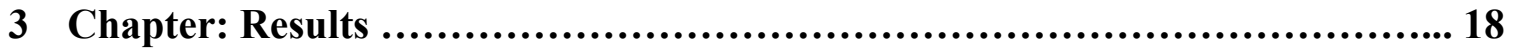

3.1 Experiment 1: Effects of prenatal and adult stress on behaviour - Elevated Plus Maze (EPM) and Social Avoidance .............................. 18 
3.2 Experiment 2a and 2b: Effects of prenatal and adult stress on plasma corticosterone levels

3.3 Experiment 2a and 2b: Effects of prenatal and adult stress on PFC mRNA expression of central $\mathrm{CRH}$, cytokines, and their receptors ................. 33

3.4 Experiment 3: Effects of prenatal and adult stress on behaviour - Social Interaction

4 Chapter: Discussion .............................................................. 55

4.1 Effects of prenatal and adult stress on behaviour ......................... 55

4.2 Effects of prenatal and adult stress on plasma corticosterone levels ......... 56

4.3 Effects of prenatal and adult stress on PFC mRNA expression of CRH and its receptors in the PFC ................................................. 57

4.4 Effects of prenatal and adult stress on PFC mRNA expression of cytokines

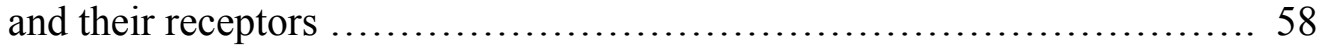

4.5 Differential effects of prenatal and adult stress on males and females ....... 60

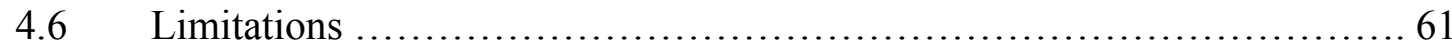

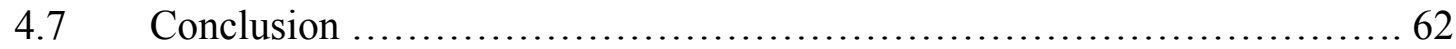

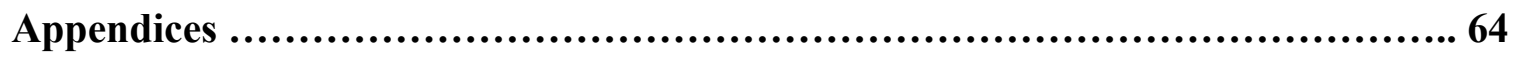

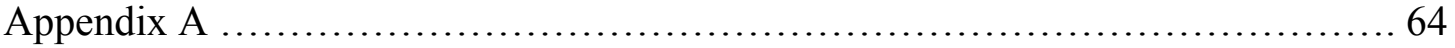

A.1 Expression of MIF and SOCS3 mRNA in the PFC ................... 64

A.2 Expression of serotonin receptor mRNA in the PFC .................. 66

A.3 Expression of BDNF and NTRK2 mRNA in the PFC ................ 70

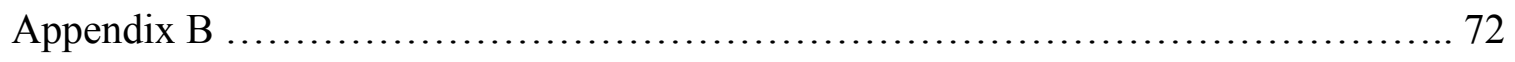

B.1 Experiment 3: Social Avoidance ................................ 72

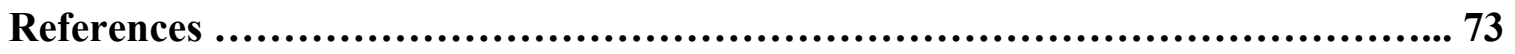




\section{List of Figures}

Figure 1. Latency to enter an open arm (seconds) of a plus-maze among male (A) and female (B) mice tested 30 minutes and 24 hours following a stressor or control treatment, and as a function of the prenatal stressor treatment. Data are represented as means \pm S.E.M. ${ }^{*} \mathrm{p}<.0005$ relative to non-prenatally stressed mice 30 minutes following a stressor or control treatment in adulthood. $* * p<.0005$ relative to prenatally stressed mice 24 hours following a stressor or control treatment in adulthood. $\# \mathrm{p}<.005$ relative to non-prenatally stressed mice.

Figure 2. Number of open arm entries in a plus-maze among male (A) and female (B) mice tested 30 minutes and 24 hours following a stressor or control treatment in adulthood, and as a function of the prenatal stressor treatment. Data are represented by means \pm S.E.M. $* \mathrm{p}<.005$ relative to prenatally stressed mice at $30 \mathrm{~min} .{ }^{* *} \mathrm{p}<.005$ relative to non-prenatally stressed mice 24 hours following a stressor or control treatment in adulthood. $\# \mathrm{p}<.05$ relative to non-prenatally stressed mice. $\# \# \mathrm{p}<.05$ relative to mice that are not stressed in adulthood.

Figure 3. Number of closed arm entries in a plus-maze among male (A) and female (B) mice tested $30 \mathrm{~min}$ and 24 hours following a stressor or control treatment in adulthood, and as a function of the prenatal stressor treatment. Data are represented by means \pm S.E.M. ${ }^{*} \mathrm{p}<.01$ relative to non-prenatally stressed mice.

Figure 4. Time spent in open arms (seconds) of a plus-maze among male (A) and female (B) mice tested 30 minutes and 24 hours following a stressor or control treatment in adulthood, and as a function of the prenatal stressor treatment. Data are represented by means \pm S.E.M. ${ }^{*} \mathrm{p}<.05$ relative to mice stressed on one occasion.

Figure 5. Time spent in closed arms (seconds) of a plus-maze among male (A) and female (B) tested 30 minutes and 24 hours following a stressor or control treatment in adulthood, and as a function of the prenatal stressor treatment. Data are represented by means \pm S.E.M.

Figure 6. Number of stretches into open arms of a plus-maze among male (A) and female (B) mice tested 30 minutes and 24 hours following a stressor or control treatment in adulthood, and as a function of the prenatal stressor treatment. Data are represented by means \pm S.E.M. $* \mathrm{p}<.05$ relative to controls.

Figure 7. Time spent in interaction zone (seconds) of a social avoidance test among male (A) and female (B) mice tested 30 minutes and 24 hours following a stressor or control treatment in adulthood, and as a function of the prenatal stressor treatment. Data are represented by means \pm S.E.M. $* * p<.0005$ relative to prenatally stressed mice 30 minutes following an adulthood stressor or control treatment. $* \mathrm{p}<.005$ relative to prenatally stressed mice during exposure to a stranger 30 minutes following an adulthood stressor or control treatment. $\# \mathrm{p}<.005$ relative to non-prenatally stressed mice during exposure to a stranger 24 hours following an adulthood stressor or control treatment. 
Figure 8. Plasma corticosterone concentrations ( $\mu \mathrm{g} / \mathrm{dl})$ in male $(\mathrm{A})$ and female $(\mathrm{B})$ mice as a function of the prenatal stressor treatment and 2 hours following the stressor or control treatment administered during adulthood. Data are represented by means \pm S.E.M. ${ }^{*} \mathrm{p}<.01$ relative to mice that were not stressed in adulthood. $\# \mathrm{p}<.05$ relative to non-prenatally stressed mice.

Figure 9. Plasma corticosterone concentrations ( $\mu \mathrm{g} / \mathrm{dl})$ in male $(\mathrm{A})$ and female $(\mathrm{B})$ mice as a function of the prenatal stressor treatment and 24 hours following the stressor or control treatment administered during adulthood. Data are represented by means \pm S.E.M. ${ }^{*} \mathrm{p}<.05$ relative to non-prenatally stressed mice.

Figure 10. Expression of CRH mRNA in the PFC of male (A) and female (B) mice as a function of the prenatal stressor treatment and 2 and 24 hours following the stressor or control treatment administered during adulthood. Data are represented by mean fold changes \pm S.E.M. $\# \mathrm{p}<.05$ relative to non-prenatally stressed mice. $\# \# \mathrm{p}<.05$ relative to mice that were not stressed in adulthood. $* \mathrm{p}<.05$ relative to mice stressed on only one occasion. $* * \mathrm{p}<.01$ relative to mice that were not stressed in adulthood.

Figure 11. Expression of CRHR1 mRNA in the PFC of male (A) and female (B) mice as a function of the prenatal stressor treatment and 2 and 24 hours following the stressor or control treatment administered during adulthood. Data are represented by mean fold changes \pm S.E.M. $* \mathrm{p}<.05$ relative to non-prenatally stressed mice.

Figure 12. Expression of CRHR2 mRNA in the PFC of male (A) and female (B) mice as a function of the prenatal stressor treatment and 2 and 24 hours following the stressor or control treatment administered during adulthood. Data are represented by mean fold changes \pm S.E.M.

Figure 13. Expression of IL-1 $\beta$ mRNA in the PFC of male (A) and female (B) mice as a function of the prenatal stressor treatment and 2 and 24 hours following the stressor or control treatment administered during adulthood. Data are represented by mean fold changes \pm S.E.M. $* \mathrm{p}<.05$ relative to non-prenatally stressed mice.

Figure 14. Expression of IL-1R1 mRNA in the PFC of male (A) and female (B) mice as a function of the prenatal stressor treatment and 2 and 24 hours following the stressor or control treatment administered during adulthood. Data are represented by mean fold changes \pm S.E.M. ${ }^{*} p<.005$ relative to non-prenatally stressed mice.

Figure 15. Expression of IL-6 mRNA in the PFC of male (A) and female (B) mice as a function of the prenatal stressor treatment and 2 and 24 hours following the stressor or control treatment administered during adulthood. Data are represented by mean fold changes \pm S.E.M. ${ }^{*} \mathrm{p}<.05$ and $\# \mathrm{p}<.05$ relative to mice that were not stressed in adulthood. 
Figure 16. Expression of IL-6R mRNA in the PFC of male (A) and female (B) mice as a function of the prenatal stressor treatment and 2 and 24 hours following the stressor or control treatment administered during adulthood. Data are represented by mean fold changes \pm S.E.M.

Figure 17. Expression of IL-10 mRNA in the PFC of male (A) and female (B) mice as a function of the prenatal stressor treatment and 2 and 24 hours following the stressor or control treatment administered during adulthood. Data are represented by mean fold changes \pm S.E.M.

Figure 18. Expression of TNF- $\alpha$ mRNA in the PFC of male (A) and female (B) mice as a function of the prenatal stressor treatment and 2 and 24 hours following the stressor or control treatment administered during adulthood. Data are represented by mean fold changes \pm S.E.M.

Figure 19. Expression of TNFR mRNA in the PFC of male (A) and female (B) mice as a function of the prenatal stressor treatment and 2 and 24 hours following the stressor or control treatment administered during adulthood. Data are represented by mean fold changes \pm S.E.M.

Figure 20. The latency to enter the novel mouse chamber (seconds) of a social interaction test among male (A) and female (B) mice tested 30 minutes and 24 hours following a stressor or control treatment in adulthood, and as a function of the prenatal stressor treatment. Data are represented by means \pm S.E.M. ${ }^{*} \mathrm{p}<.05$ relative to mice tested 30 minutes following a stressor in adulthood.

Figure 21. The number of entries to the novel mouse chamber in a social interaction test among male (A) and female (B) mice tested 30 minutes and 24 hours following a stressor or control treatment in adulthood, and as a function of the prenatal stressor treatment. Data are represented by means \pm S.E.M. ${ }^{*} \mathrm{p}<.005$ relative to non-prenatally stressed mice.

Figure 22. The number of entries to the novel object chamber of a social interaction test among male (A) and female (B) mice tested 30 minutes and 24 hours following a stressor or control treatment in adulthood, and as a function of the prenatal stressor treatment. Data are represented by means \pm S.E.M. ${ }^{* *} \mathrm{p}<.005$ relative to non-prenatally stressed mice. $* \mathrm{p}<.05$ relative to mice that were stressed in adulthood.

Figure 23. The time spent in the novel mouse chamber (seconds) of a social interaction test among male (A) and female (B) mice tested 30 minutes and 24 hours following a stressor or control treatment in adulthood, and as a function of the prenatal stressor treatment. Data are represented by means \pm S.E.M. $* \mathrm{p}<.05$ relative to mice that were prenatally stressed. 
Figure 24. The time spent in the novel object chamber (seconds) of a social interaction test among male (A) and female (B) mice tested 30 minutes and 24 hours following a stressor or control treatment in adulthood, and as a function of the prenatal stressor treatment. Data are represented by means \pm S.E.M. 


\section{List of Appendices}

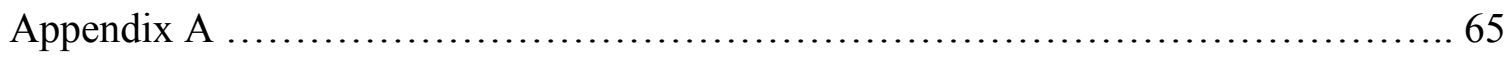

A.1 Expression of MIF and SOCS3 mRNA in the PFC ….................... 65

A.2 Expression of serotonin receptor mRNA in the PFC ....................... 67

A.3 Expression of BDNF and NTRK2 mRNA in the PFC .................... 71

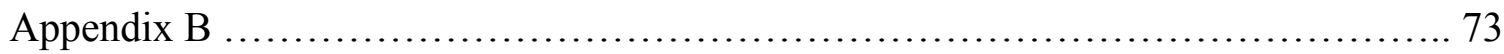

B.1 Experiment 3: Social Avoidance …................................... 73 


\section{Chapter: Introduction}

Females who experience unfavorable environmental or psychological challenges during pregnancy risk significant alterations of the biochemical environment in which their fetus develops, thereby affecting fetal programming (Lau et al., 2011). The extent to which stressors affect the fetus are dependent on a mother's stressor perceptions, which may be influenced by genetic dispositional and experiential factors, particularly those that favour the appearance of mood disorders (Knackstedt et al., 2005). In this regard, maternal stress responses influence fetal programming both directly through alterations in fetal gene expression, as might occur through epigenetic changes, and indirectly, through changes in metabolic processes within the placenta, including modifications of several hormones, neurotransmitters, cytokines, and growth factors (Merlot et al., 2008). To an extent, these physiological modifications in the developing fetus may be seen as adaptations to the altered uterine environment. Yet, these variations might culminate in a variety of adverse psychological and physical outcomes (Talge et al., 2007). The processes by which these changes may result in disease manifestation is still uncertain, but given the wide array of biological changes that occur, a substantial number could act to increase illness.

Of the many effects that stem from prenatal stressors, it seems that vulnerability to disorders such as depression, illness, and anxiety are especially likely to develop in the offspring. One possible reason for this is that prenatal stressors alter basal levels of neurobiological processes in the offspring, or that these stressors influence neurobiological reactivity so that stressor experiences in later adulthood result in more pronounced and lasting variations of neurobiological processes. In the present 
investigation we assessed the influence of a chronic stressor regimen that spanned prenatal Days 5-16 on adult cortisol, brain cytokine, growth factor, and monoamine receptor expression in stress-sensitive brain regions. Increased stress reactivity, including the heightened hypothalamic-pituitary-adrenal (HPA) response, is often seen in patients with depression (Pariante \& Lightman, 2008) and this may be accompanied by an extended period for normalization of this system to occur (Burke et al., 2005). As well, we examined the influence of the pre- and postnatal stressors on anxiety reflected in a plus-maze test, as well social behaviors that have frequently been used as an index of anxiety and/or depressive-like behaviors (Grahn et al., 1995; Haller \& Bakos 2002; Kaidanovich-Beilin et al., 2011).

\subsection{Impact of the maternal stress response on the fetus}

Stressful events affect several neurochemical processes, but one that has been of particular attention in relation to prenatal stressors is the corticoid variations that occur. Activation of the paraventricular neurons within the hypothalamus during stress are accompanied by the release of corticotropin-releasing-hormone (CRH), which stimulates the anterior pituitary to release adrenocoticotropic hormone (ACTH), leading to stimulation of the adrenal cortex and the resulting release of cortisol (Munck et al., 1984). Cortisol has multiple beneficial effects that are necessary to deal with stressors, and in the pregnant woman, cortisol also stimulates the release of placental CRH (Davis \& Sandman, 2010).

In contrast to the negative feedback regulation of the HPA axis, whereby elevated cortisol levels stimulate hippocampal glucocorticoid receptors, which then causes the hypothalamus to cease $\mathrm{CRH}$ release, placental $\mathrm{CRH}$ has the effect of positively regulating 
this system in the placenta (King et al., 2001). Consequently, stress-induced elevations of maternal cortisol during pregnancy may further increase circulating levels of CRH, ACTH, and cortisol (Davis \& Sandman, 2010). This said, however, unanimity does not exist concerning the contribution of placental $\mathrm{CRH}$ on prenatal development, as it has been suggested that either $\mathrm{CRH}$ is not present in rodents or appears in negligible amounts (Sandman et al., 2011; Huang et al. 2011).

Normally, increases of fetal cortisol at specific times during pregnancy are necessary for fetal growth, organ maturation, and possibly ensuring appropriate timing of labour (Buss et al., 2012). However, excess cortisol may activate apoptotic pathways in offspring, resulting in growth restriction, changes in brain morphology, and increased sensitivity to stressors later in life (Xiong \& Zhang, 2013; McTernan et al., 2001; Fujioka et al., 2006).

The binding of cortisol to its receptors is, in part, determined by the receptor affinity for glucocorticoids (GC). Mineralcorticoid receptors (MR) have a greater affinity for cortisol than do glucocorticoid receptors (GR) (Fujioka et al., 2006; Diaz et al., 1998), and the latter are activated only when levels of cortisol are sufficiently high. Although this might have adaptive effects in the organism at various phases of life, in the developing fetus such changes may have a detrimental effect. In particular, glucocorticoid receptor signaling pathways influence apoptosis through caspase enzymes and p53, two proteins involved in programmed cell death (Van den Hove et al., 2006). Ordinarily, in the fetal brain, these pathways aid in tissue remodeling during rapid periods of growth (Madden \& Cotter, 2008), but in the presence of excessive glucocorticoid levels apoptosis may become excessive. In effect, although stressor- 
induced cortisol release is ordinarily diminished in female rodents and humans (Gangestad et al., 2012), if the stressor is sufficiently great the corticosterone or cortisol release that does occur may enter the fetal circulation via the placenta and inappropriately activate apoptotic pathways in the developing brain, culminating in a reduction of fetal brain volume (Fujioka et al., 2006).

In prenatally stressed male and female rats, decreased cell proliferation and increased caspase-3 activity was detected in the hippocampus 1-5 days after birth (Van den Hove et al., 2006). Similarly, changes were also seen in the hippocampus of rhesus monkeys as a result of early and late prenatal stress. Indeed, at the age of 2-3 years, monkeys displayed reduced hippocampal volume and inhibition of neurogenesis in the dentate gyrus as a result of the prenatal stressor (Coe et al., 2002). These findings were correlated with heightened HPA activity as well as increased emotionality (Coe et al., 2002). As communication also occurs between neurons in the hippocampus and both the amygdala and the prefrontal cortex (PFC), stress effects within the hippocampus might also be reflected in other regions (Shin et al., 2006). For example, male offspring of prenatally stressed rats displayed increased levels of CRH in amygdala extracts at the age of 8-16 weeks. Considering that the amygdala is receptive to GC and CRH beginning at mid-gestation, increases of either of these factors might permanently alter neuronal activity in this region (Cratty et al., 1995).

These studies, together with others showing changes in brain morphology and chemistry as a result of prenatal stress, have made it clear that GC mediate some of the effects of prenatal stressors on fetal brain development and future HPA activity in the offspring. Ordinarily, protective mechanisms exist against increased GC during 


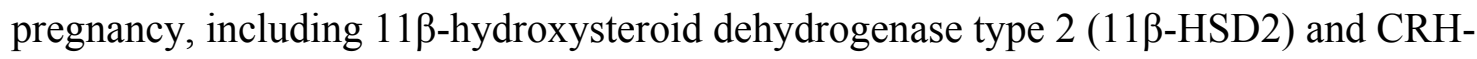
binding protein (CRH-BP), both of which are produced by fetoplacental tissues. Cortisol is converted to its inactive form cortisone by $11 \beta$-HSD2, while CBP's bind CRH which halts continuous activation of the HPA axis (McTernan et al., 2001; Karteris et al., 2001). These processes, however, are disrupted in response to chronic prenatal stress, impeding the placenta's ability to protect the fetus from excessive cortisol, and placing the offspring at risk of altered brain pathology and increased sensitivity to stress later in life (McTernan et al., 2001).

\subsection{The effects of prenatal stress on immune functioning}

Stressful events not only influence HPA activity and GR signaling, but also affect cytokines that serve as signaling molecules of the immune system. These actions are evident with respect to circulating cytokines that are produced by macrophages, $\mathrm{T}$ and $\mathrm{B}$ cells, as well as by microglia within the brain. They function as growth factors in the periphery and within the brain they may act to facilitate repair of microdamage that can occur. In addition to regulating immune responses, brain cytokines may alter neurochemical levels just as stressors may act in this capacity, and it has been suggested that cytokine variations may be interpreted much like stressors are. The dynamic relationship that exists between immune and stress responses may contribute to the development of depressive-like symptoms (Anisman \& Merali, 2002).

Ordinarily, the blood-brain barrier (BBB) restricts most cytokines from entering the brain. However the integrity of the BBB may be comprised by stressors, thereby increasing susceptibility to cytokine-induced changes in neurotransmitters involved with mood regulation (Watkins et al., 1995; Najjar et al. 2013; Anisman \& Merali, 2002). 
During fetal development, aspects of a BBB are present very early in gestation, however, modifications to the BBB occur throughout development that, depending on the timing and species in question, may render the fetus particularly vulnerable to maternal cytokine fluctuations (Saunders et al., 1999; Dammann \& Leviton, 1997).

Changes to the maternal immune system are necessary during pregnancy in order to accommodate and protect the fetus. Periods of both inflammation and immune suppression occur at different times throughout gestation (Mor \& Cardenas, 2010). As such, the timing of exposure to prenatal stressors determines the changes to fetal immunological programming and subsequent susceptibility to disease. These changes are also species-dependent given that the duration and progression of pregnancy varies between species (Merlot et al., 2008). The immune systems of precocious offspring (guinea pigs) largely develop in utero, although immune functioning is not complete at this time. In contrast, within altricial offspring (mice, rats) immune functioning develops during late gestational and postnatal development (Holladay \& Smialowicz, 2000; Merlot et al., 2008). Regardless of the species, a stressful pregnancy is detrimental to immune activity in offspring in the sense that it reduces the inflammatory response to pathogens, rendering the offspring more susceptible to disease.

A balance of cytokines regulates immune activity and fetal maturation during pregnancy. These pro-inflammatory cytokines are released from microglia within the fetal brain at different times of gestation even in the absence of a pathogenic threat, likely contributing to neural proliferation, differentiation, and myelinization, as well as synaptic maturation within the developing fetal brain (Deverman \& Patterson, 2009; Zubareva \& Klimenko, 2013). It is also thought that tumor necrosis factor alpha (TNF- $\alpha$ ), a pro- 
inflammatory cytokine expressed in fetoplacental tissues, regulates cell proliferation and embryonic modeling. This cytokine may contribute to pregnancy loss in response to prenatal stressors and infections through the activation of apoptotic pathways. These actions of TNF- $\alpha$ may exist to eliminate the possibility of the fetus developing structural abnormalities (Toder et al., 2003).

Pro-inflammatory cytokines ordinarily stimulate HPA activity and the subsequent release of cortisol, which causes the suppression of the continued production of proinflammatory cytokines, thus precluding excessive immune activation (Corwin et al., 2013). An imbalance between pro- and anti-inflammatory cytokines in the developing fetus may lead to abnormal brain and behavioural development (Meyer et al., 2009). In the absence of infection during pregnancy, stressors may reduce cytokine levels and dampen their activity in the developing brain. This outcome may come about owing to the effects of GC suppression of fetal cytokines, or through the passage of stress-induced cytokines from the mother to the fetus via the placenta (Marques et al., 2013). Furthermore, stressors experienced during pregnancy may induce GC resistance in the mother, which may lead to modifications in the amount and ratio of pro- and antiinflammatory cytokines entering the fetal circulation (Pace et al., 2007).

The cumulative effects of stress in utero contribute to the development of immunological changes that are evident postnatally. In this regard, greater reactivity and sensitivity of the HPA axis promotes particularly marked suppression of the inflammatory response in offspring of stressed mothers. In juvenile rhesus monkeys that were prenatally stressed, GC sensitivity and modified cytokine responses were observed following an in vitro challenge with lipopolysaccharide (LPS). Specifically, leukocytes of 
prenatally stressed offspring displayed significantly lower amounts of TNF- $\alpha$ and interleukin-6 (IL-6), another pro-inflammatory cytokine, in response to LPS than in controls. Additionally, the administration of a synthetic glucocorticoid, dexamethasone, inhibited the production of TNF- $\alpha$ and IL-6 in control animals subjected to LPS, ultimately producing a cell phenotype similar to that seen in prenatally stressed animals. These results support the hypothesis that prenatal stressors causes changes in offspring immune responses, and may do so through heightened HPA axis activity and GC suppression of cytokines (Coe et al., 2002).

Considerable support exists for the role of pro-inflammatory cytokines, notably TNF- $\alpha$, IL-6, and interleukin- $1 \beta$ (IL-1 $1 \beta$ ), as key moderators of the effects of prenatal stressors on the developing fetal immune system. As well, the anti-inflammatory cytokine interleukin-10 (IL-10), which is also produced in brain, may act against excessive proinflammatory cytokine activity, particularly in the presence of disease, thus serving in an important protective capacity (Strle et al., 2001). Additionally, when levels of IL-10 are diminished, this cytokine might contribute to the provocation of depression (Anisman et al., 2008). Specifically, IL-10 knockout mice displayed depressive-like behaviour in the forced-swim test, which could be attenuated by treatment with IL-10. As well, mice that overexpressed the cytokine showed decreased depressive-like behaviour (Mesquita et al., 2008). Stressors and immune challenges may synergistically affect IL-10 within blood, and IL-10 mRNA expression in brain of adult mice, but it is uncertain whether these interactions are also apparent in utero. 


\subsection{The proposed research}

The aim of this study is to assess the effects of a chronic prenatal stressor on the offspring's response to an acute social stressor in adulthood. Behaviour, plasma corticosterone, and mRNA expression of $\mathrm{CRH}$, cytokines, and their respective receptors will be examined in mice at two different time points following the social stressor. A chronic, unpredictable stressor regimen will be applied during the prenatal period. This 12-day regimen will begin on the fifth day and end on the $16^{\text {th }}$ day of gestation. These dates were selected to allow adequate time for the female to rest in order to avoid early termination of the pregnancy or cannibalism of pups (Wang \& Dey, 2006; DeSantis \& Schmaltz, 1984).

To the best of our knowledge, there appear to be no studies that have examined the effects of prenatal stress on the offspring's response to a social stressor, over a 24-hr period. Given the potential impact of social adversities on psychological well-being (Chaouloff, 2013), it was of interest to determine whether prenatal stressors influence the impact of later social disturbances on the provocation of behavioral and biochemical changes that might reflect depression (Björkqvist, 2001). In addition to evaluating the immediate effects of the adult stressor, in the present investigation we assessed whether any effects that had been provoked by the treatments had normalized on the following day. It was hypothesized that a social stressor experienced in adulthood would induce a greater and more prolonged behavioural response in prenatally stressed mice than in controls. As well, it was expected that a social stressor would increase basal and stressorinduced corticosterone in prenatally-stressed mice as well as changes in brain CRH, cytokines, and their receptors. 


\section{Chapter: Materials and Methods}

\subsection{Subjects}

Naïve male and female CD-1 mice were obtained from Charles River (St.

Constance, Quebec) at 4-6 weeks of age and were allowed to acclimatize to laboratory settings for approximately one week prior to the start of the experiment. For experiments 1,2 , and 3, animals were house in standard $(27 \times 21 \times 14 \mathrm{~cm})$ polypropylene cages, and in Experiment 4, animals were housed individually in ventilated $\left(31 \times 15 \times 14 \mathrm{~cm}^{3}\right)$ polysulfone cages (Sealsafe Next IVC Blue Line, Tecniplast). Males were housed individually while females were housed in groups of 4-5. All mice were maintained on a 12-hr light cycle, from 8:00 AM to 8:00 PM, in a temperature $\left(22-23^{\circ} \mathrm{C}\right)$ controlled room with food (standard mouse chow, Teklad 2014) and water available ad libitum. The study complied with the guidelines set by the Canadian Council on Animal Care and were approved by the Carleton University Animal Care Committee.

One female was placed with each male and placed in a new cage after identification of a vaginal plug. A plug signified Day 1 of gestation (G1). Beginning on G5, half of the pregnant mice were stressed for 12 days, whereas the remaining mice served as non-stressed controls. The stressors were applied on successive days: tail pinch, warn air stress, wet bedding, continuous light, cage tilt, and foreign bedding. Tail pinch was applied twice a day. A piece of gauze was placed at the base of the tail and secured with a foldback binder clip for 5-min. For warm air stress, a hair dryer was used to deliver warm air, manually held by the experimenter so that it was pointed at the mouse irrespective of where it was within the cage. This was done twice a day for 2-min on each occasion. For wet bedding, $200 \mathrm{~mL}$ of water was added to a pregnant dam's cage and left 
to soak for 2-hrs, after which the mouse was placed in a new cage. Continuous light involved the placement of a pregnant dam in a room with the lights on overnight. A cage tilt was applied for 2-hrs during which the cage rested at a $45^{\circ}$ angle. Foreign bedding included the addition of rat feces to a cage for 15-min, twice a day. Mice were placed in a new cage following this 15-min period. The stressors, administered between 8:30 and 13:30 hours each day, were repeated in the same order over a total of 12 days ending on G16.

Following birth, full litters remained with the dam until postnatal day (PD)-21, after which males and females were housed separately in groups of 2-4. In adulthood, beginning at about 67 days of age ( \pm 4 days), mice were subjected to social defeat. This stressor involved the placement of the experimental mice with a bully for a maximum of 15-min. For males, the bully used was a retired breeder obtained from Charles River. The experimental mouse was placed in the bully's cage and both mice were allowed to interact until fighting began, at which point the mice were divided by a wire mesh and left together for the remainder of the 15-min. For females, the aggressor was a lactating dam. Prior to the stressor, pups were placed into a novel cage next to the dam. The experimental mouse was then placed in the dams cage and allowed to interact for 15-min. Typically, the nursing dam only displayed aggressive gestures, but in the instance of a fight, the females were separated by a wire mesh. For both males and females, the timing of defeat and separation were recorded behaviours such as grooming. This procedure was used in each of the experiments. 


\subsection{Experiment 1}

Between the ages of 65-70 days, 32 male and 32 female mice from control and stressed litters were housed individually, transferred to a stress room, and allowed to acclimate for one hour. Thereafter, 16 male and 16 female mice underwent social defeat, whereas the remaining 32 mice served as controls. Behavioural testing occurred 30-min and 24-hr after the stressor, between 8:30am and 14:00 hours. The elevated plus maze (EPM) was used followed by the social avoidance test at both time points.

The EPM was composed of four arms measuring $24.8 \mathrm{~cm} \times 7.7 \mathrm{~cm}$, two of which are enclosed by $21 \mathrm{~cm}$ high walls. During the test, several factors were recorded over a period of five minutes: latency to enter an open arm, entries to open and closed arms, time in open and closed arms, and number of stretches into an open arm. The social avoidance test was an open field box measuring $(50 \mathrm{~cm} \times 50 \mathrm{~cm})$. A wire cage $(10 \mathrm{~cm} \mathrm{x}$ $11 \mathrm{~cm})$, used to house the novel mouse, was placed at one side of the box. Using masking tape, an interaction zone ( $8 \mathrm{~cm}$ from each side of the cage) was marked around the wire cage. At the start of the test, the experimental mouse was allowed to acclimate to the open field for 2.5-min and was then removed to its cage for a minute. During this time a novel mouse, of the same age and sex as the experimental mouse, was placed in the wire cage. The experimental mouse was reintroduced to the open field for an additional 2.5min. The time spent in the interaction zone with and without the novel mouse was recorded. Both apparatus' were cleaned with 75\% ethanol between animals.

\subsection{Experiment 2a and $2 b$}

Between the ages of 64 and 66, 32 male and 32 female mice from control and stressed litters were housed individually, transferred to a stress room, and allowed to 
acclimate overnight. Following this acclimation period, 16 male and 16 female mice underwent social defeat as described earlier. Twenty-four hours after the stressor, the mice were decapitated. Trunk blood was collected for corticosterone and cytokine analysis. The brain was also removed to determine mRNA levels of $\mathrm{CRH}$, cytokines, BDNF, and their receptors, as well as 5-HT receptors. Experiment $2 \mathrm{~b}$ followed the same procedure however animals were between the ages of 69-71 and were decapitated 2-hrs after the stressor.

\subsection{Experiment 3}

Between the ages of 66-71 days, 48 male and 48 female mice from control and stressed litters were housed individually, transferred to a stress room, and allowed to acclimate for one hour. Following this acclimation period, 24 male and 24 female mice underwent social defeat. The other 48 mice served as controls. Behavioural testing occurred 30-min and 24-hr after the stressor, between 8:30am and 14:30 hours. Social avoidance was used followed by a modified version of the Crawley Interaction Test (social interaction).

A three-chamber apparatus was made of acrylic plastic $(50 \times 61 \times 24 \mathrm{~cm})$, with each chamber measuring $20 \mathrm{~cm} \times 49 \mathrm{~cm}$. A $24 \mathrm{~cm} \times 10 \mathrm{~cm}$ hole in the two innermost plastic pieces allowed passage between the three chambers. The two outermost chambers contained a cage housing either a novel mouse or object. These cages were made-up of fencing wire. Separate cages were used for each novel mouse (male and female) as well as for the novel objects (one object for males, another for females) to avoid contamination with an animal scent. During testing, the location of the novel mouse alternated between test subjects to eliminate the effect of side preference. The novel mice 
were allowed to acclimate to the apparatus for three days prior to testing, for 15-min each day.

Test subjects were allowed 5-min to acclimate to the apparatus which contained the appropriate, but empty, mouse and object cages. At the end of this period the mouse was guided to the center chamber but entry to the adjacent areas was prevented for a 1min period, after which access to the adjacent areas, now containing the novel mouse or object, was permitted. The mouse was then allowed to explore the apparatus for 10-min during which time several measures were recorded: latency to enter novel mouse chamber, entries into the novel mouse and object chambers, and time spent with the novel mouse and object. Both the social avoidance and interaction apparatus' were cleaned with $75 \%$ ethanol between animals.

\subsection{Blood Collection and Corticosterone Analysis}

Mice were killed by decapitation and trunk blood was collected, centrifuged for 8 min at $3500 \mathrm{~g}$, and plasma stored - at $80^{\circ} \mathrm{C}$ until assayed. A commercial radioimmunoassay RIA kit (MP Biomedicals) was used to determine corticosterone levels. For each experiment, assays were performed in a single run to avoid inter-assay variability. Intra-assay variability was less than $10 \%$.

\subsection{Brain Removal}

Following decapitation, brains were removed and placed on a stainless steel dissection block, resting on dry ice, with slots spaced approximately $.5 \mathrm{~mm}$ apart. Guided by the slots, razor blades were used to provide coronal brain sections. The amygdala, hippocampus, and PFC were collected following the mouse atlas of Franklin and Paxinos 
(1997). The tissue was stored at $-80^{\circ} \mathrm{C}$ for subsequent analysis of $\mathrm{CRH}$, cytokines, BDNF, and their receptors, as well as 5-HT receptor mRNA levels.

\subsection{Reverse Transcription-Quantitative polymerase chain reaction analysis (RT- QPCR)}

Brain RNA was extracted and purified by standard methodologies using Trizol according to the manufacturer's protocol (Invitrogen; Burlington, ON, Canada). The total RNA was reverse transcribed using Superscript II reverse transcriptase (Invitrogen; Burlington, ON, Canada). Aliquots of this reaction were used in simultaneous quantitative polymerase chain reactions (qPCR).

A Bio-Rad MyiQ2 real time thermocycler was employed to collect the data. For qPCR, the SYBR green detection was used according to the manufacturer's protocol (Bio-Rad, CA, USA). Each of the PCR primer pairs generated amplicons between 120 and 200 base pairs. Amplicon identity was checked by restriction analysis. The primer efficiency was determined from the slope relation between absolute copy number of RNA quantity and the cycle threshold $\left(\mathrm{C}_{\mathrm{t}}\right)$ using the Bio-Rad IQ5 version 2.0 software (BioRad, CA, USA). All primer pairs had a minimum of $90 \%$ efficiency. Primers that amplify Glyceraldehyde-3-phosphate dehydrogenase (GAPDH) and synaptophysin mRNA were used as a control to normalize the data. The expression of each species was normalized by subtracting the averaged $\mathrm{C}_{\mathrm{t}}$ of GAPDH and synaptophysin, from the gene of interest $\mathrm{C}_{\mathrm{t}}\left(\Delta \mathrm{C}_{\mathrm{t}}\right)$. Following the procedure described by Livak \& Schmittgen, 2001, normalized brain mRNA expression values were converted to fold changes relative to controls. Primer sequences used for qPCR were as follows: Mus GAPDH, forward: GGT CGG TGT GAA CGG ATT TG, reverse: TGC CGT TGG AGT CAT ACT G. Synaptophysin, 
forward: GGA CGT GGT GAA TCA GCT GG, reverse: GGC GAA GAT GGC AAA GAC C. Mus IL-1 $\beta$, forward: TGT CTG AAG CAG CTA TGG CAA C, reverse: CTG CCT GAA GCT CTT GTT GAT G. Mus IL-1R1, forward: ATG AGT TAC CCG AGG TCC AGT G, reverse: TAC TCG TGT GAC CGG ATA TTG C. Mus TNF- $\alpha$, forward: GTA GCC CAC GTC GTA GCA AA, reverse: GCT GGC ACC ACT AGT TGG TT. Mus TNFR, forward: CAG AAC ACC GTG TGT AAC TGC C, reverse: GGG TTT GTG ACA TTT GCA AGC. Mus IL-6, forward: ACG GCC TTC CCT ACT TCA CA, reverse: TGC CAT TGC ACA ACT CTT TTC TC. Mus IL-6R, forward: CTC TCC AAC CAC GAA GGC TG, reverse: TGC AAC GCA CAG TGA CAC TAT G. Mus IL-10, forward: AGGCGCTGTCATCGATTTCTC, reverse:

CATGGCCTTGTAGACACCTTGG. SOCS3, forward: GCG GGC ACC TTT CTT ATC C, reverse: TCC CCG ACT GGG TCT TGA C. Mus HTR1A, forward: CAT GGG CAC CTT CAT CC, reverse: TTG AGC AGG GAG TTG GAG TAG C. Mus HTR1B, forward: GTC AAA GTG CGA GTC TCA GAC G, reverse: ACA GAT AGG CAT CAC CAG GGA G. Mus HTR2A, forward: TGC CAC CAA CTA TTT CCT GAT G, reverse: ACA TCC AGG TAA ATC CAG ACG G. Mus HTR2C, forward: CGA GTC CGT TTC TCG TCT AGC, reverse: TAG GTG ACA ACC CAC TAG CGT C. Mus CRH, forward: CAA GGG AGG AGA AGA GAG, reverse: AGC GGG ACT TCT GTT GAG. Mus CRHR1, forward: GTG GAC CTC ATT GGC ACC TG, reverse: ATT GTT TGT GGT GTT GTA GCG G. Mus CRHR2, forward: CTG GGC AGT TGG CAA ACT CTA C, reverse: CAA CAG CAC AAG CAT GAC GG. Mus BDNF, forward: GTC TCC AGG ACA GCA AAG CCA C, reverse: CCT TGT CCG TGG ACG TTT ACT TC. Mus NTRK2, forward: CAA CCT GCG GCA CAT AAA TTT C, reverse: CAG GAG CAC 
GTG AAC GGA TTA C. Mus MIF, forward: AGA ACG GCA ACT ACA GTA AG, reverse: CAG CGT TCA TGT CGT AAT AG.

\subsection{Data Analysis}

For Experiment 1 and 4, EPM and social interaction test measurements were analyzed using a 2 (prenatally stressed vs non-prenatally stressed) x 2 (adult stress vs no adult stress) x 2 (30-min vs 24-hrs) between-groups analysis of variance (ANOVA) to determine statistical significance. For the social avoidance test, measurements were analyzed using a 2 (prenatally stressed vs non-prenatally stressed) x 2 (adult stress vs no adult stress) x 2 (30-min vs 24-hrs) x 2 (no stranger vs stranger) ANOVA. Follow-up tests for significant interactions were conducted using Bonferonni corrected t tests.

For Experiment 2 and 3, plasma corticosterone and fold changes for the mRNA expression of various factors in the PFC were analyzed using a 2 (prenatally stressed vs non-prenatally stressed) x 2 (adult stress vs no adult stress) ANOVA to determine statistical significance. Follow-up comparisons of the means of significant interactions were again performed using t tests with a Bonferroni correction to maintain the $\alpha$ level at .05. Several samples were lost during both behavioural studies, thus the degrees of freedom differed across the outcome measures. All tests were performed with SPSS version 20.0 (SPSS inc., Chicago, IL, USA). 


\section{Chapter: Results}

\subsection{Experiment 1: Effects of prenatal and adult stress on behaviour - EPM and}

\section{Social Avoidance}

Repeated measures ANOVA of the latency to enter an open arm by male mice (Figure 1A) revealed a significant Prenatal Stress $\mathrm{x}$ Time interaction, $\mathrm{F}_{(1,24)}=17.16, \mathrm{p}<$ .0004 . Follow-up comparisons of the simple effects of this interaction indicated that significantly longer latencies to enter an open arm occurred in prenatally stressed than non-prenatally stressed mice 30 minutes following a social stressor or control treatment. This effect was reversed 24 hours later when prenatally stressed mice displayed shorter latencies than those that were not prenatally stressed. In contrast, among prenatally stressed female mice shorter latencies to enter an open arm were observed relative to that evident in non-prenatally stressed female mice, $\mathrm{F}_{(1,24)}=9.95, \mathrm{p}<.005$ (Figure 1B). However, the latency to enter an open arm was not affected by the adult stressor treatment in either male or female mice. 
A

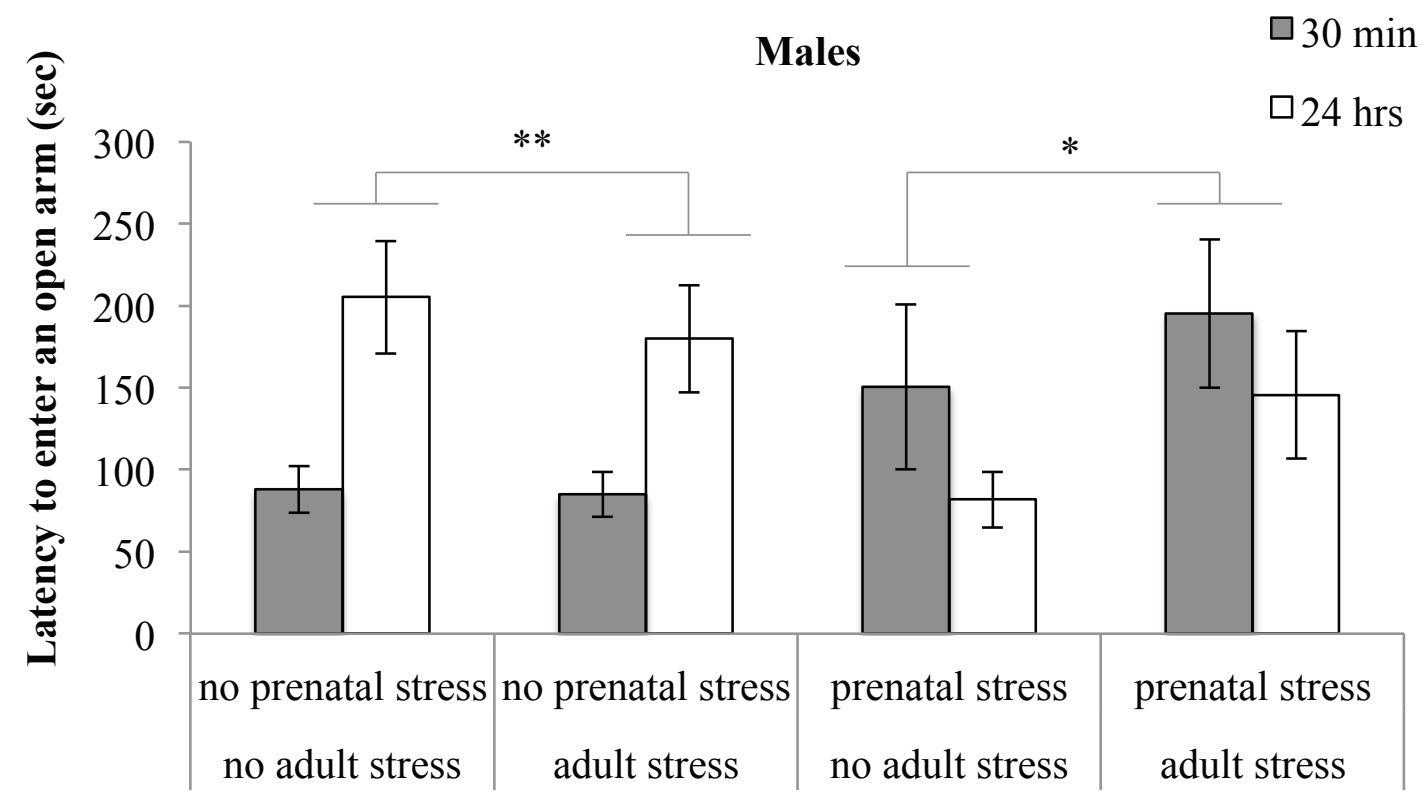

Group

B

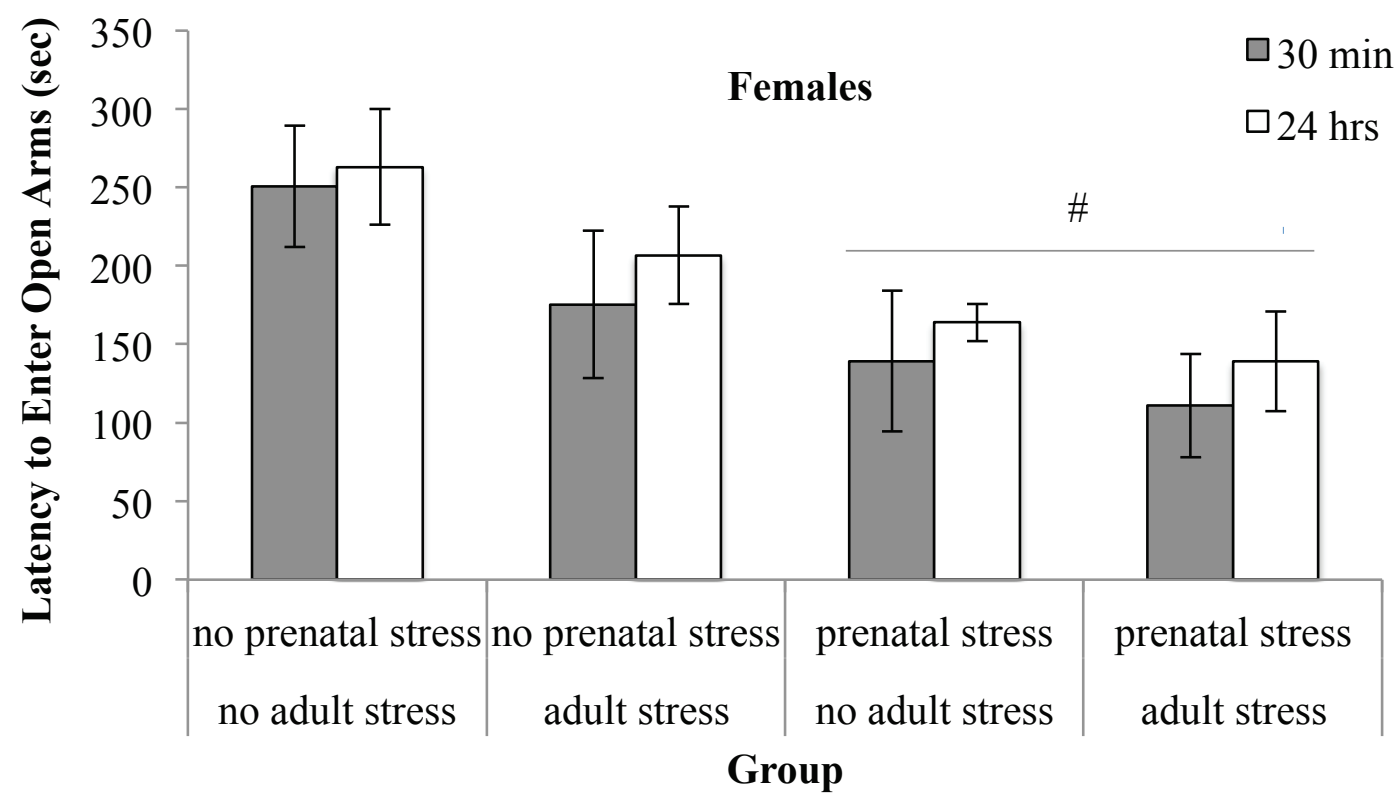

Figure 1. Latency to enter an open arm (seconds) of a plus-maze among male (A) and female (B) mice tested 30 minutes and 24 hours following a stressor or control treatment, and as a function of the prenatal stressor treatment. Data are represented as means \pm S.E.M. ${ }^{*} \mathrm{p}<.0005$ relative to non-prenatally stressed mice 30 minutes following a stressor or control treatment in adulthood. $* * \mathrm{p}<.0005$ relative to prenatally stressed mice 24 hours following a stressor or control treatment in adulthood. $\# \mathrm{p}<.005$ relative to non-prenatally stressed mice. 
Analysis of the number of open arm entries revealed a significant Prenatal Stressor $\mathrm{x}$ Time interaction, $\mathrm{F}_{(1,24)}=10.33, \mathrm{p}<.005$ in male mice (Figure $2 \mathrm{~A}$ ). The follow-up comparisons confirmed that 30 minutes following the adult stressor or control treatment, prenatally stressed male mice made fewer open arm entries than those that were not prenatally stressed. However, when mice were retested 24 hours later, prenatally stressed mice made more open arm entries than did non-prenatally stressed mice. In contrast to the findings in males, prenatally stressed female mice as well as those stressed in adulthood displayed a significantly greater number of open arm entries than did mice that were not stressed, F's ${ }_{(1,24)}=5.02,4.28 \mathrm{p}<.05$, respectively (Figure $2 \mathrm{~B}$ ).

The number of closed arm entries was greater in prenatally stressed than nonprenatally stressed male mice, $\mathrm{F}_{(1,24)}=8.32, \mathrm{p}<.01$ (Figure $3 \mathrm{~A}$ ). Additionally males made fewer closed arm entries 24 hours after the adult stressor than at 30 minutes, $\mathrm{F}_{(1,24)}$ $=10.92, \mathrm{p}<.003$. In contrast, as seen in Figure 3B, among females, the number of closed arm entries were unaffected by the stressor treatments and did not vary as a function of the time of testing. No significant effects were seen in females. 

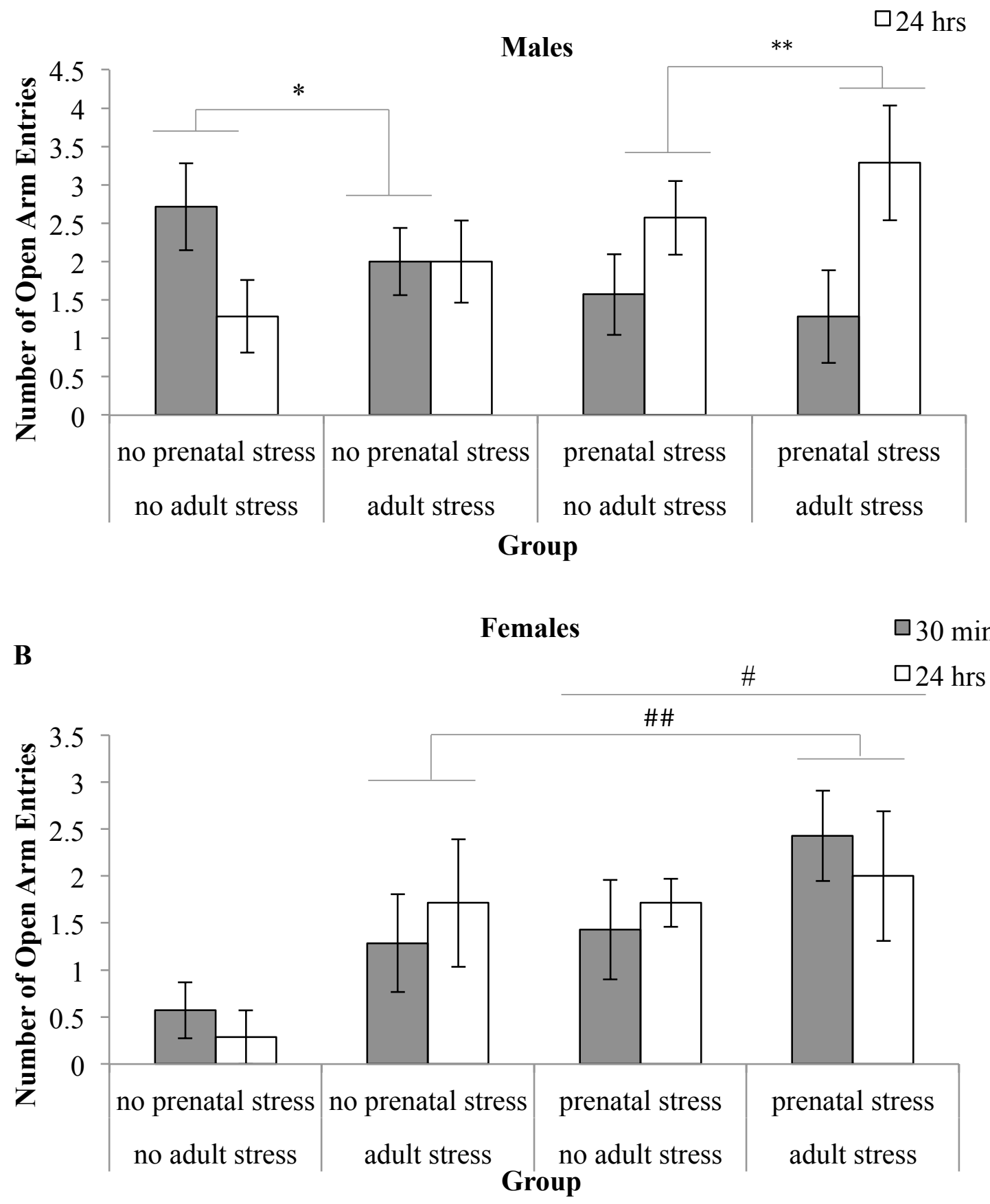

Figure 2. Number of open arm entries in a plus-maze among male (A) and female (B) mice tested 30 minutes and 24 hours following a stressor or control treatment in adulthood, and as a function of the prenatal stressor treatment. Data are represented by means \pm S.E.M. ${ }^{*} \mathrm{p}<.005$ relative to prenatally stressed mice at $30 \mathrm{~min} .{ }^{* *} \mathrm{p}<.005$ relative to non-prenatally stressed mice 24 hours following a stressor or control treatment in adulthood. $\# \mathrm{p}<.05$ relative to non-prenatally stressed mice. $\# \# \mathrm{p}<.05$ relative to mice that are not stressed in adulthood. 


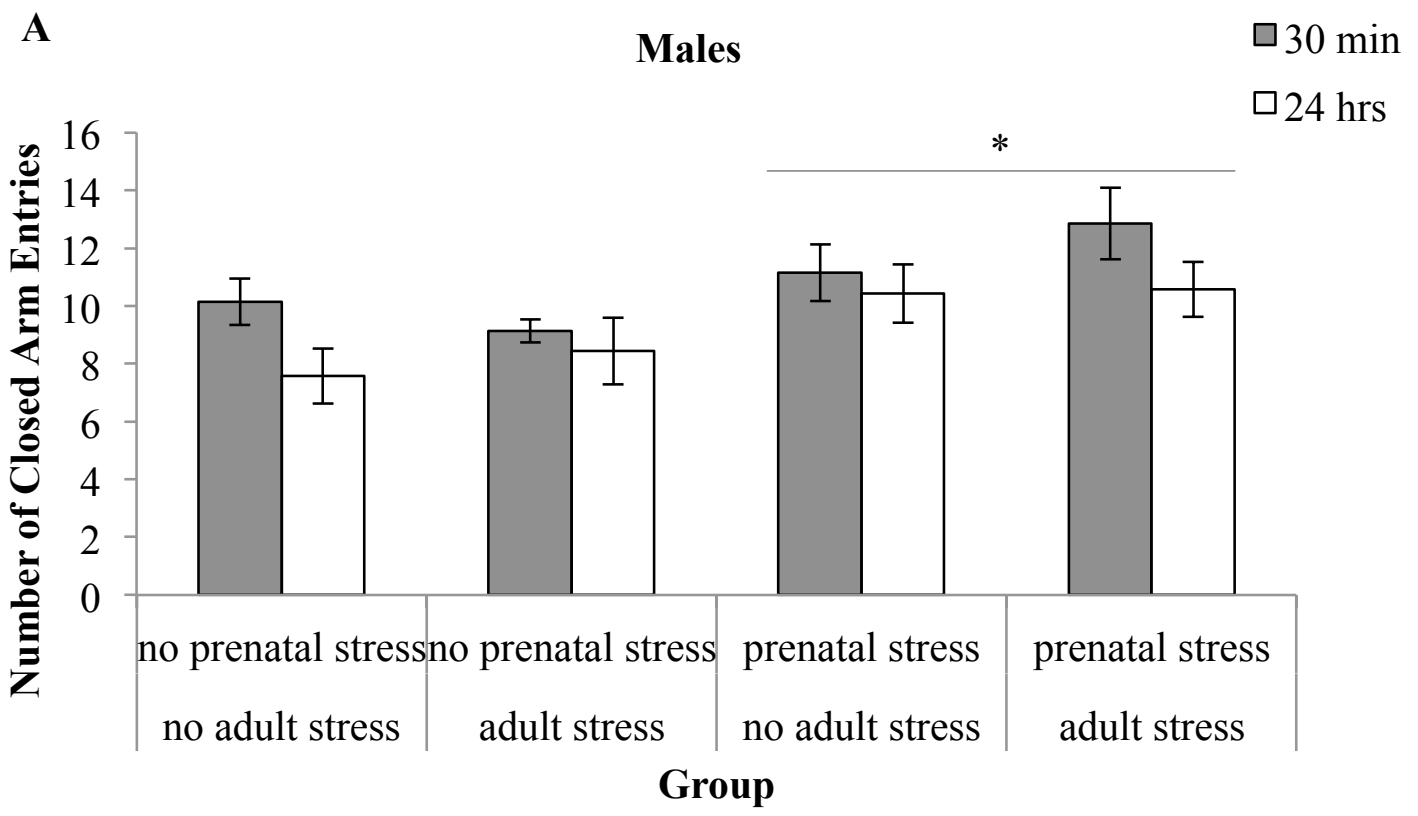

B

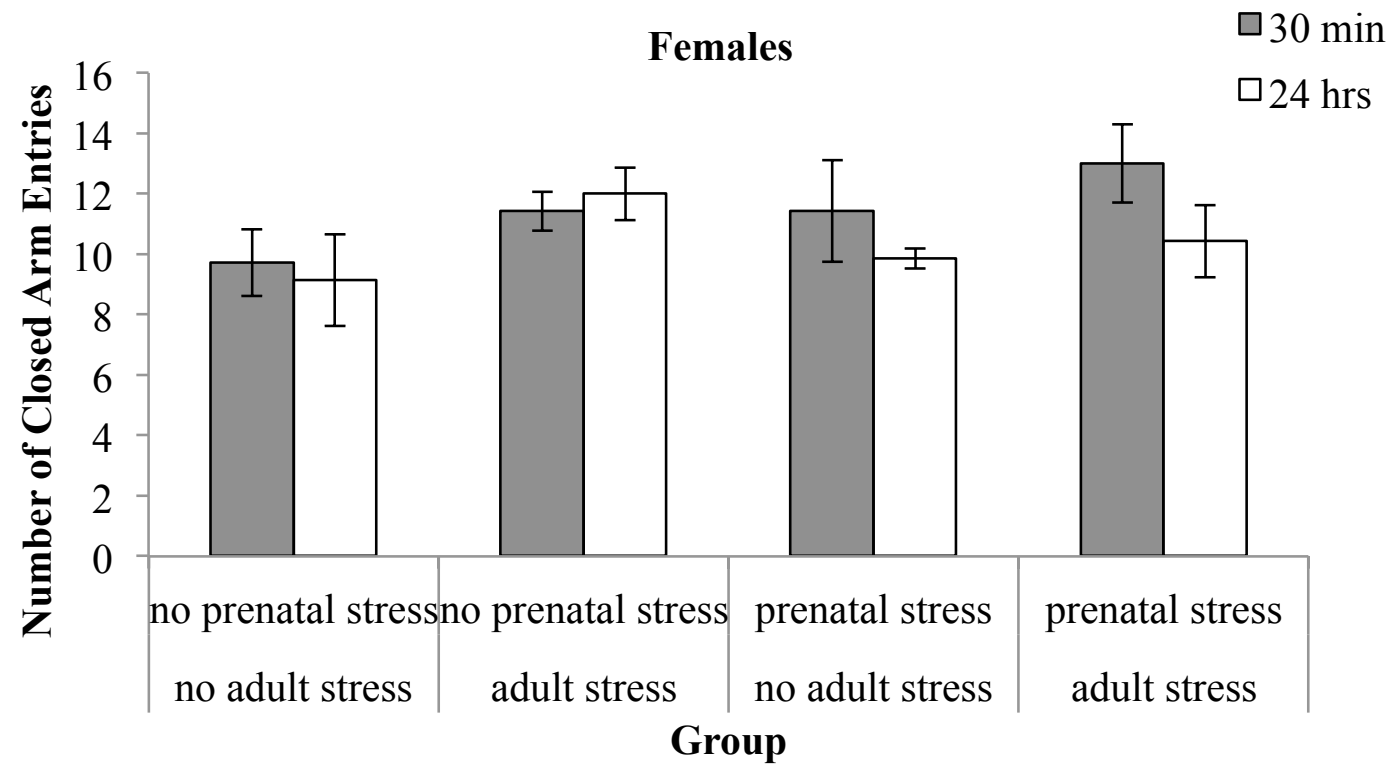

Figure 3. Number of closed arm entries in a plus-maze among male (A) and female (B) mice tested 30 min and 24 hours following a stressor or control treatment in adulthood, and as a function of the prenatal stressor treatment. Data are represented by means \pm S.E.M. ${ }^{*} \mathrm{p}<.01$ relative to non-prenatally stressed mice. 
No significant effects were found with respect to the amount of time spent in open arms by male mice (Figure 4A). In contrast, female mice displayed a significant Prenatal Stress x Adult Stressor $\mathrm{x}$ Time interaction $\mathrm{F}_{(1,24)}=4.94, \mathrm{p}<.05$. As seen in Figure 4B, among mice assessed 30 minutes after the social stressor or control treatment in adulthood, time spent in open arms did not differ between animals who had never been stressed and those stressed on one occasion. However, mice stressed prenatally and in adulthood exhibited increased time in open arms than mice stressed on one occasion, although it should be said that animals in former condition exhibited variable scores.

When animals were retested 24 hours later, the non-stressed animals exhibited a small non-significant decline in the time spent in open arms, whereas mice that were only prenatally stressed showed an increase in the time spent in open arms. A similar outcome was also apparent in mice stressed only in adulthood, but the differences were not significant. Finally, mice that are stressed on both occasions exhibited a modest decline in the time spent in open arms between 30 minutes and 24 hours following the social stressor, and as a result did not differ from any other group. 

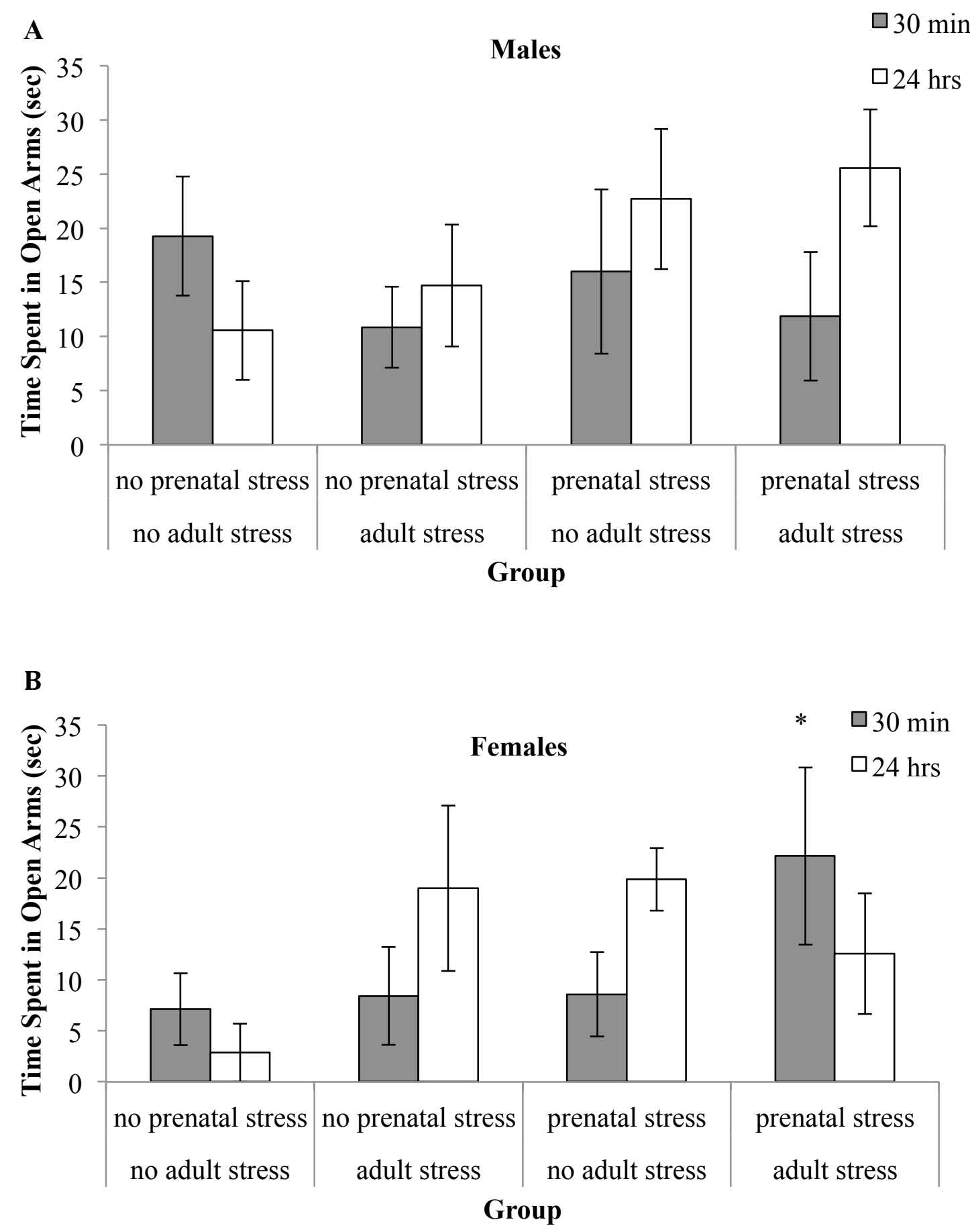

Figure 4. Time spent in open arms (seconds) of a plus-maze among male (A) and female (B) mice tested 30 minutes and 24 hours following a stressor or control treatment in adulthood, and as a function of the prenatal stressor treatment. Data are represented by means \pm S.E.M. $* \mathrm{p}<.05$ relative to mice stressed on one occasion. 
Male mice spent significantly more time in the closed arms at 24 hours than at 30 minutes following the control treatment in adulthood, $\mathrm{F}_{(1,24)}=7.56, \mathrm{p}<.02$ (Figure $5 \mathrm{~A}$ ). It also appeared that prenatally stressed males spent more time in closed arms than nonprenatally stressed males, an effect that nearly reached significance $(\mathrm{p}=.059)$. Likewise, females spent significantly more time in the closed arms at 24 hours than 30 minutes following the social stressor or control treatment, $F_{(1,24)}=9.63, p=.005$. No other significant effects were found in females (Figure 5B).

In contrast, male mice made fewer stretches into open arms when assessed at 24 hours than at 30 minutes following the adulthood stressor or control treatment, $\mathrm{F}_{(1,24)}=$ 38.64, $\mathrm{p}<.00001$ (Figure 6A). This effect was also seen in females, $\mathrm{F}_{(1,24)}=18.71, \mathrm{p}<$ .001. Additionally, there was a significant Prenatal Stress x Adult Stressor treatment interaction, $\mathrm{F}_{(1,24)}=4.69, \mathrm{p}<.05$ (Figure $6 \mathrm{~B}$ ). Females stressed only prenatally made more stretches into open arms than controls. 

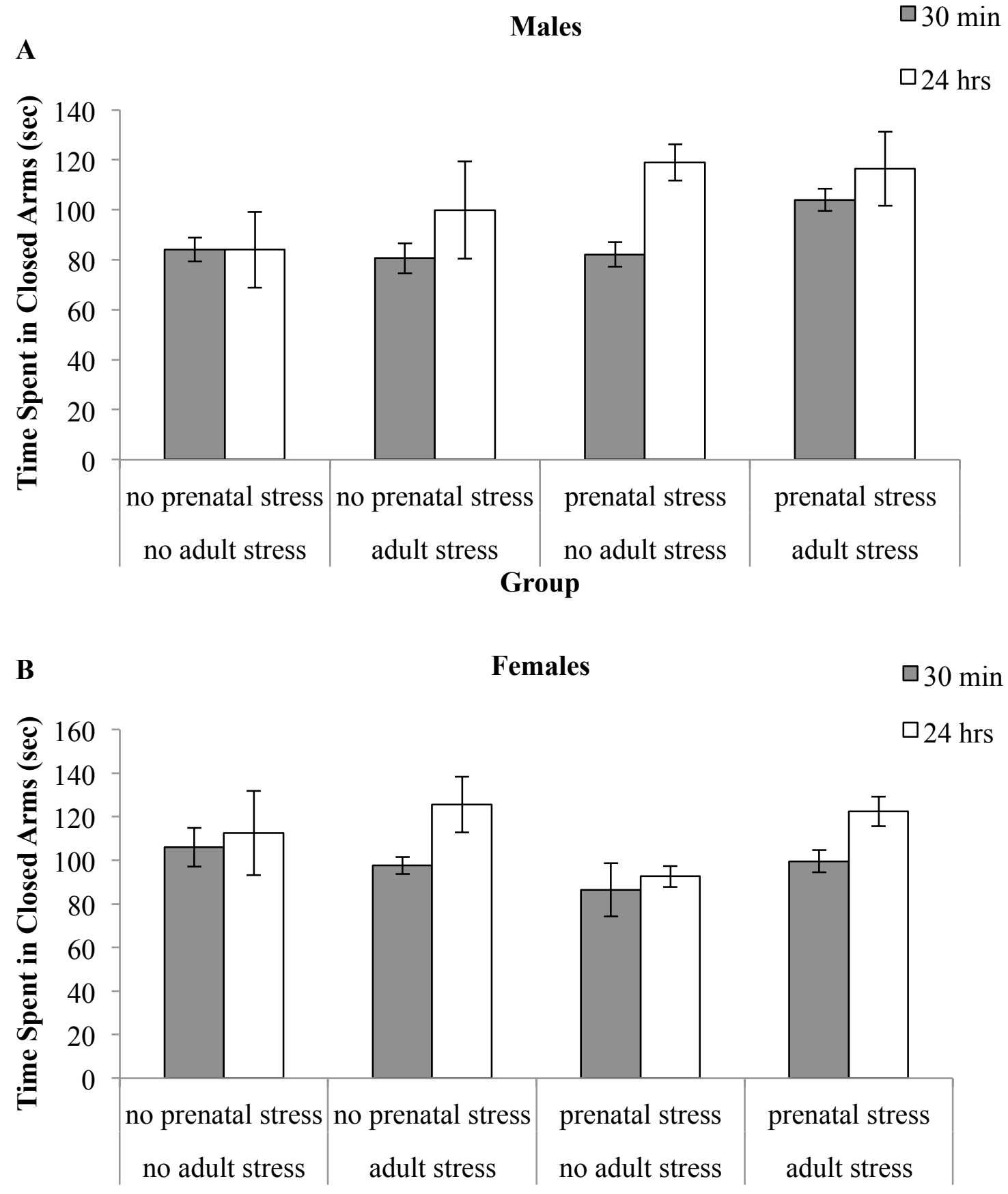

\section{Group}

Figure 5. Time spent in closed arms (seconds) of a plus-maze among male (A) and female (B) tested 30 minutes and 24 hours following a stressor or control treatment in adulthood, and as a function of the prenatal stressor treatment. Data are represented by means \pm S.E.M. 


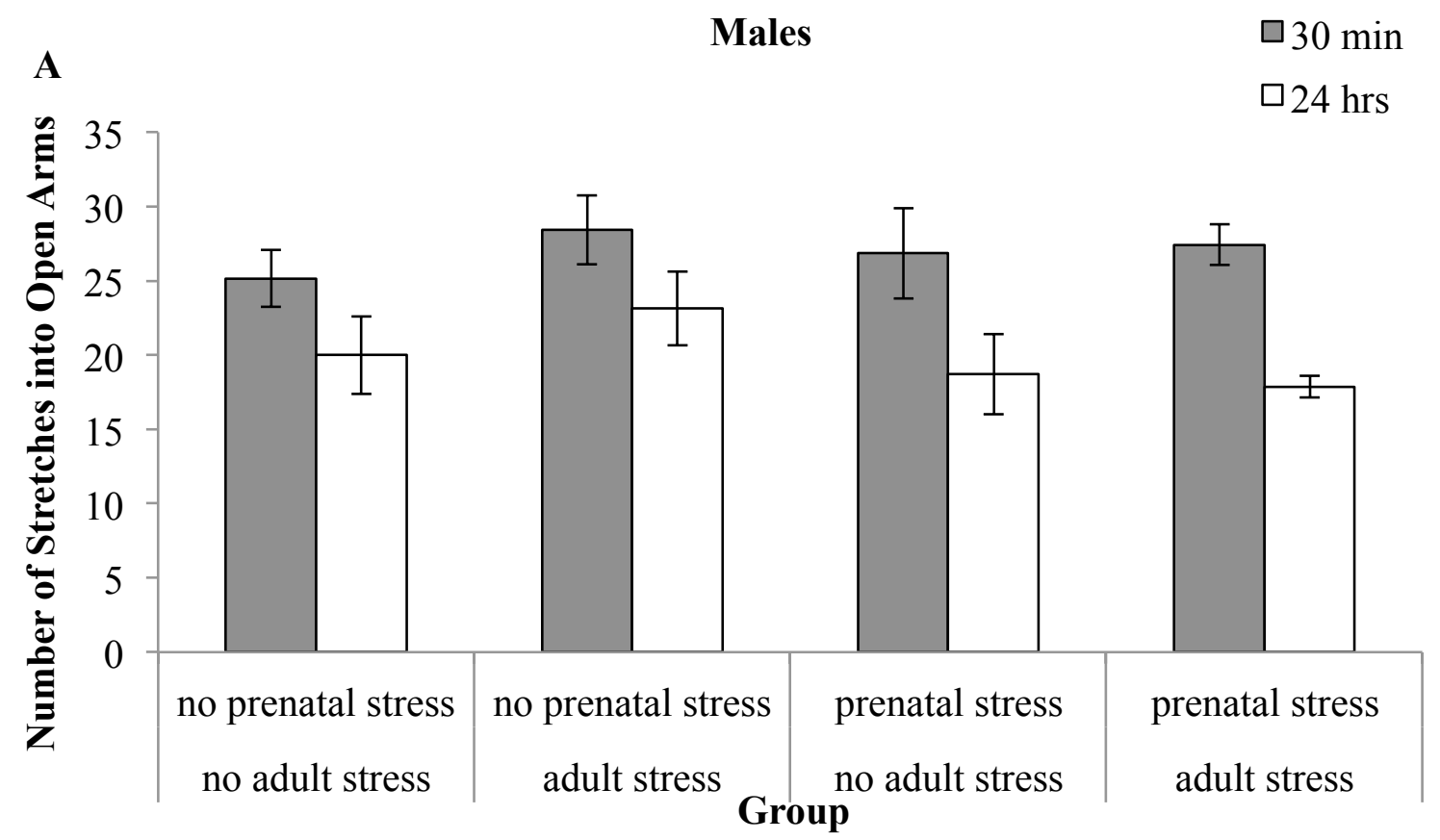

B

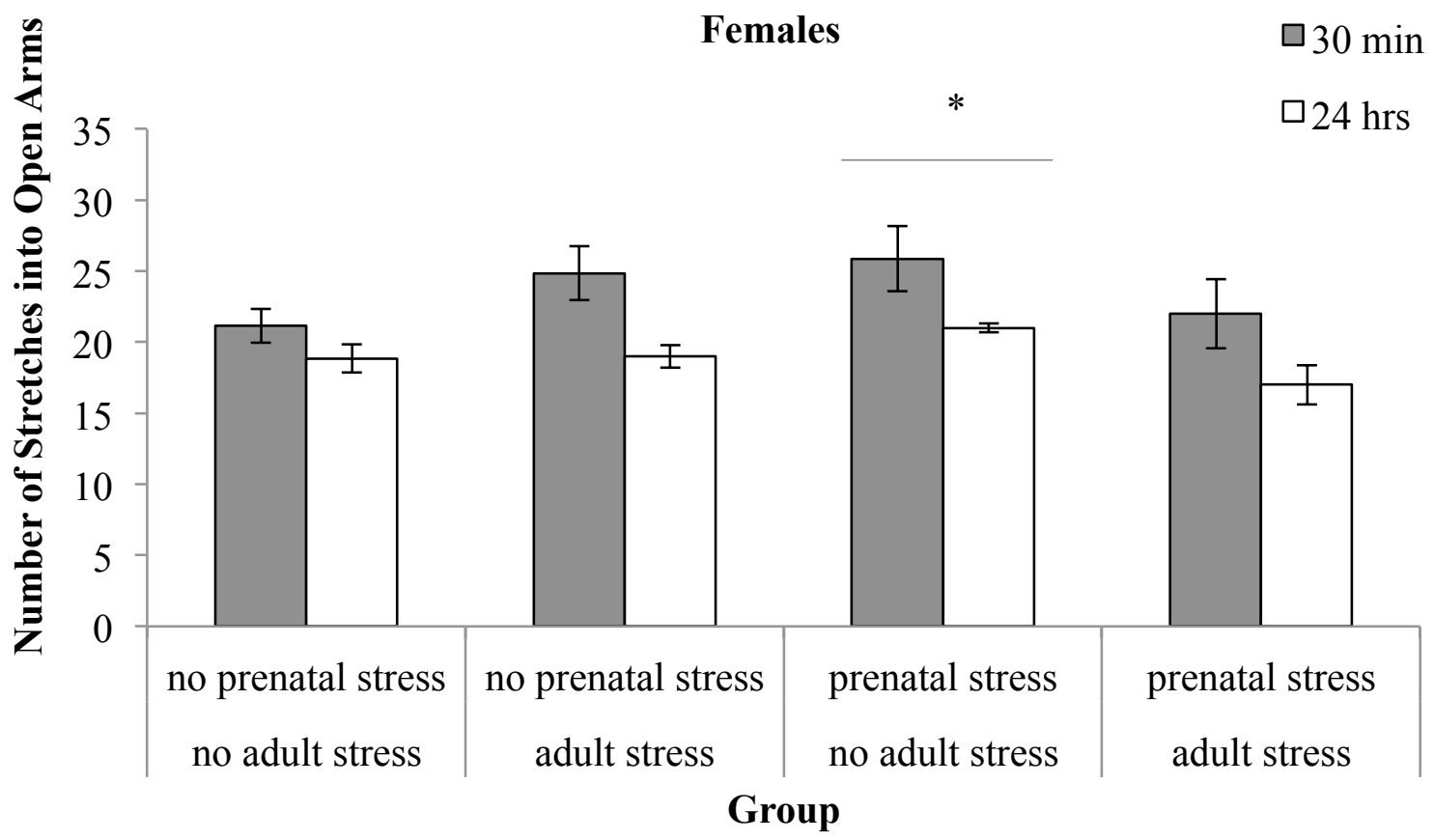

Figure 6. Number of stretches into open arms of a plus-maze among male (A) and female (B) mice tested 30 minutes and 24 hours following a stressor or control treatment in adulthood, and as a function of the prenatal stressor treatment. Data are represented by means \pm S.E.M. ${ }^{*} \mathrm{p}<.05$ relative to controls. 
In males, analysis of the time spent in the interaction zone revealed a significant Prenatal Stressor $\mathrm{x}$ Time interaction, $\mathrm{F}_{(1,24)}=19.27, \mathrm{p}<.0002$, as well as a significant Prenatal Stressor $x$ Stranger $x$ Time interaction in male mice, $F_{(1,24)}=9.81, p<.005$ (Figure 7A). Thirty minutes following an adulthood stressor or control treatment, prenatally stressed male mice spent less time in the interaction zone than those that were not prenatally stressed. Additionally, 30 minutes following an adulthood stressor or control treatment and during exposure to a stranger, prenatally stressed mice spent less time in the interaction zone than non-prenatally stressed mice. This trend was reversed 24 later during exposure to a stranger, when prenatally stressed mice spent more time in the interaction zone than non-prenatally stressed mice. In contrast, female mice spent less time in the interaction zone when exposed to a stranger mouse than those that were not, $F_{(1,24)}=6.00, p<.05$. These effects are shown in Figure 7B. 

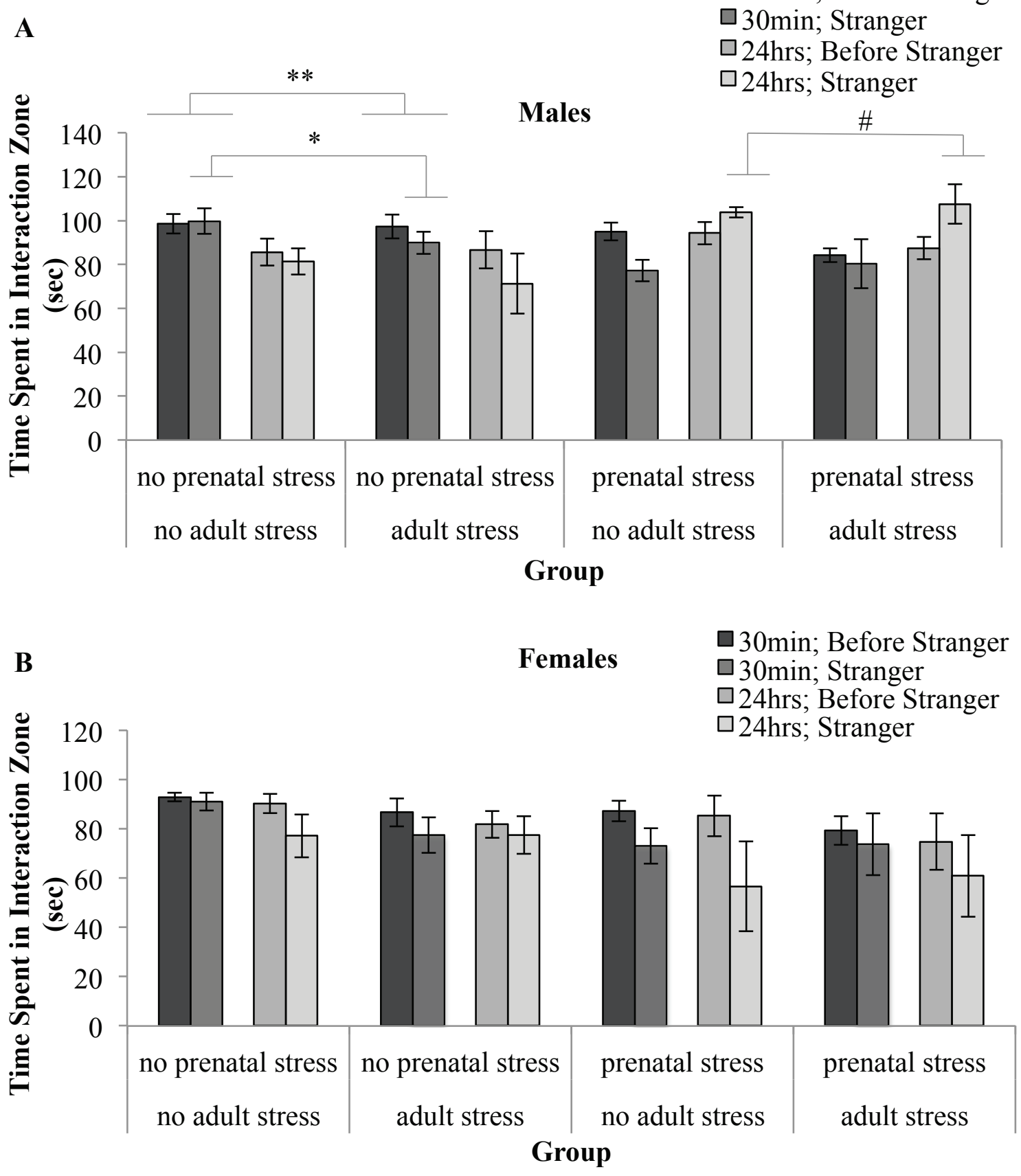

Figure 7. Time spent in interaction zone (seconds) of a social avoidance test among male (A) and female (B) mice tested 30 minutes and 24 hours following a stressor or control treatment in adulthood, and as a function of the prenatal stressor treatment. Data are represented by means \pm S.E.M. $* * p<.0005$ relative to prenatally stressed mice 30 minutes following an adulthood stressor or control treatment. $* \mathrm{p}<.005$ relative to prenatally stressed mice during exposure to a novel mouse 30 minutes following an adulthood stressor or control treatment. $\# \mathrm{p}<.005$ relative to non-prenatally stressed mice during exposure to a novel mouse 24 hours following an adulthood stressor or control treatment. 


\subsection{Experiment 2a and 2b: Effects of prenatal stress and adult stress on plasma corticosterone levels}

Male mice displayed significantly greater plasma corticosterone concentrations 2 hours following an adulthood stressor than those that were not stressed in adulthood, $\mathrm{F}_{(1,28)}=8.39, \mathrm{p}<.01$. As seen in Figure 8A, prenatally stressed male mice also appear to display greater plasma corticosterone concentrations than non-prenatally stressed male mice, an effect that nearly reached significance $(p=.055)$. In females however, plasma corticosterone concentrations were significantly greater in prenatally stressed than in nonprenatally stressed mice, $\mathrm{F}_{(1,28)}=5.14, \mathrm{p}<.05$ (Figure $8 \mathrm{~B}$ ).

As seen in Figure 9A, plasma corticosterone concentrations were significantly greater in prenatally than non-prenatally stressed male mice tested 24 hours following an adulthood stressor or control treatment, $F_{(1,28)}=4.96, p<.05$. No significant effects were found in females (Figure 9B). 

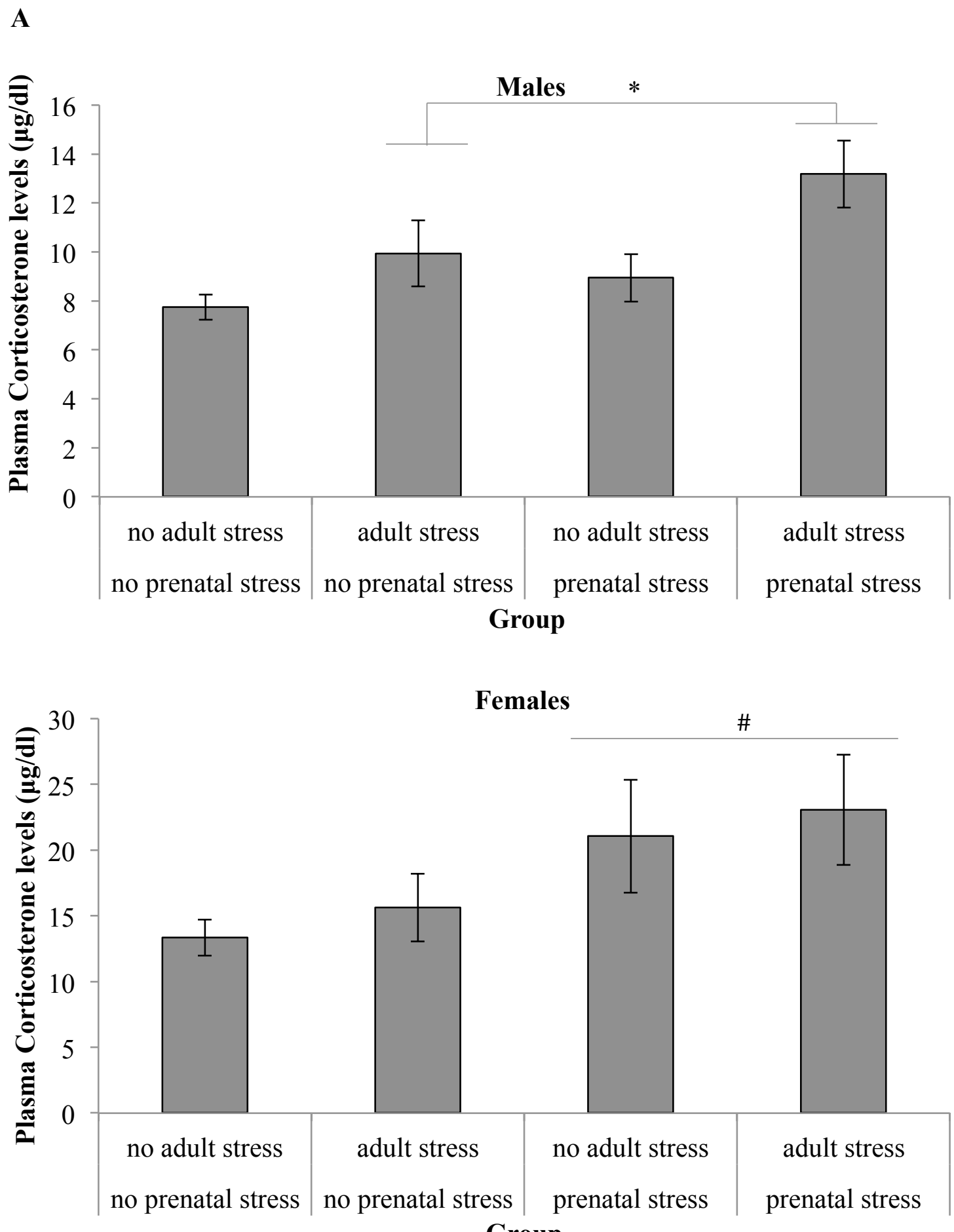

\section{Group}

Figure 8. Plasma corticosterone concentrations ( $\mu \mathrm{g} / \mathrm{dl})$ in male (A) and female (B) mice as a function of the prenatal stressor treatment and 2 hours following the stressor or control treatment administered during adulthood. Data are represented by means \pm S.E.M. ${ }^{*} \mathrm{p}<.01$ relative to mice that were not stressed in adulthood. $\# \mathrm{p}<.05$ relative to non-prenatally stressed mice. 

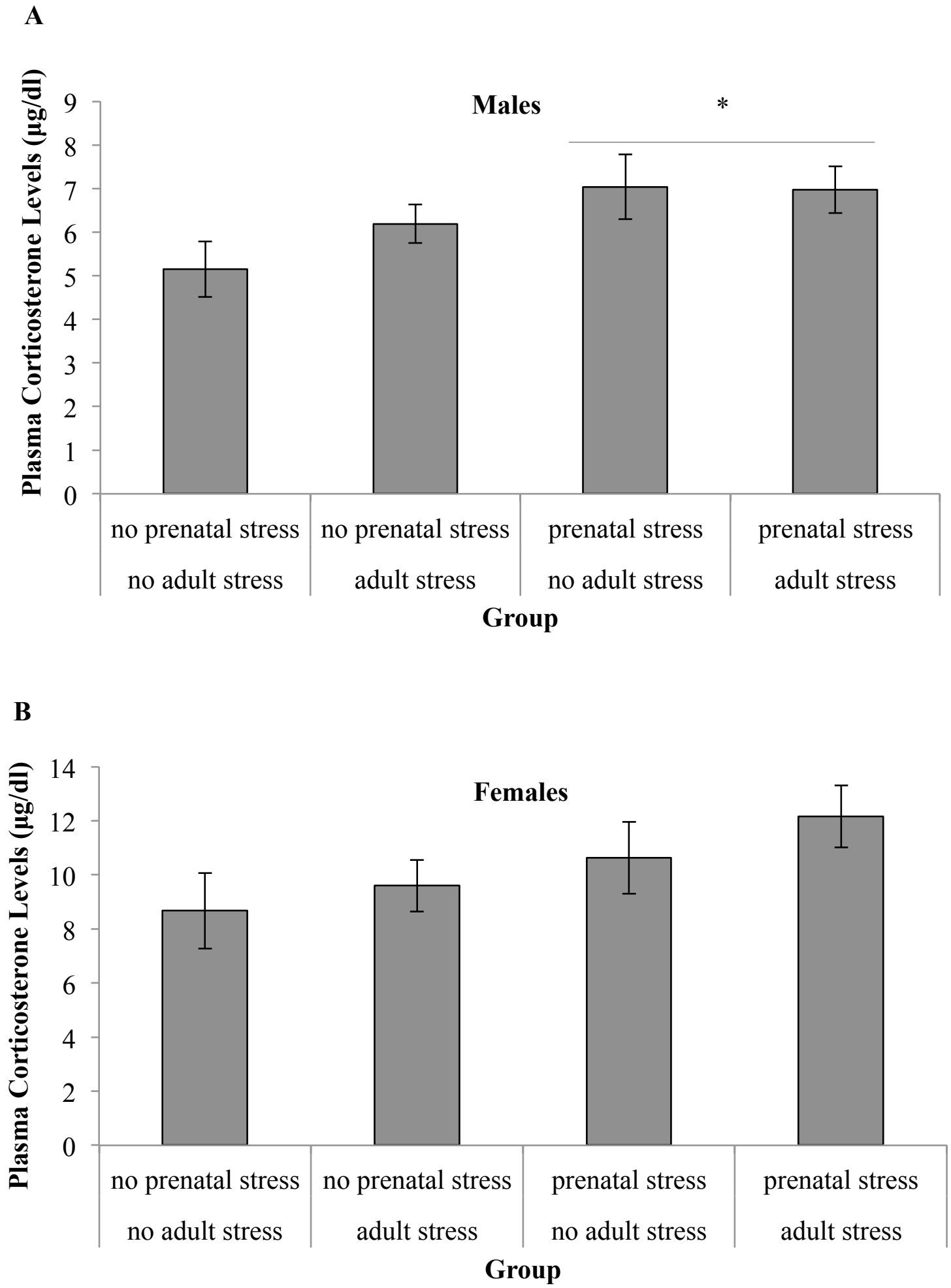

Figure 9. Plasma corticosterone concentrations ( $\mu \mathrm{g} / \mathrm{dl})$ in male $(\mathrm{A})$ and female $(\mathrm{B})$ mice as a function of the prenatal stressor treatment and 24 hours following the stressor or control treatment administered during adulthood. Data are represented by means \pm S.E.M. ${ }^{*} \mathrm{p}<.05$ relative to non-prenatally stressed mice. 


\subsection{Experiment 2a and 2b: Effects of prenatal and adult stress on PFC mRNA expression of CRH, cytokines, and their receptors.}

No significant changes of PFC CRH levels were found in male mice (Figure 10A). However, as seen in Figure 10B, prenatally stressed female mice as well as those stressed in adulthood expressed significantly greater CRH levels in the PFC 2 hours following the stressor or control treatment in adulthood than did mice that were not stressed, F's $_{(1,26)}=6.978,5.398, \mathrm{p}<.05$, respectively. Although the prenatal stress by adult stress interaction was not statistically significant, follow up comparisons were made of the simple main effects comprising this interaction based on an a priori hypothesis. This analysis revealed that a stressor applied on both occasions resulted in CRH expression that exceed that evident among mice stressed on only a single occasion. Additionally, female mice stressed in adulthood displayed significantly greater CRH mRNA levels 24 hours following the stressor, $\mathrm{F}_{(1,27)}=8.69, \mathrm{p}<.01$. Changes in PFC CRH receptor 1 (CRHR1) and CRH receptor 2 (CRHR2) mRNA expression were not observed in male mice (Figure $11 \mathrm{~A}$ and $12 \mathrm{~A}$ respectively). In contrast, significantly greater CRHR1 levels were found in the PFC of prenatally stressed than non-prenatally stressed female mice 2 hours following a stressor or control treatment in adulthood, $\mathrm{F}_{(1,28)}$ $=5.14, \mathrm{p}<.05$ (Figure 11B). No CRHR2 level changes were found in female mice (Figure 12B). 

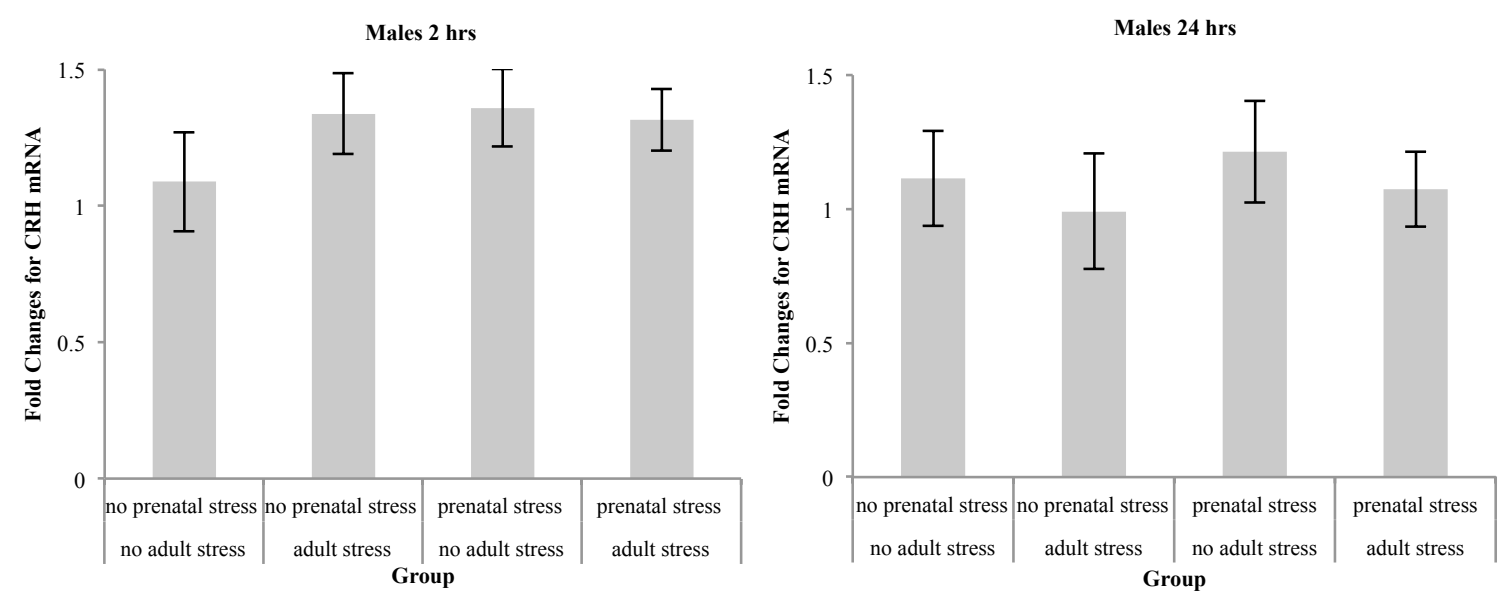

B
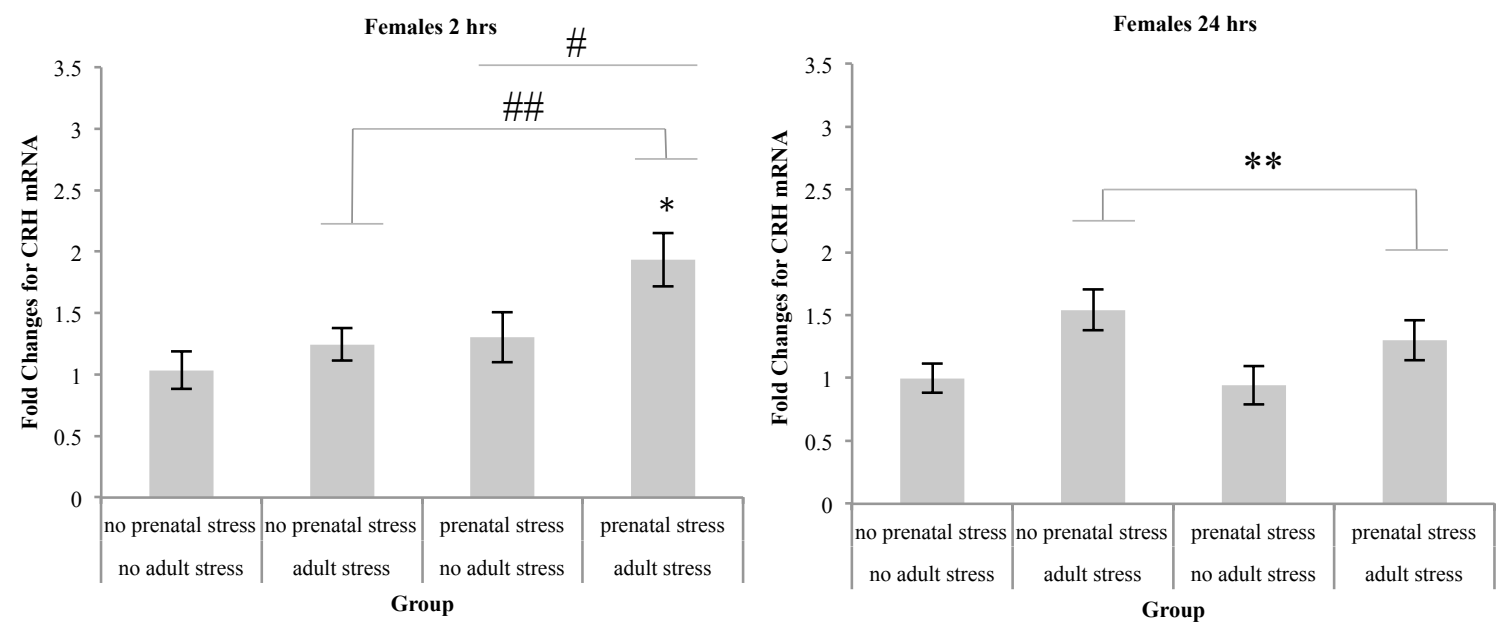

Figure 10. Expression of CRH mRNA in the PFC of male (A) and female (B) mice as a function of the prenatal stressor treatment and 2 and 24 hours following the stressor or control treatment administered during adulthood. Data are represented by mean fold changes \pm S.E.M. $\# \mathrm{p}<.05$ relative to non-prenatally stressed mice. $\# \# \mathrm{p}<.05$ relative to mice that were not stressed in adulthood. $* \mathrm{p}<.05$ relative to mice stressed on only one occasion. ${ }^{* *} \mathrm{p}<.01$ relative to mice that were not stressed in adulthood. 

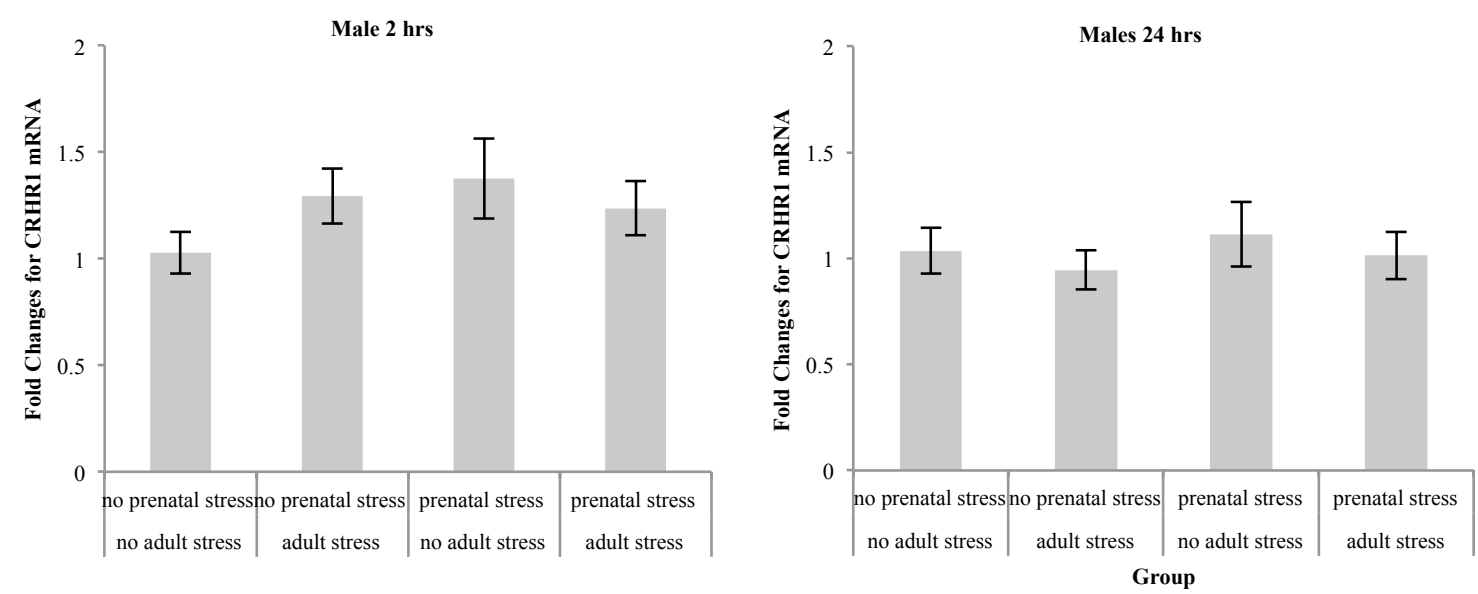

B
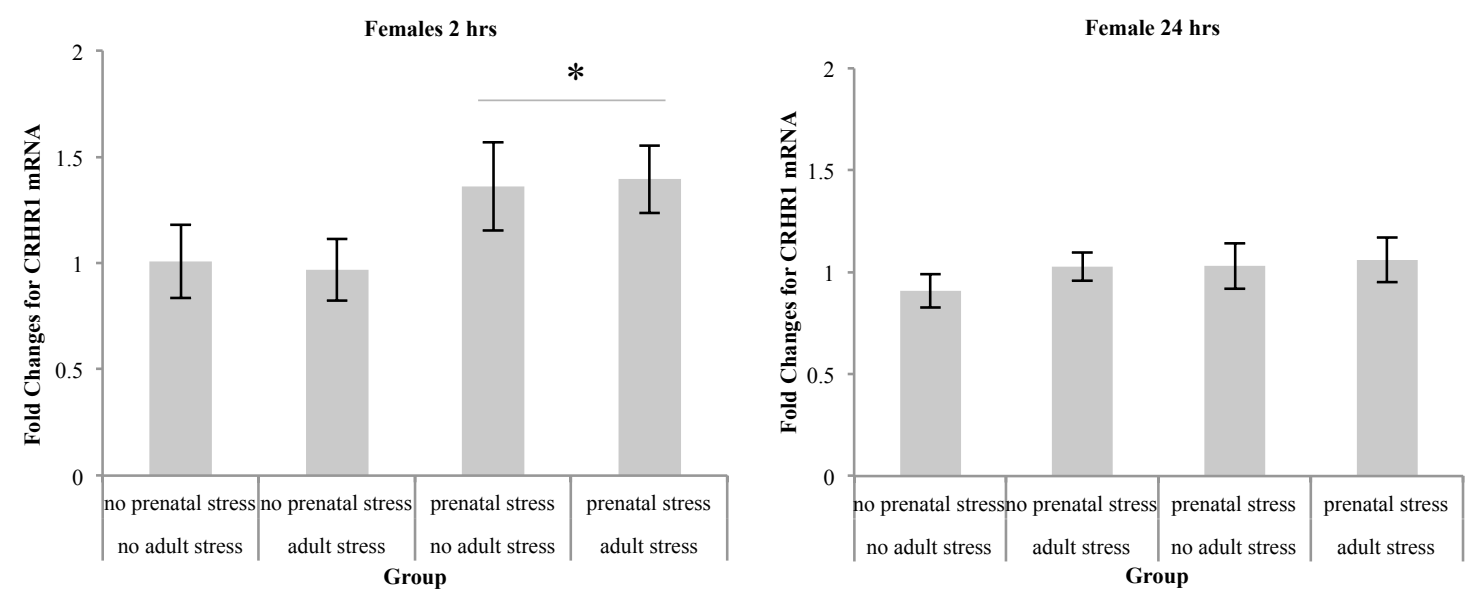

Figure 11. Expression of CRHR 1 mRNA in the PFC of male (A) and female (B) mice as a function of the prenatal stressor treatment and 2 and 24 hours following the stressor or control treatment administered during adulthood. Data are represented by mean fold changes \pm S.E.M. $* \mathrm{p}<.05$ relative to non-prenatally stressed mice. 

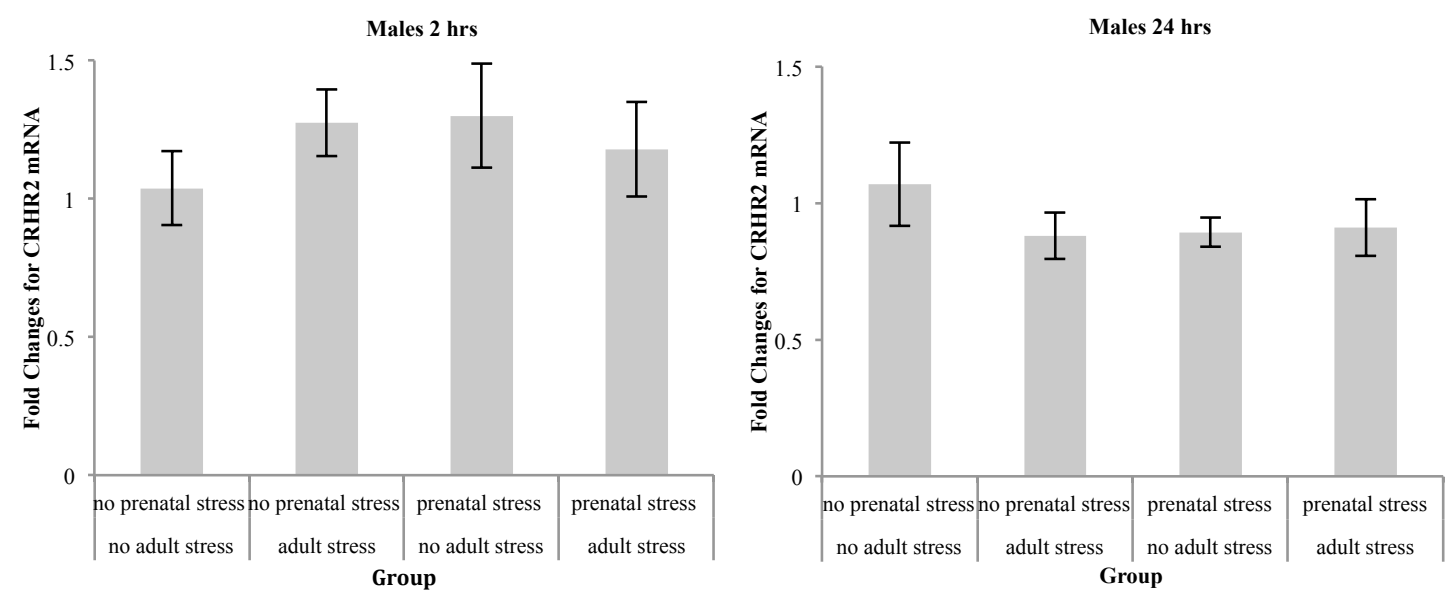

B
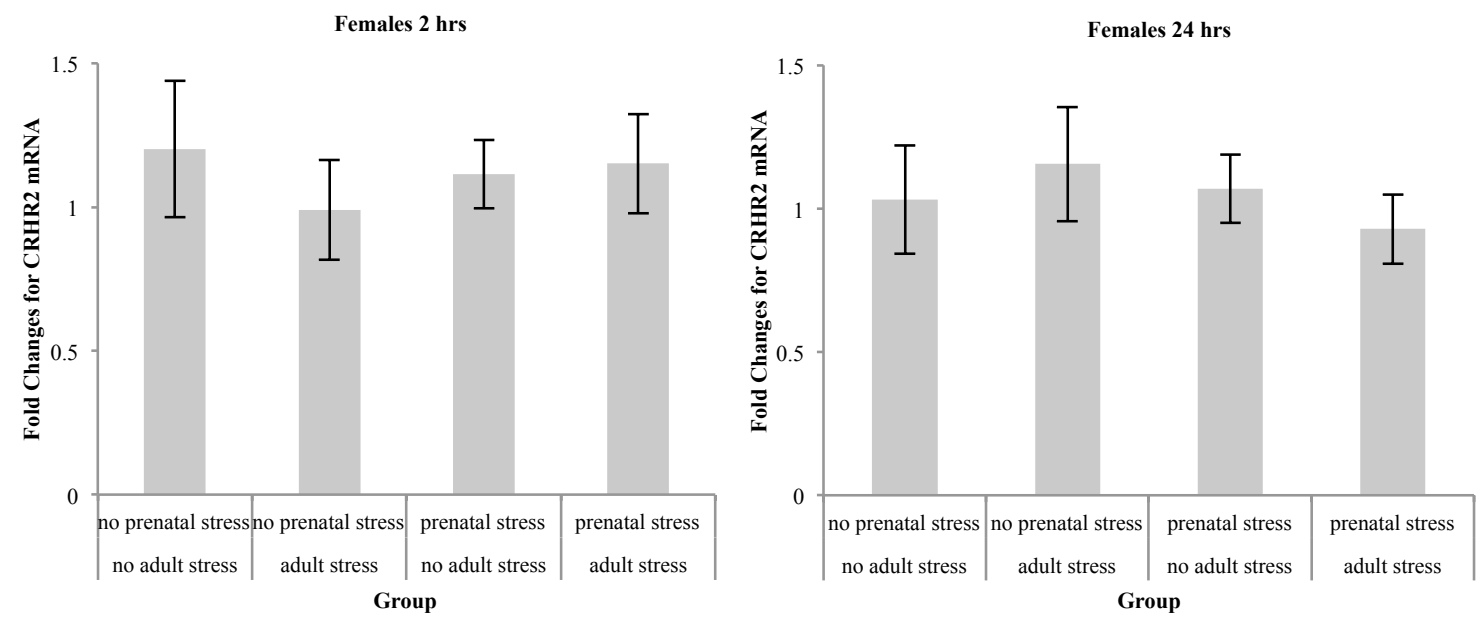

Figure 12. Expression of CRHR2 mRNA in the PFC of male (A) and female (B) mice as a function of the prenatal stressor treatment and 2 and 24 hours following the stressor or control treatment administered during adulthood. Data are represented by mean fold changes \pm S.E.M. 
Analysis of variance revealed no significant changes in PFC IL-1 $\beta$ mRNA levels at both 2 and 24 hours following the social stressor in adulthood in male mice (Figure 13A). Although, as seen in Figure 13B, prenatally stressed females showed significantly greater IL-1 $\beta$ mRNA levels 2 hours following the social stressor than those that were not prenatally stresse, $\mathrm{F}_{(1,26)}=4.90, \mathrm{p}<.05$. Significant treatments effects on PFC IL-1 receptor (IL-1R1) mRNA levels were not observed in males (Figure 14A). However, prenatally stressed female mice displayed significantly greater IL-1R1 mRNA levels 24 hours following a stressor or control treatment in adulthood than those that were not prenatally stressed $\mathrm{F}_{(1,29)}=11.63, \mathrm{p}<.005$ (Figure 14B). 
A
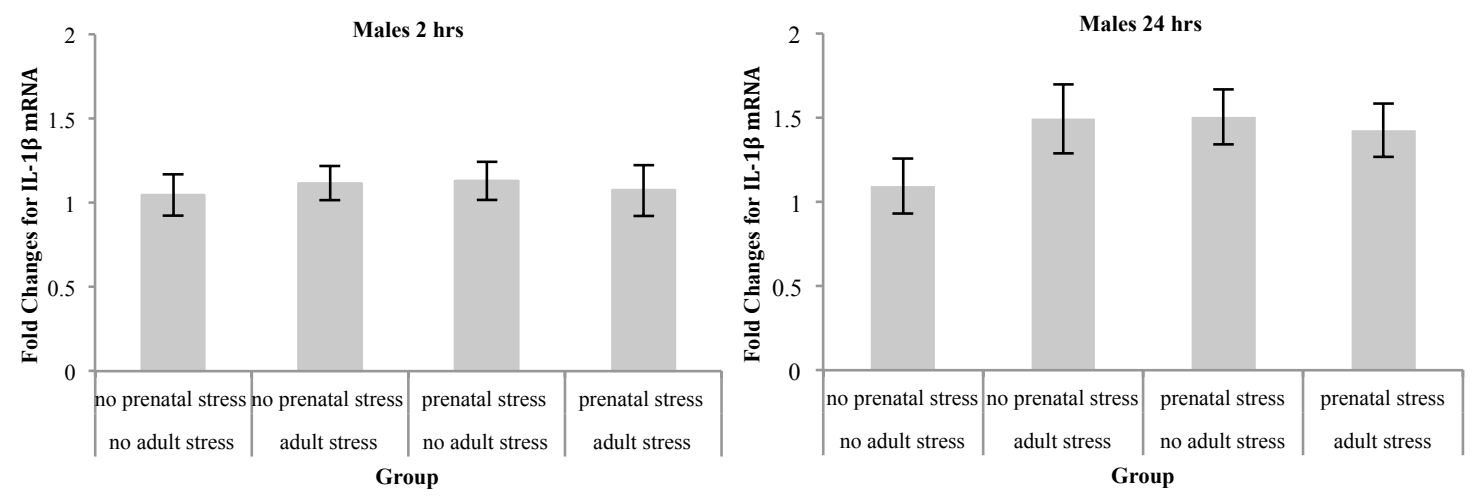

B
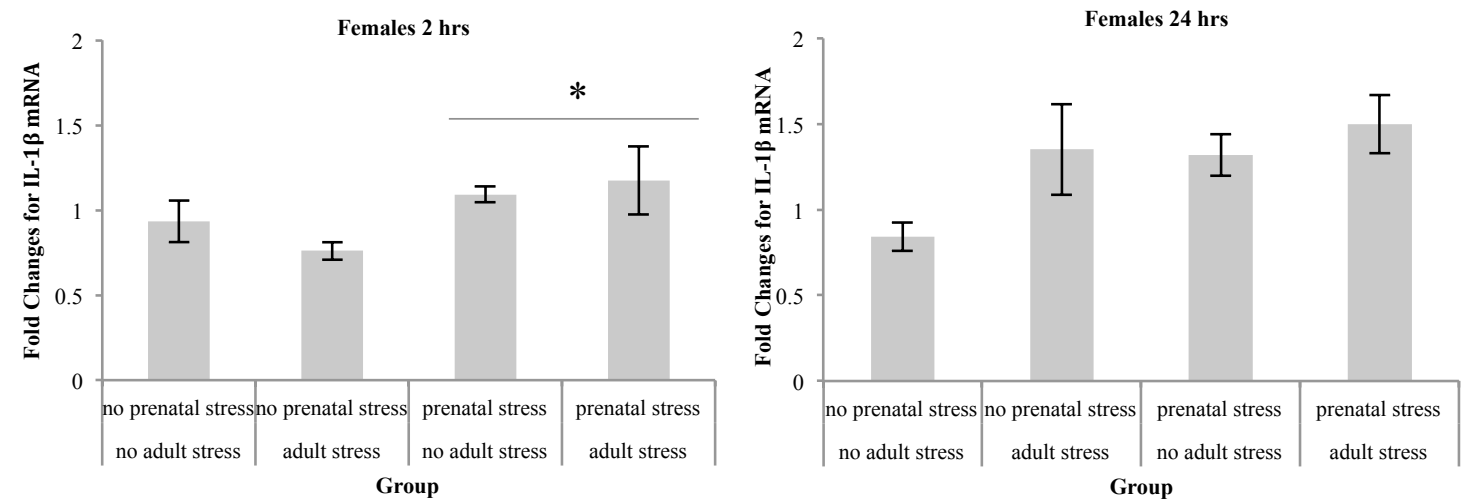

Figure 13. Expression of IL-1 $\beta$ mRNA in the PFC of male (A) and female (B) mice as a function of the prenatal stressor treatment and 2 and 24 hours following the stressor or control treatment administered during adulthood. Data are represented by mean fold changes \pm S.E.M. $* \mathrm{p}<.05$ relative to non-prenatally stressed mice. 
A
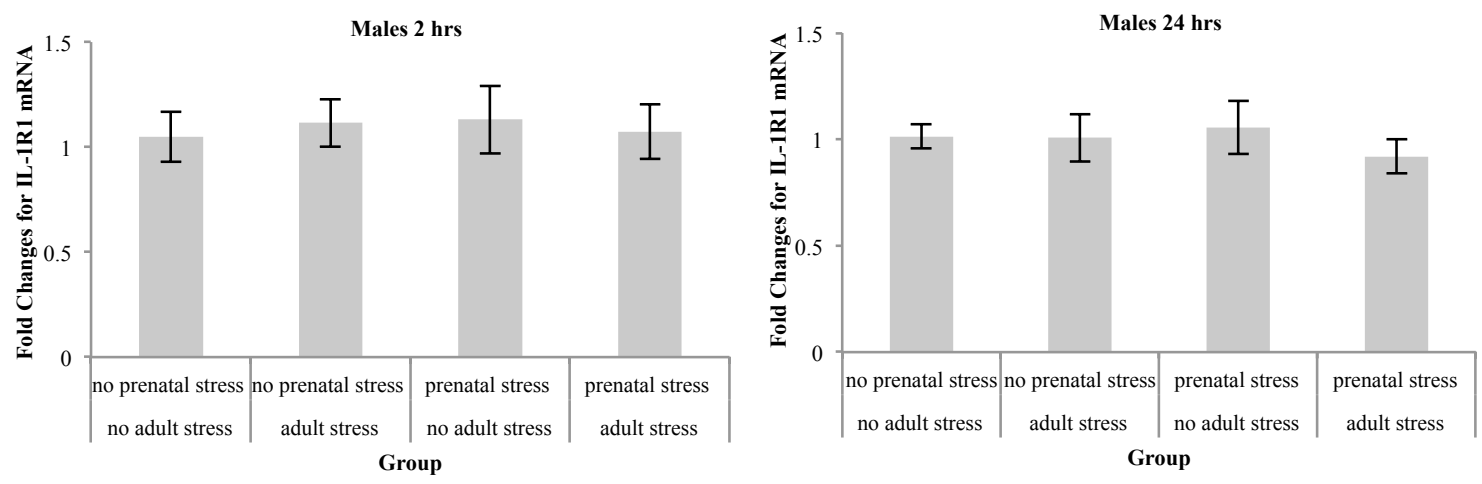

B
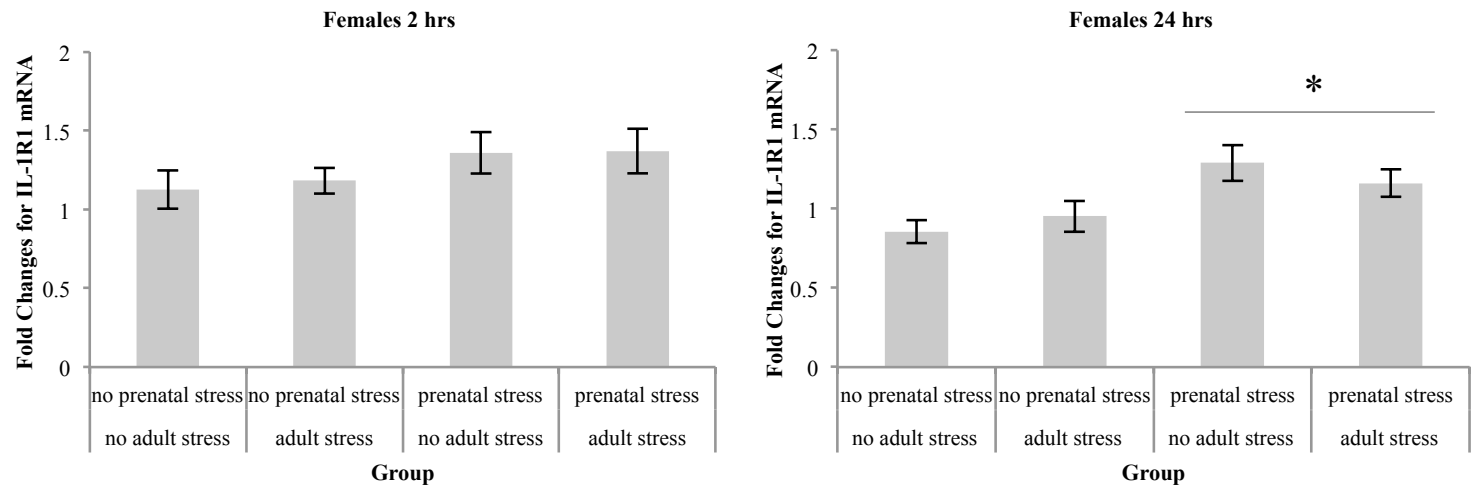

Figure 14. Expression of IL-1R1 mRNA in the PFC of male (A) and female (B) mice as a function of the prenatal stressor treatment and 2 and 24 hours following the stressor or control treatment administered during adulthood. Data are represented by mean fold changes \pm S.E.M. ${ }^{*} \mathrm{p}<.005$ relative to non-prenatally stressed mice. 
In contrast to IL-1 $\beta$, male mice stressed in adulthood displayed significantly greater PFC IL-6 mRNA expression 2 hours following the social stressor than those that were not stressed in adulthood, $\mathrm{F}_{(1,26)}=4.58, \mathrm{p}<.05$. This difference was largely absent when measured 24 hours after the last treatment (Figure 15A). A similar effect was observed in females 24 hours following the social stressor, where mice stressed in adulthood showed significantly greater IL-6 mRNA expression than those that were not stressed in adulthood, $\mathrm{F}_{(1,26)}=5.50, \mathrm{p}<.05$ (Figure 15B). Additionally, no significant effects were found in males and females with regard to changes in PFC IL-6 receptor (IL6R) mRNA expression (Figure 16). Although, female mice displayed somewhat lower IL-6R levels 2 hours following a stressor in adulthood than those that were not stressed in adulthood, this difference was just shy of significance, $\mathrm{p}=.059$. 
A
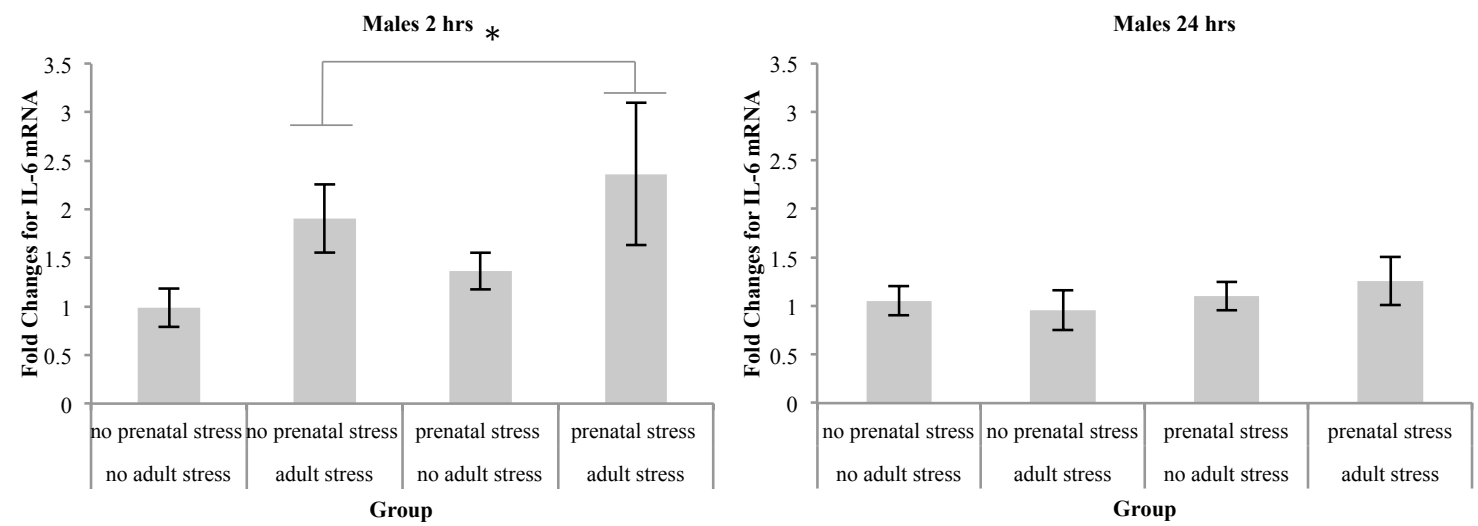

B
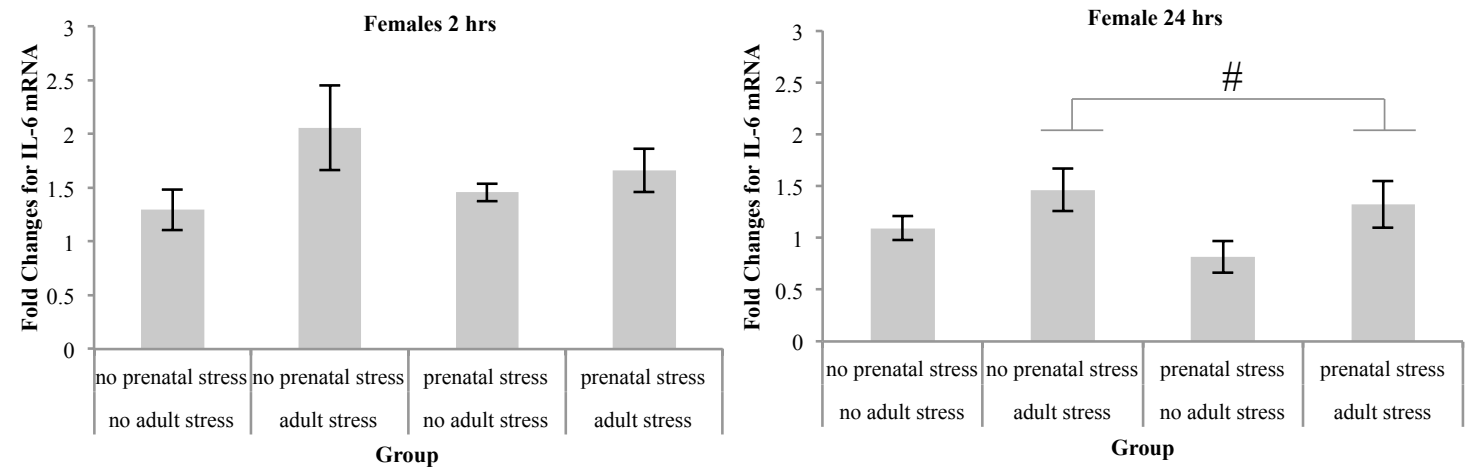

Figure 15. Expression of IL-6 mRNA in the PFC of male (A) and female (B) mice as a function of the prenatal stressor treatment and 2 and 24 hours following the stressor or control treatment administered during adulthood. Data are represented by mean fold changes \pm S.E.M. ${ }^{*} p<.05$ and $\# p<.05$ relative to mice that were not stressed in adulthood. 
A
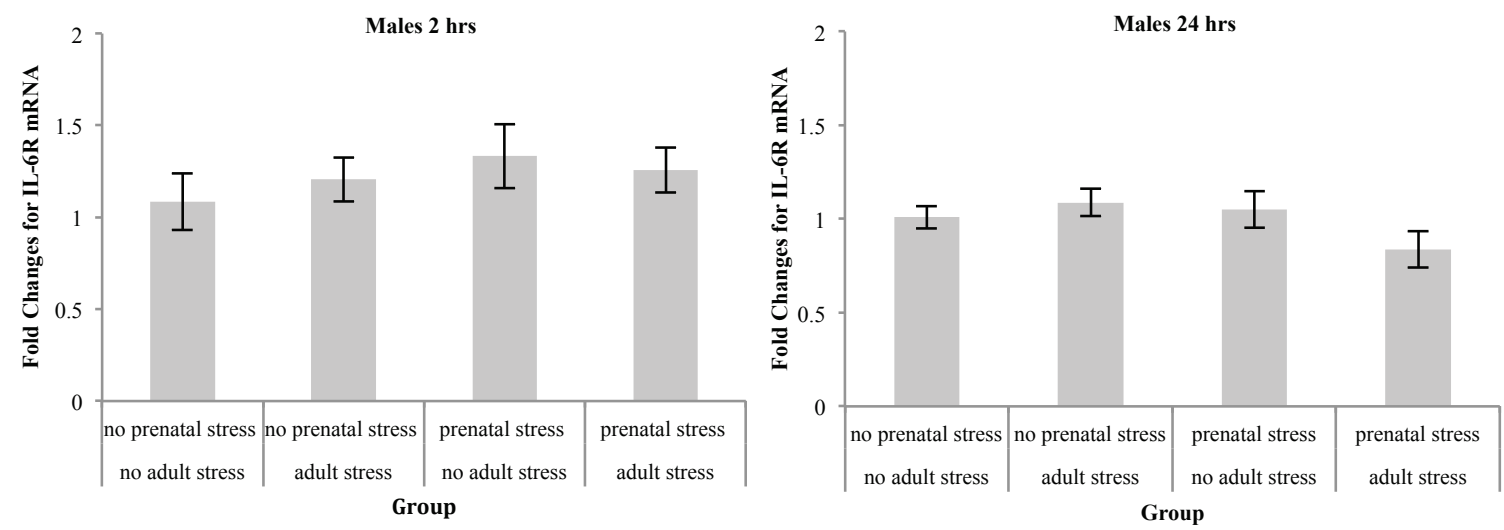

B
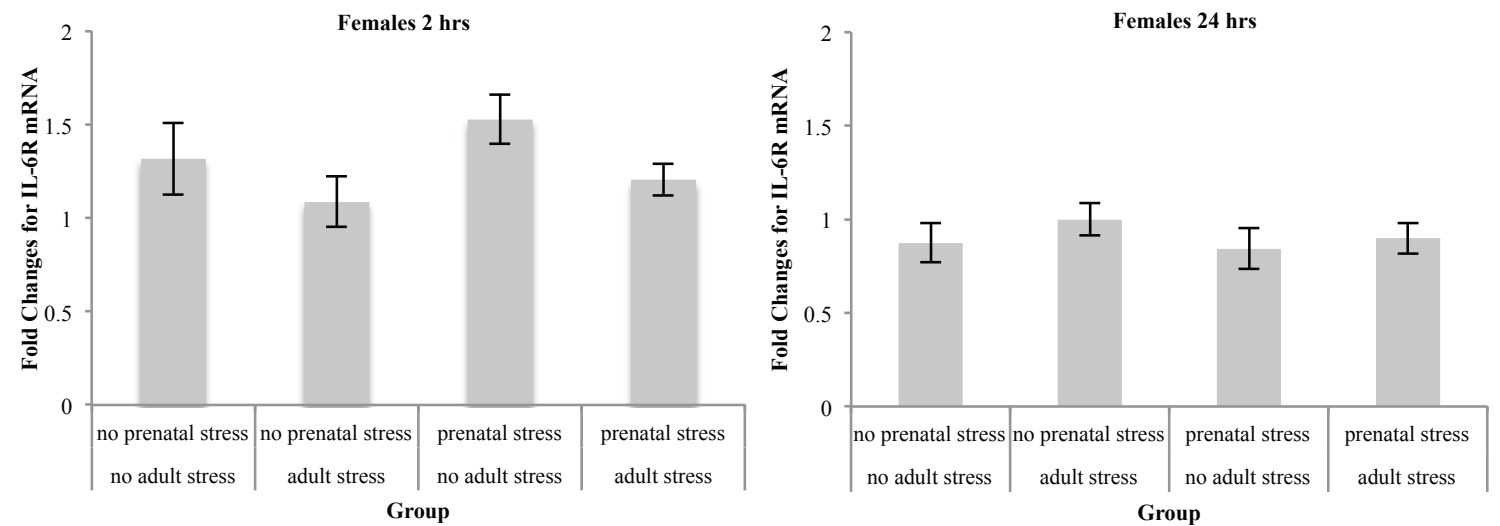

Figure 16. Expression of IL-6R mRNA in the PFC of male (A) and female (B) mice as a function of the prenatal stressor treatment and 2 and 24 hours following the stressor or control treatment administered during adulthood. Data are represented by mean fold changes \pm S.E.M. 
No significant effects were found in males or females with regards to PFC IL-10 mRNA levels (Figure 17).

Likewise, no significant effects were found in PFC TNF- $\alpha$ and TNFR mRNA levels among male mice (Figure 18A and 19A respectively). However, as seen in Figure 19B, TNFR mRNA expression was greater in prenatally stressed than non-prenatally stressed female mice 24 hours following the adulthood stressor or control treatment, this difference was nearly significant $(\mathrm{p}=.051)$ 

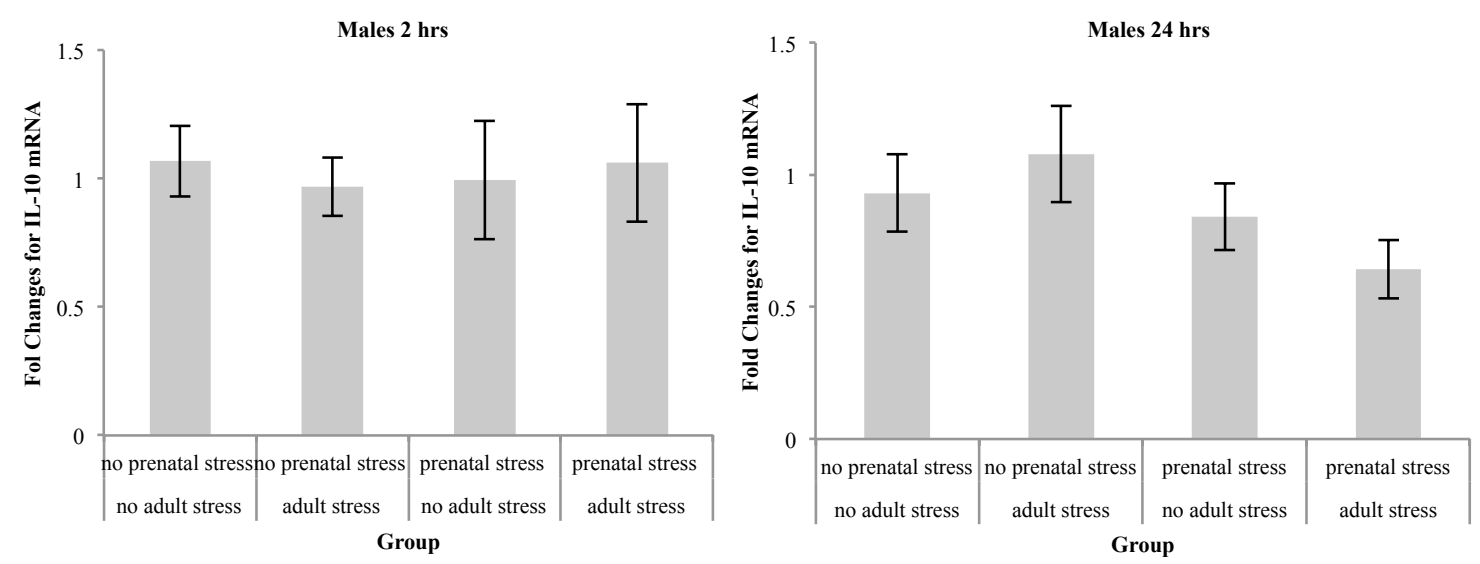

B
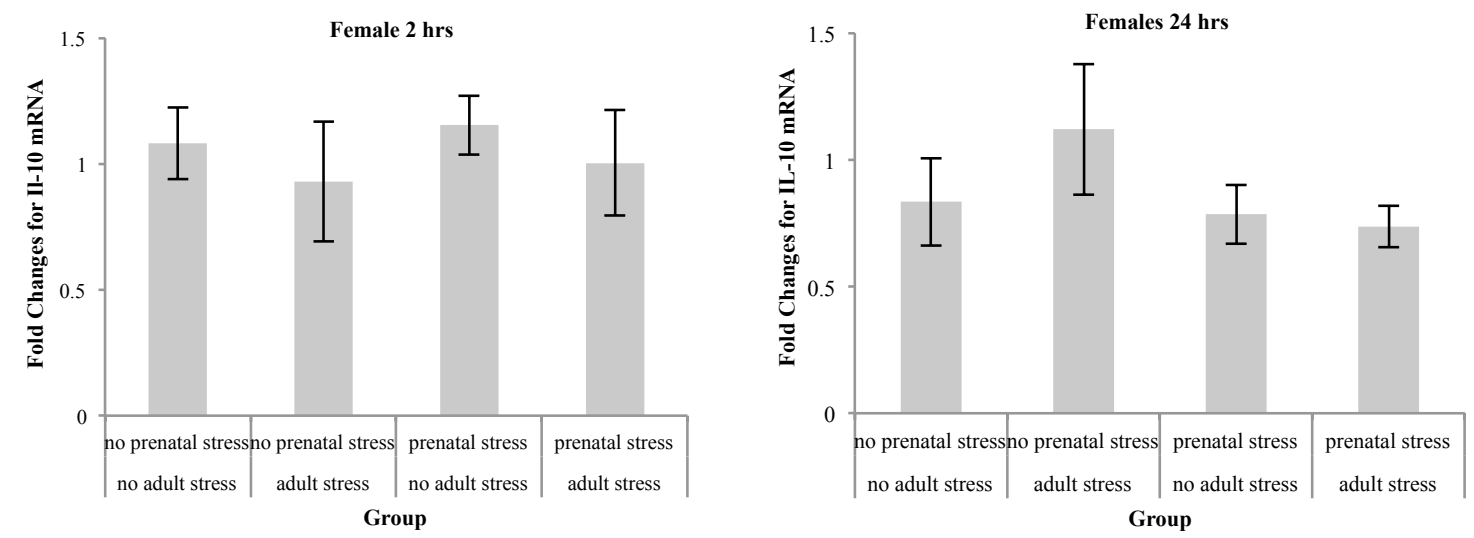

Figure 17. Expression of IL-10 mRNA in the PFC of male (A) and female (B) mice as a function of the prenatal stressor treatment and 2 and 24 hours following the stressor or control treatment administered during adulthood. Data are represented by mean fold changes \pm S.E.M. 

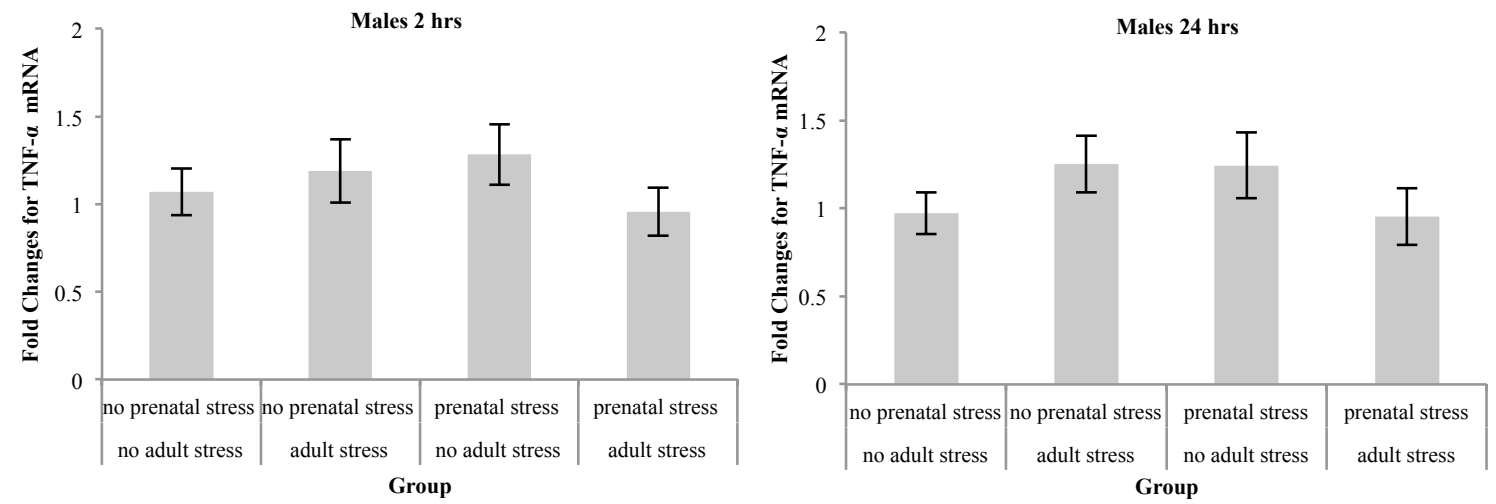

B
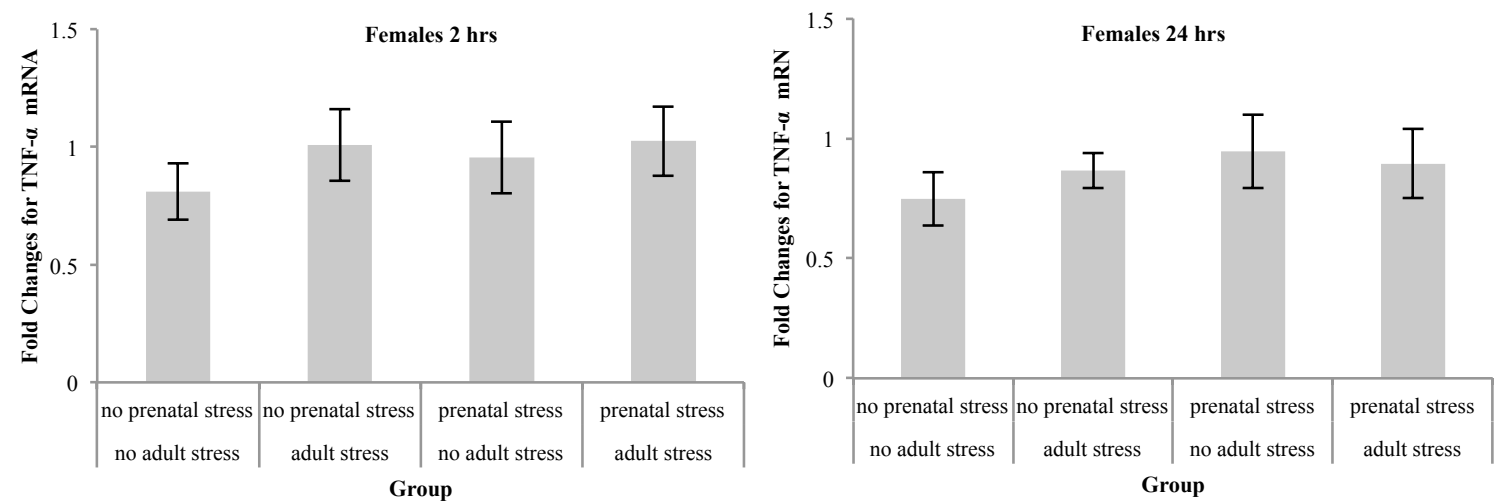

Figure 18. Expression of TNF- $\alpha$ mRNA in the PFC of male (A) and female (B) mice as a function of the prenatal stressor treatment and 2 and 24 hours following the stressor or control treatment administered during adulthood. Data are represented by mean fold changes \pm S.E.M. 

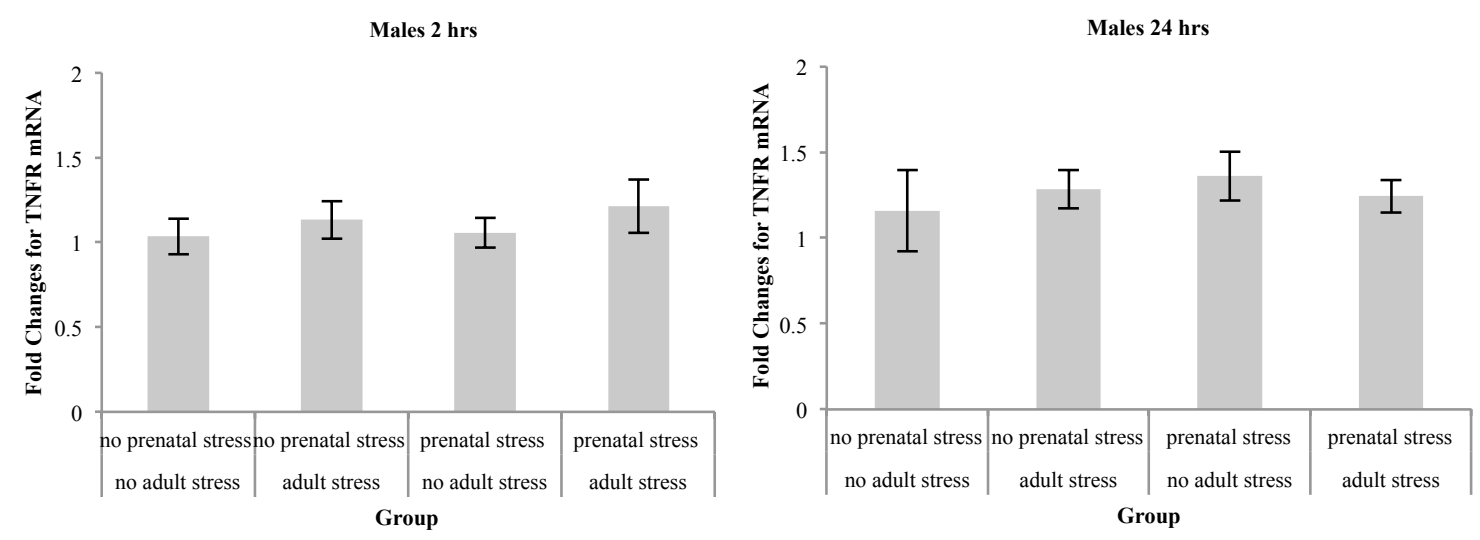

B
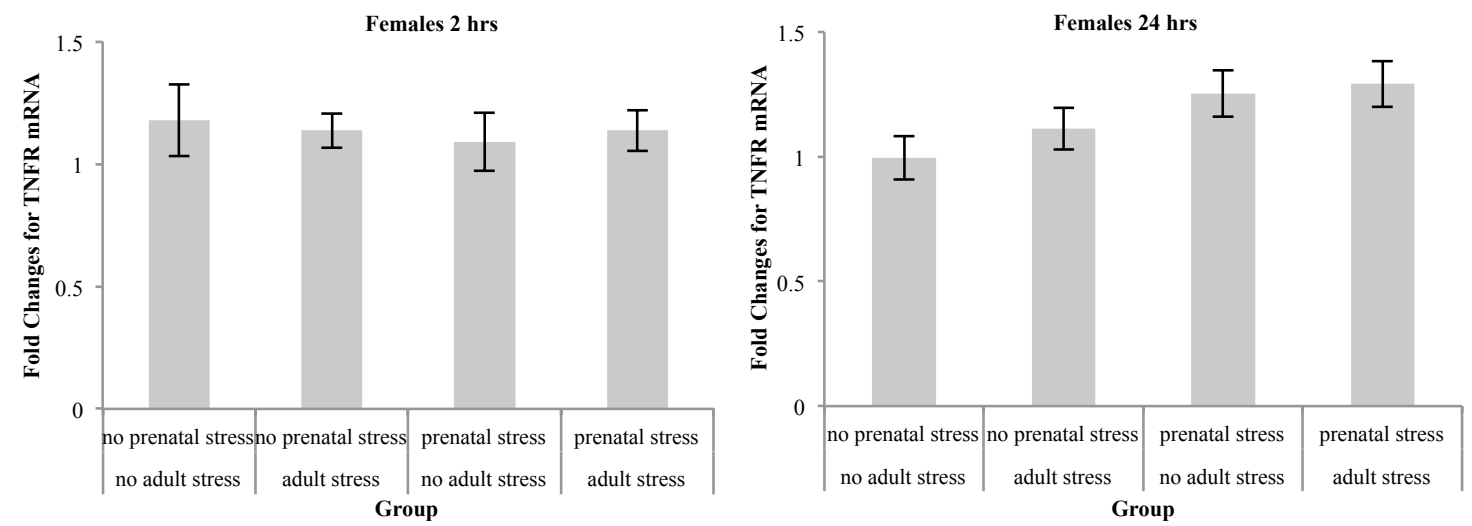

Figure 19. Expression of TNFR mRNA in the PFC of male (A) and female (B) mice as a function of the prenatal stressor treatment and 2 and 24 hours following the stressor or control treatment administered during adulthood. Data are represented by mean fold changes \pm S.E.M. 


\subsection{Experiment 3: Effects of prenatal stress and adult stress on mouse behaviour - Social Interaction}

Among males, the latency to enter the novel mouse chamber was unaffected by any of the treatments (Figure 20A). In contrast, among female mice a significant Adult Stressor $\mathrm{x}$ Time interaction was apparent, $\mathrm{F}_{1,35}=5.91, \mathrm{p}<.05$ (Figure 20B). Females tested 30 minutes following the adulthood stressor displayed shorter latencies to enter the novel mouse chamber than did those that were not stressed in adulthood. 


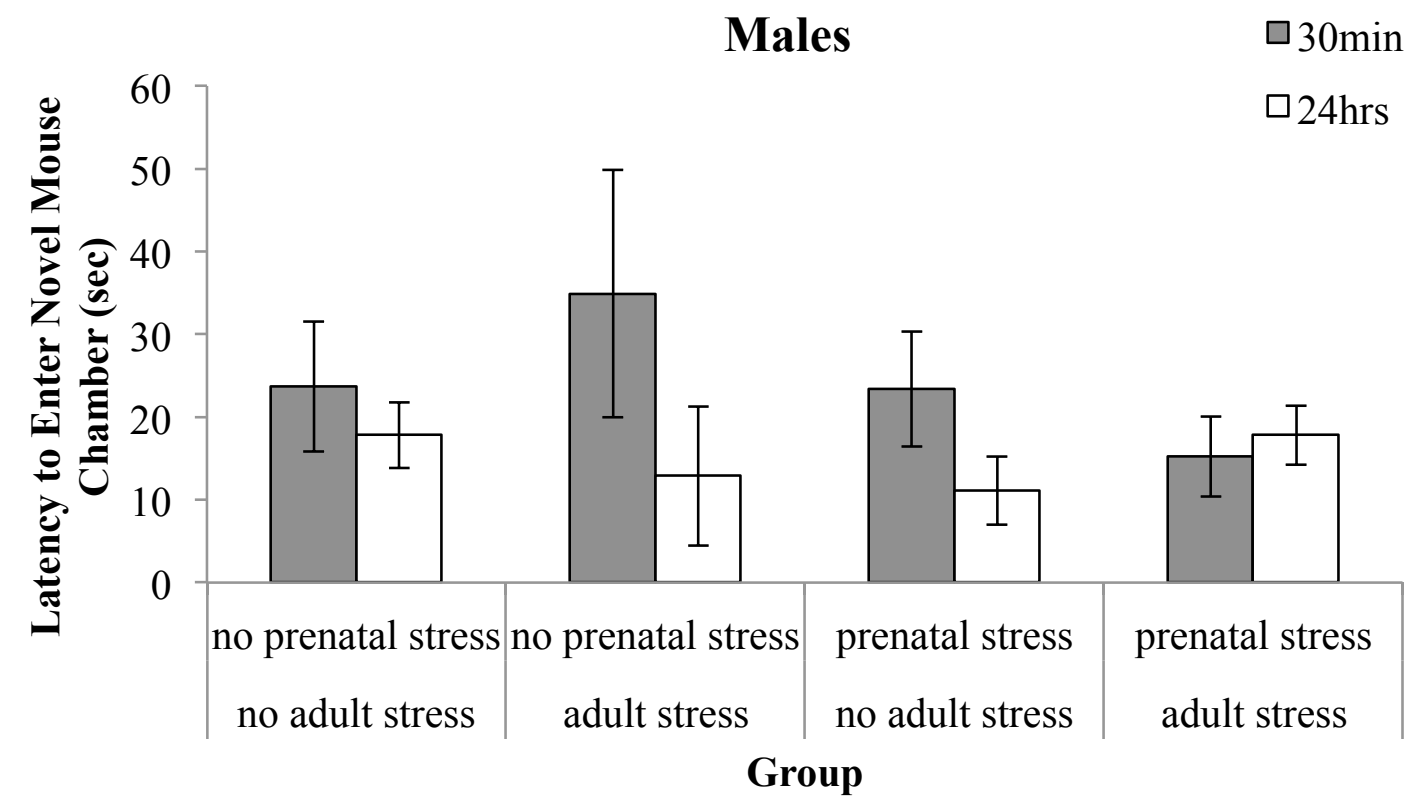

B

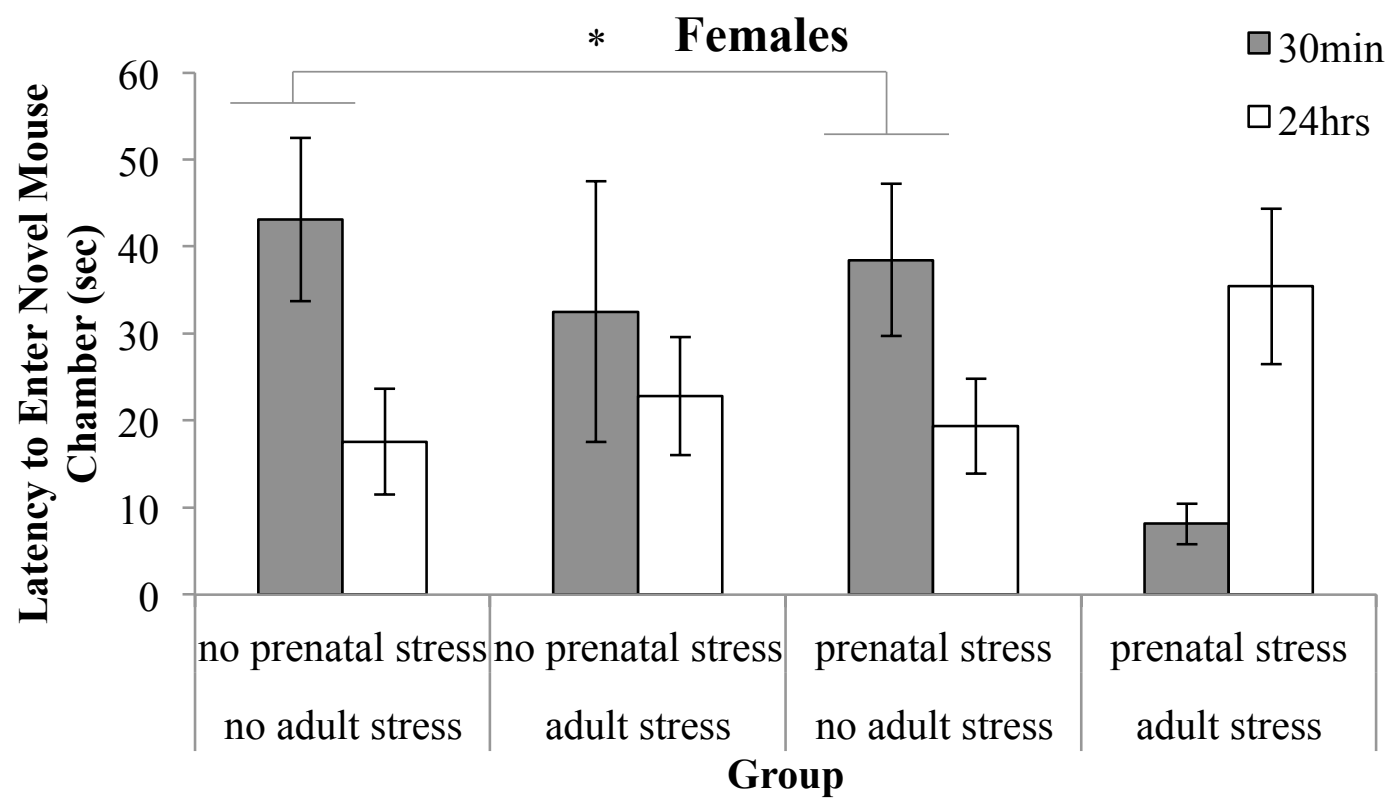

Figure 20. The latency to enter the novel mouse chamber (seconds) of a social interaction test among male (A) and female (B) mice tested 30 minutes and 24 hours following a stressor or control treatment in adulthood, and as a function of the prenatal stressor treatment. Data are represented by means \pm S.E.M. ${ }^{*} \mathrm{p}<.05$ relative to mice tested 30 minutes following a stressor in adulthood. 
Prenatally stressed male mice displayed significantly greater entries to the novel mouse chamber than those that were not prenatally stressed, $\mathrm{F}_{1,35}=11.80, \mathrm{p}<.005$ (Figure 21A). Additionally, male mice made more entries to the novel mouse chamber at 24 hours than at 30 minutes following a stressor or control treatment in adulthood, $F_{1,35}=$ $37.10, \mathrm{p}<.00001$. Female mice displayed a significant time effect as well, however the trend was reversed, where mice made fewer entries to the novel mouse chamber at 24 hours than at 30 minutes following a stressor or control treatment in adulthood, $\mathrm{F}_{1,35}=$ 19.30, $\mathrm{p}<.0001$ (Figure 21B).

Similar to the effects seen in entries to the novel mouse chamber, prenatally stressed male mice made more entries to the object chamber than those that were not prenatally stressed, $\mathrm{F}_{1,35}=11.86, \mathrm{p}<.005$ (Figure $22 \mathrm{~A}$ ). However, males that were stressed in adulthood displayed significantly fewer entries than those that were not stressed in adulthood, $\mathrm{F}_{1,35}=4.75, \mathrm{p}<.05$. In contrast, the stressors did not influence the behavior of female mice (Figure 22B). The female mice were found to make more entries to the object chamber at 24 hours than at 30 minutes following a stressor or control treatment in adulthood., $\mathrm{F}_{1,35}=15.15, \mathrm{p}<.0005$. 
Males

$\square 30 \mathrm{~min}$

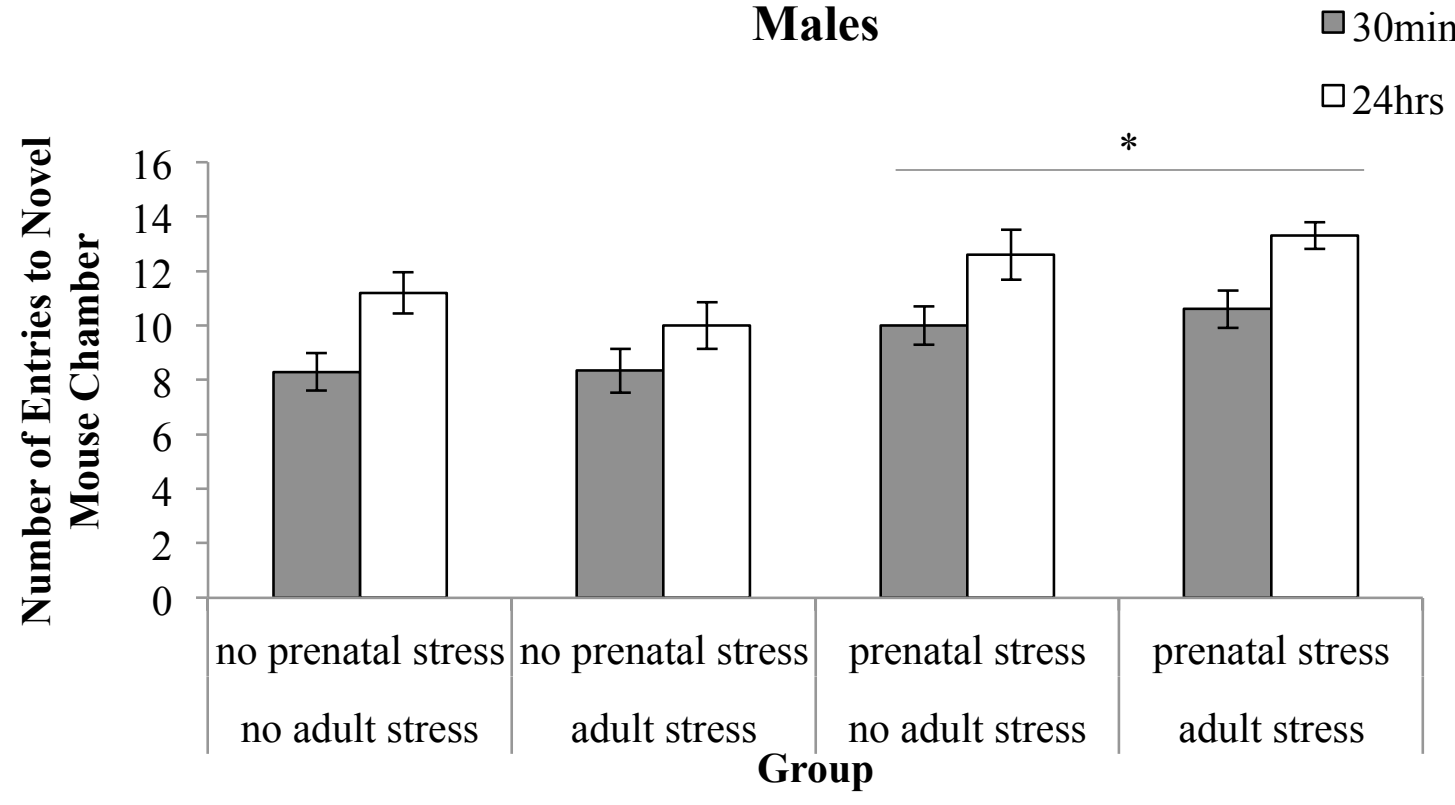

B

Females

$\square 30 \mathrm{~min}$

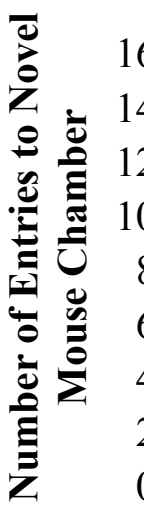

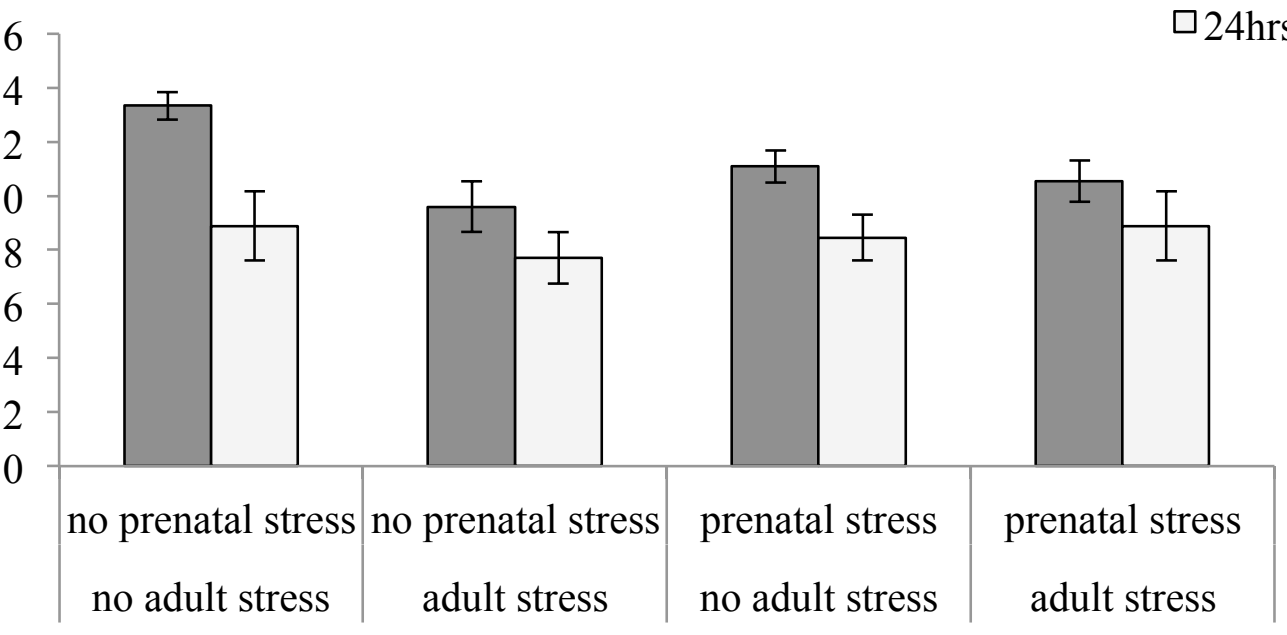

Group

Figure 21. The number of entries to the novel mouse chamber in a social interaction test among male (A) and female (B) mice tested 30 minutes and 24 hours following a stressor or control treatment in adulthood, and as a function of the prenatal stressor treatment. Data are represented by means \pm S.E.M. ${ }^{*} \mathrm{p}<.005$ relative to non-prenatally stressed mice. 


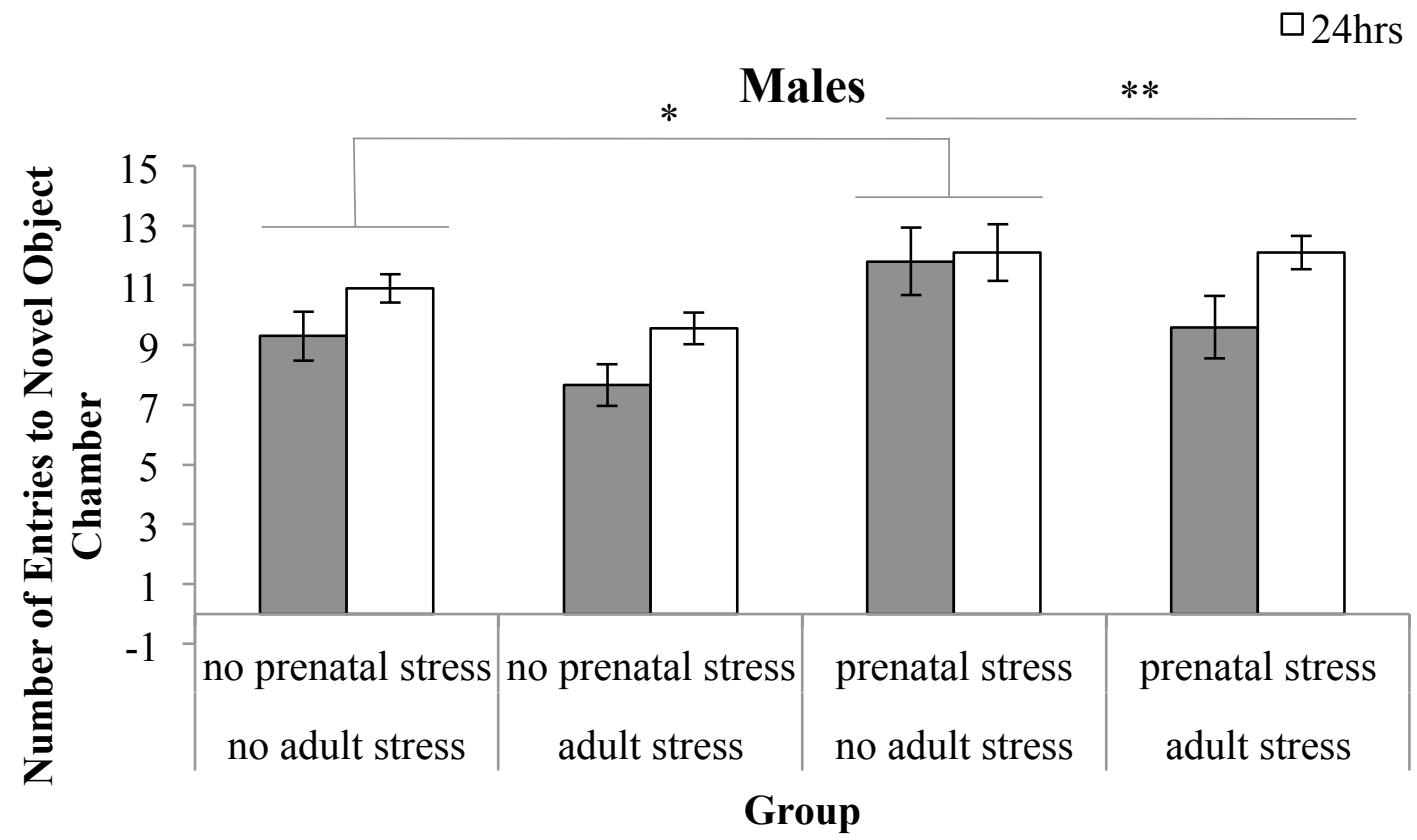

B

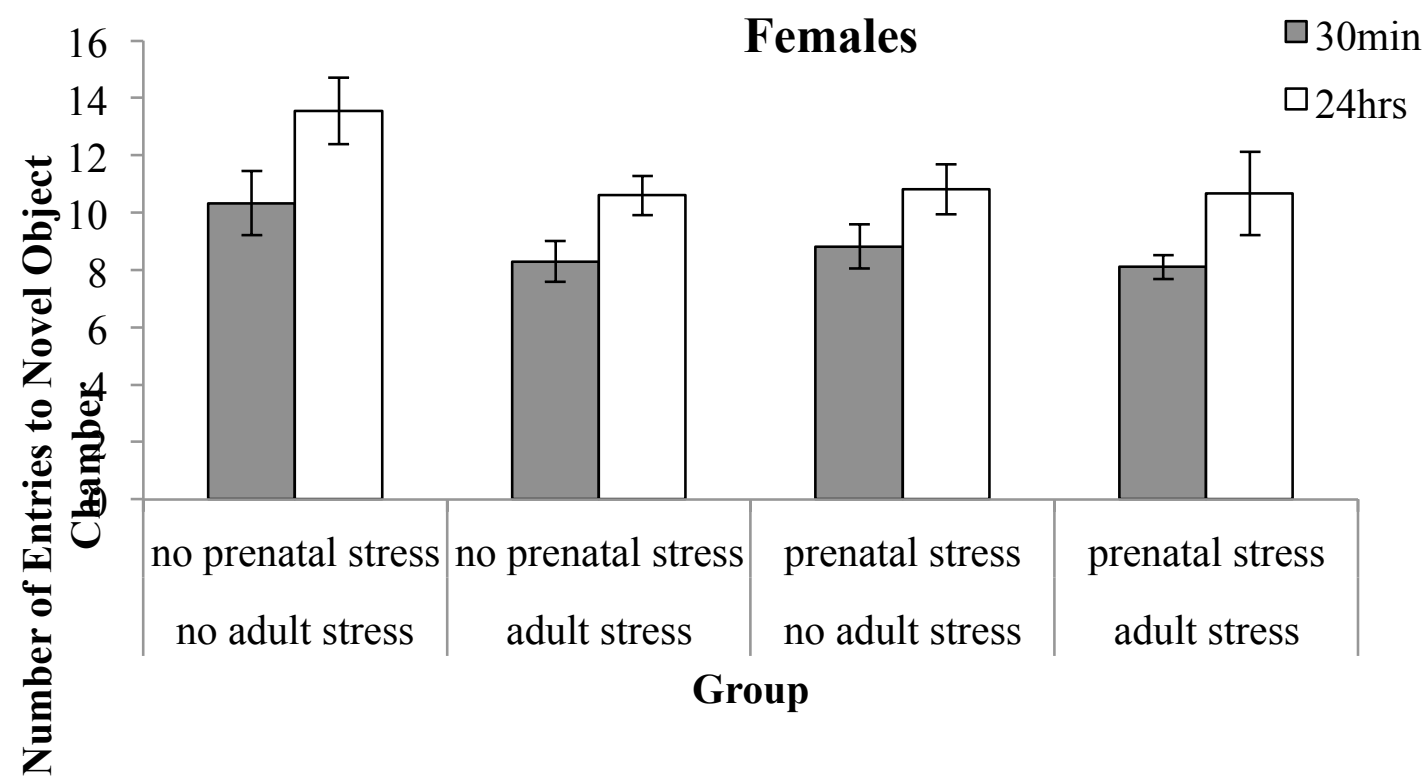

Figure 22. The number of entries to the novel object chamber of a social interaction test among male (A) and female (B) mice tested 30 minutes and 24 hours following a stressor or control treatment in adulthood, and as a function of the prenatal stressor treatment. Data are represented by means \pm S.E.M. $* * p<.005$ relative to non-prenatally stressed mice. $* \mathrm{p}<.05$ relative to mice that were stressed in adulthood. 
The time spent in the novel mouse chamber was significantly greater in male mice tested at 24 hours than at 30 minutes following the stressor or control treatment in adulthood, $F_{1,35}=9.54, p<.005$. Amongst females, prenatally stressed mice spent significantly less time in the novel mouse chamber than those that were not prenatally stressed, $\mathrm{F}_{1,35}=4.61, \mathrm{p}<.05$ (Figure 23B).

No significant treatment effects were found in males and females regarding the time spent in the object chamber (Figure 24). 


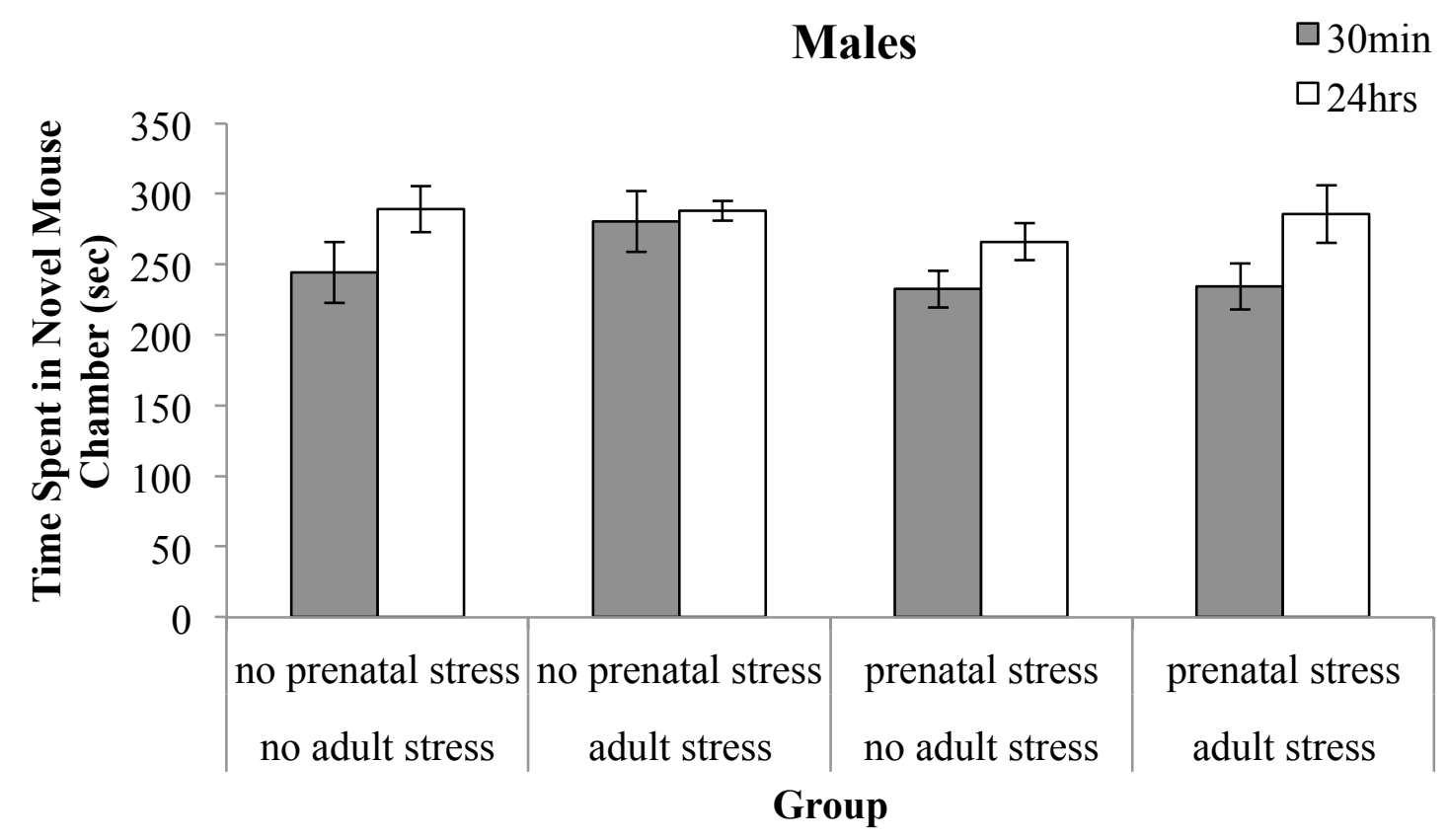

B

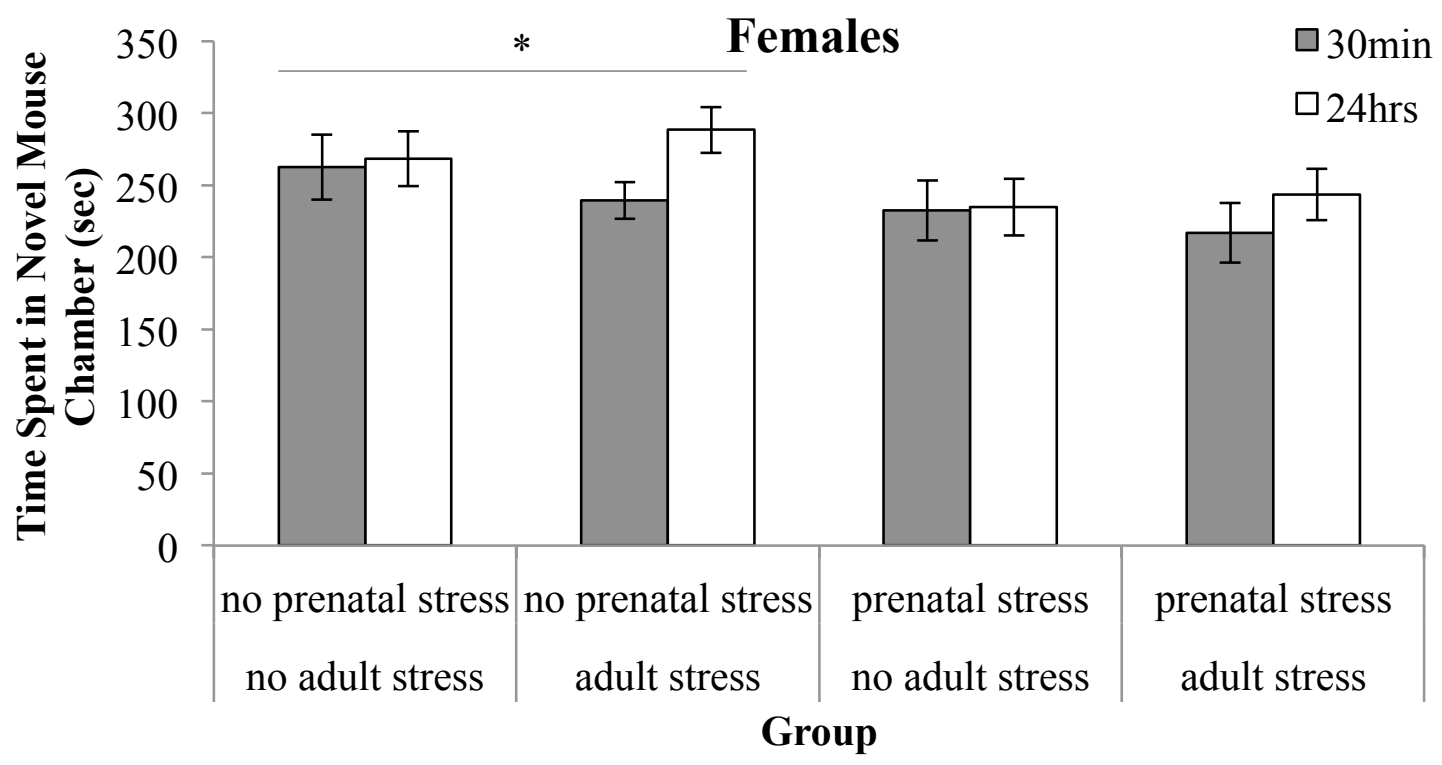

Figure 23. The time spent in the novel mouse chamber (seconds) of a social interaction test among male (A) and female (B) mice tested 30 minutes and 24 hours following a stressor or control treatment in adulthood, and as a function of the prenatal stressor treatment. Data are represented by means \pm S.E.M. ${ }^{*} p<.05$ relative to mice that were prenatally stressed. 


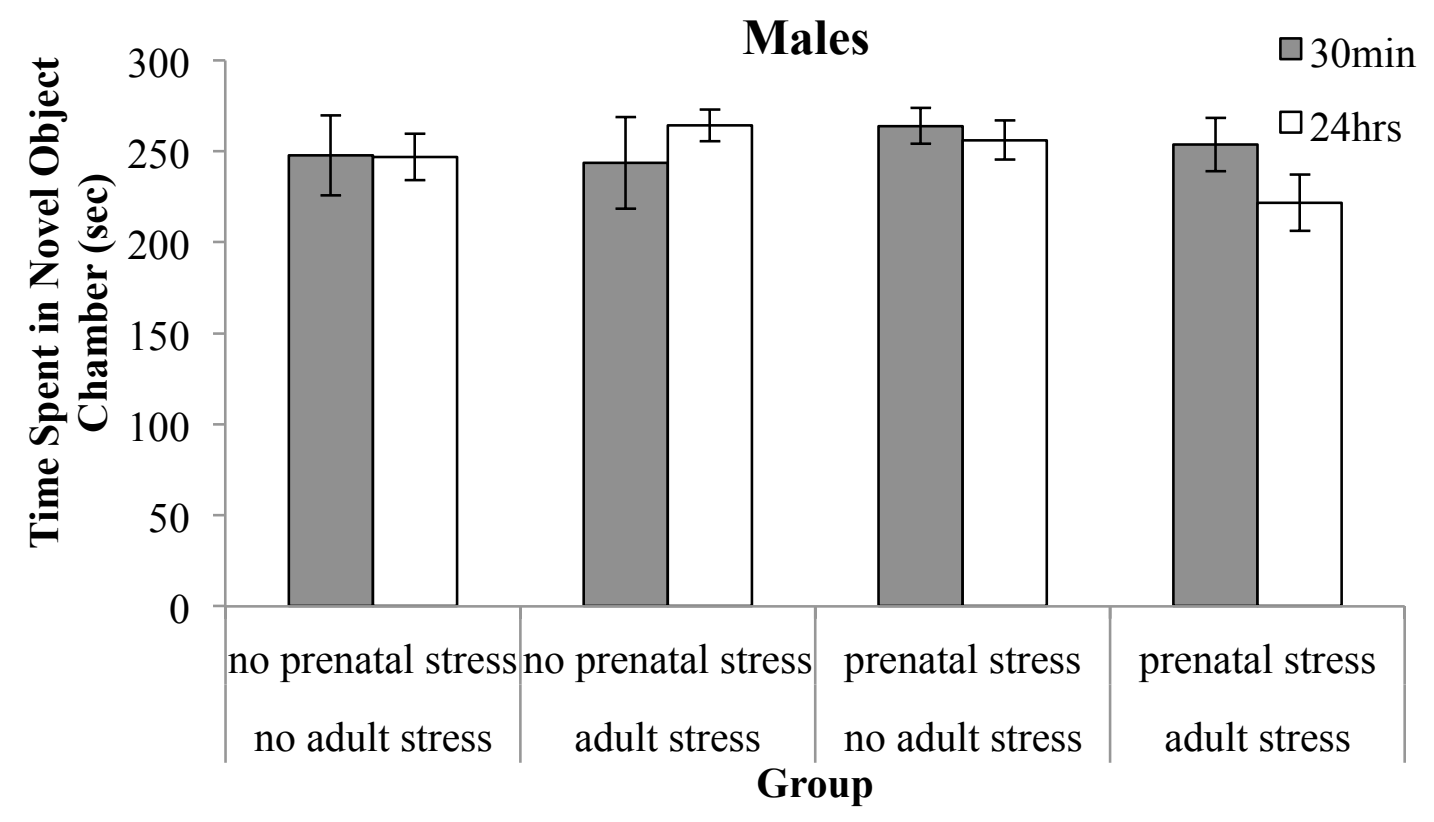

B

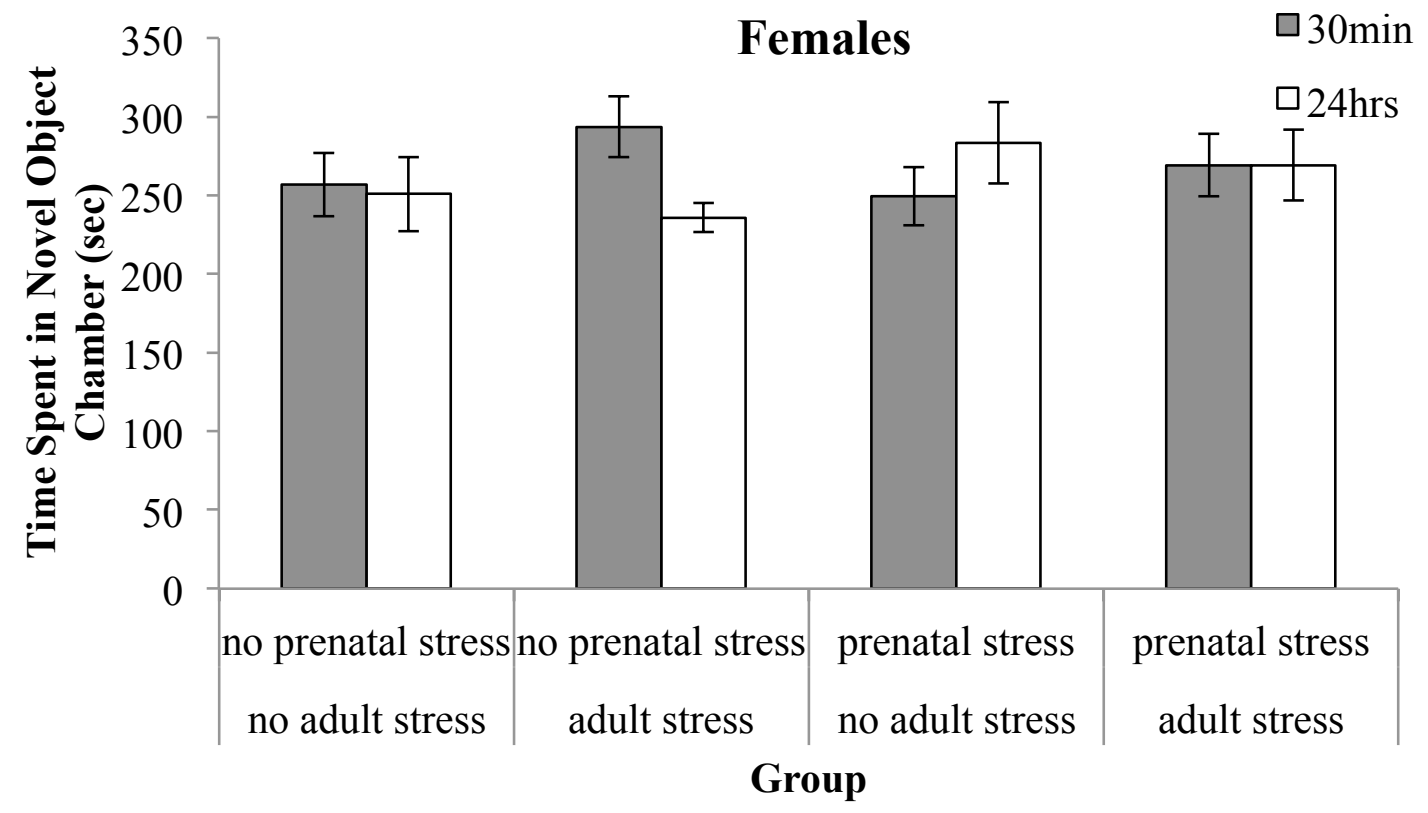

Figure 24. The time spent in the novel object chamber (seconds) of a social interaction test among male (A) and female (B) mice tested 30 minutes and 24 hours following a stressor or control treatment in adulthood, and as a function of the prenatal stressor treatment. Data are represented by means \pm S.E.M. 


\section{Chapter: Discussion}

\subsection{Effects of prenatal and adult stress on behaviour}

Prenatal stressors may cause gender-dependent behavioural alterations in the offspring that persist into adulthood or that may become evident following re-exposure to a stressor experienced as an adult (Weinstock, 2001). In our experiments, differential results were observed amongst males and females in the EPM and social interaction tests, suggesting that early life experiences alter adult behavioural tendencies in a gender dimorphic manner.

In Experiment 1, increased anxiety was observed in prenatally stressed male mice tested in a plus maze 30 minutes following a stressor or control treatment in adulthood. These results are consistent with previous reports that have shown increased anxiety-like behaviour in male rodents that had been stressed prenatally (Estanislau \& Morato, 2005; Kofman, 2002). The elevated anxiety appeared to be relatively transient, and when tested 24 hours later, prenatally stressed mice showed reduced anxiety relative to that evident initially. Paralleling these findings, in the social avoidance test, prenatally stressed males continued to show anxiety-like behaviour by spending less time in the interaction zone when exposed to a stranger 30 minutes following the adult stressor.

In contrast, irrespective of the time of testing, prenatally stressed females displayed reduced anxiety-like behaviour in the EPM as demonstrated by shorter latencies to enter an open arm and increased open arm entries. Additionally, those that were stressed both prenatally and as adults spent more time in the open arms than did those that had been stressed on a single occasion. Other studies similarly indicated that 
prenatally stressed female mice made more open arm entries and female rats spent more time in the open arms of a plus maze (Pallarés et al., 2007; Zuena et al., 2008).

Unlike the effects observed in the EPM and social avoidance tests, prenatally stressed males made more entries into the novel mouse and object chambers than did mice that had not been prenatally stressed. The former finding appears to contradict previous results as it indicates more social, and consequently less anxious behaviour (Kaidanovich-Beilin et al., 2011). Prenatal stress has been shown to increase aggression in males (Kinsley \& Svare, 1987), and so it is possible that males made more entries into the novel mouse chamber owing to an increased propensity for aggression rather than a result of decreased anxiety. This effect was absent in mice stressed in adulthood who made fewer entries into the novel mouse chamber. Overall, it appears that prenatal and adult stressors elicit anxiety-like behaviour in male social interactions.

As seen in the EPM, prenatally stressed females appeared more explorative and impulsive. Similarly, they continued to be so in the social interaction test as reflected by shorter latencies to enter the novel mouse chamber, although they spent less time in it. These results appear to contradict one another given that the former finding is an index of decreased anxiety and the latter is a measure of increased anxiety in the social interaction test. It seems that prenatal stressors have differential effects on female behaviour depending on whether they are in close contact with a novel mouse.

\subsection{Effects of prenatal and adult stress on corticosterone levels}

HPA axis dysfunction, in part represented by increased basal and stress-induced cortisol or corticosterone (CORT), is a common finding amongst studies of mood disorders (Baumeister et al., 2014). In the same regard, prenatal stressors have been 
shown to modify HPA activity (Seckl, 2004). In Experiment 2a, only an adult stressor effect on CORT was observed in males 2 hours following a social stressor. Previous studies also report increased CORT in male mice following social defeat (Audet et al., 2011; Keeney et al., 2001). In contrast, prenatally stressed female mice showed increased CORT levels relative to those of mice that were not prenatally stressed. Hyperactivity of the HPA axis was also observed in prenatally stressed female rats who exhibited increased basal and stress-induced CORT (Szuran et al., 2000). In this regard, the effects of prenatal stress on CORT was apparent in males at least as long as 24 hours following the adult treatment (Experiment 2b). This was an admittedly unexpected finding as corticoid changes typically persist for a matter of a few hours at most, and thus this finding bears repetition.

\subsection{Effects of prenatal and adult stress on PFC mRNA expression of CRH and its receptors}

As previously discussed, dysregulation of the HPA system may contribute to the emergence of mood disorders. Impaired negative feedback of this axis may result in prolonged hypersecretion of $\mathrm{CRH}, \mathrm{ACTH}$ and consequently cortisol. Furthermore, modifications of the two known CRH receptors, CRHR1 and CRHR2, have been shown to play a role in HPA axis dysfunction and increased anxiety-like behaviour (Kishimoto et al., 2000; Müller \& Wurst, 2004). Therefore, in addition to measuring corticosterone, we assessed the PFC mRNA levels of CRH and two of its receptors, CRHR1 and CRHR2.

In Experiments 2a and 2b, males showed no changes in $\mathrm{CRH}$ and its receptors, however, females stressed prenatally and as adults exhibited significantly elevated CRH 
mRNA expression in the PFC 2 hours later in comparison to non stressed mice or those stressed on only a single occasion. Those that were stressed prenatally also exhibited increased CRHR1 mRNA expression relative to those that were not prenatally stressed. However, 24 hours after the adult treatment the influence of the prenatal stressor was absent, although the females stressed in adulthood continued to express significantly more $\mathrm{CRH}$ than those that were not stressed as adults. Previous studies have shown that

prenatal stressors reduced methylation of the $\mathrm{CRH}$ gene promoter in the rat hypothalamus (Xu et al., 2014) and increased CRH and CRHR1 amygdala expression, but only in female rats (Zohar \& Weinstock, 2011). It is possible that the altered CRH and CRH receptor changes in the PFC that were associated with prenatal stressor exposure stemmed from similar epigenetic processes. Although such effects were described in mice as a function of stressors experienced in adulthood (Jaferi \& Bhatnagar, 2007), to date no such effects have been reported regarding the actions of prenatal stressors.

\subsection{Effects of prenatal and adult stress on brain cytokine expression}

In addition to their roles in immunity, cytokines are potent mediators of HPA axis activity (Dunn, 2011) and induce neurotransmitter and behavioural changes similar to those associated with depression (Anisman \& Merali, 2002). For these reasons, cytokine variations have been implicated in mood disorders (Anisman \& Merali, 2002).

Additionally, both immunological and psychological stressors have been shown to induce cytokine alterations in utero (Coussons-Read et al., 2005; Hava et al., 2006). As a result, it may be likely that prenatal stress provokes cytokine changes in the mother that reach the fetus via the placenta, and ultimately affect the development and future mental health of the offspring (Howerton \& Bale, 2012). Indeed, increased expression of IL-1 $\beta$ was 
observed in the medial prefrontal cortex of adult female mice that were prenatally exposed to polyriboinosinic-polyribocytidilic acid (PolyI:C), a synthetic double-stranded RNA that induces time-limited inflammation in mammals (Fortier et al., 2004; Meyer et al., 2008).

In line with these findings, in Experiment $2 \mathrm{a}$ and $2 \mathrm{~b}$, changes of cytokines were observed in the PFC of offspring that were stressed prenatally or in adulthood. Male mice that had been prenatally stressed showed no significant changes of PFC IL-1 $\beta$ mRNA levels at either 2 or 24 hours following the adult treatment. However, prenatally stressed females showed significantly greater IL- $1 \beta$ mRNA levels 2 hours following the adult stressor or control treatment than those that were not prenatally stressed. Interestingly, it has been shown that IL-1 $\beta$ is sensitized by previous stressor experiences and this appeared to be the case in our experiment as well (Audet et al., 2011). The present study also revealed increased IL-1R1 mRNA expression in prenatally stressed females 2 and 24 hours following the adult treatment, although this effect was only significant at the latter time point. Together, the elevated mRNA expression of both IL-1 $\beta$ and IL-1R1 suggests increased activity of this cytokine in the PFC of adult prenatally stressed females. As a result of the cytokine variations, disruption of neuronal signaling may occur in the PFC and subsequently impair stress regulation and emotional processing in prenatally stressed offspring (Arnsten \& Rubia, 2012; Gądek-Michalska et al., 2013).

In contrast to IL- $1 \beta$, the level of IL-6 increased as a function of adult as opposed to the prenatal stressor in both males and females. As previously observed in male mice (Audet et al., 2011), prefrontal cortex IL-6 mRNA expression was significantly elevated in males at 2 hours and in females at 24 hours following the social stressor. Females 
appeared to show a similar trend 2 hours following the adult treatment, but this effect was only modest and not statistically significant.

\subsection{Differential effects of prenatal and adult stress on males and females}

In our experiments, fewer effects were identified in males than in females. In males we observed some anxiety-like behaviour in the plus maze, and increased PFC IL6 mRNA expression as a function of adult stress. Furthermore, prenatal stress appeared to have some effect on CORT and no effect on cytokines within the PFC. A possible explanation for these results might stem from the viability-vulnerability hypothesis.

During fetal development, male energy expenditure is largely applied to growth. This poses consequences in the event of harsh developmental conditions when adaptation is crucial to survival. With little energy remaining, males are limited in their ability to adapt and as a result are more likely to perish. In effect, male fetuses are less viable under prenatal adversities than they would be under normal conditions. However, female fetuses invest far less energy in growth than males and instead are more readily able to adapt to unfavourable developmental conditions, ultimately rendering them more viable. Yet, adaptions in utero are accompanied by a trade-off wherein females tend to exhibit higher variability in behaviour, gene, and protein expression than males. Consequently, this may render them more vulnerable to future environmental insults (Van den Hove, 2013; Sandman et al., 2013). Whether or not adaptations are beneficial largely depends on the nature of the environment in which animals were assessed. Fetal adaptations are particular to uterine conditions and so, when the postnatal environment differs from that of the uterine one, the adaptions may no longer be advantageous in the offspring (Glover et al., 2010; Gluckman et al., 2005). 
In keeping with the viability-vulnerability hypothesis, as previously mentioned, fewer changes were observed in males than in females in our study, particularly within the PFC. It may be that more adaptions occurred during fetal development in females than in males. As a result, females may be more susceptible to the development of psychopathologies depending on the nature of postnatal environments.

Alternatively, prenatal stressors may elicit hormonal changes in the fetus that contribute to sex-specific alterations in brain circuitry and behaviour (Weinstock, 2011). In the developing fetal brain, conversion of testosterone to estradiol by aromatase (Martini \& Melcangi, 1991) is essential for masculinization of the male brain (Cooke et al., 1998) and in females, increased activity of this enzyme defeminizes the brain (Bakker et al., 2006). Prenatal stress has been associated with reduced expression of fetal brain aromatase (Weisz et al., 1982). Given its role in sex-specific brain development, decreased levels of this enzyme may contribute to the differential behavioural and physiological changes observed in male and female offspring of stressed mothers. To be sure, differences of sex hormones are only one of many neurobiological changes that have been observed in response to prenatal stressors, and it is certainly possible that other hormonal or neurotransmitter variations might have contributed to the behavioral dimorphisms observed in the present study.

\subsection{Limitations}

The findings of the present investigation are not without limitations. Prenatal stressors may trigger preterm delivery and result in low fetal birth weight amongst other complications (Coussons-Read et al., 2012; Nkansah-Amankra et al., 2010). It is possible 
that reduced volumes of the brain and other organs involved in stress processes may contribute to the behavioural and physiological alterations observed in our study.

Furthermore, a stressful pregnancy has been shown to reduce maternal care of pups and contribute to the effects of prenatal stressors on the offspring (Bosch et al., 2007). Thus, the effects observed in our study may be the culmination of stressor effects experienced by the mother before and after delivery of her pups, as opposed to just prenatal stressors.

Behaviour observed in females is also influenced by the estrous cycle stage during testing. Females in proestrus exhibited reduced anxiety-like behaviour than those in diestrus, and this effect was associated with increased circulating estradiol (Marcondes et al., 2001). Female behaviour observed in our experiment may have been influenced by variations in estrous stages amongst females.

\subsection{Conclusion}

The repercussions of prenatal stress extend well into later life and become more pronounced with re-exposure to stressors. They are strongly gender-dependent, and may vary with the context in which prenatal stressors are experienced (e.g., stage of pregnancy, presence of other social of environmental challenges). Indeed, in our experiment males appeared more anxious overall than females. We also observed HPA axis changes and cytokine alterations in both sexes. Cumulatively, these changes represent characteristics ordinarily elicited by stressful experiences, but it is also possible that they reflect factors that contribute to the emergence of anxiety and depressive disorders (Weinstock, 2008). 
Clinical studies have mirrored these effects wherein offspring of stressed mothers exhibit learning disorders, emotional instability, and delayed mental development (King \& Laplante, 2005; Gutteling et al., 2005; Davis \& Sandman, 2010). Interestingly, prenatal stress effects have also been shown to persist for two generations owing to epigenetic modifications (Harris \& Seckl, 2011). Taken together, human and animal studies, including the one presented here, support the developmental origins of psychopathologies. It goes without saying that attention to prenatal care and well-being is an important preventative measure that may help ensure the mental health of offspring. 


\section{Appendices}

\section{Appendix A}

\section{A.1 Expression of MIF and SOCS3 mRNA in the PFC}

\section{A}
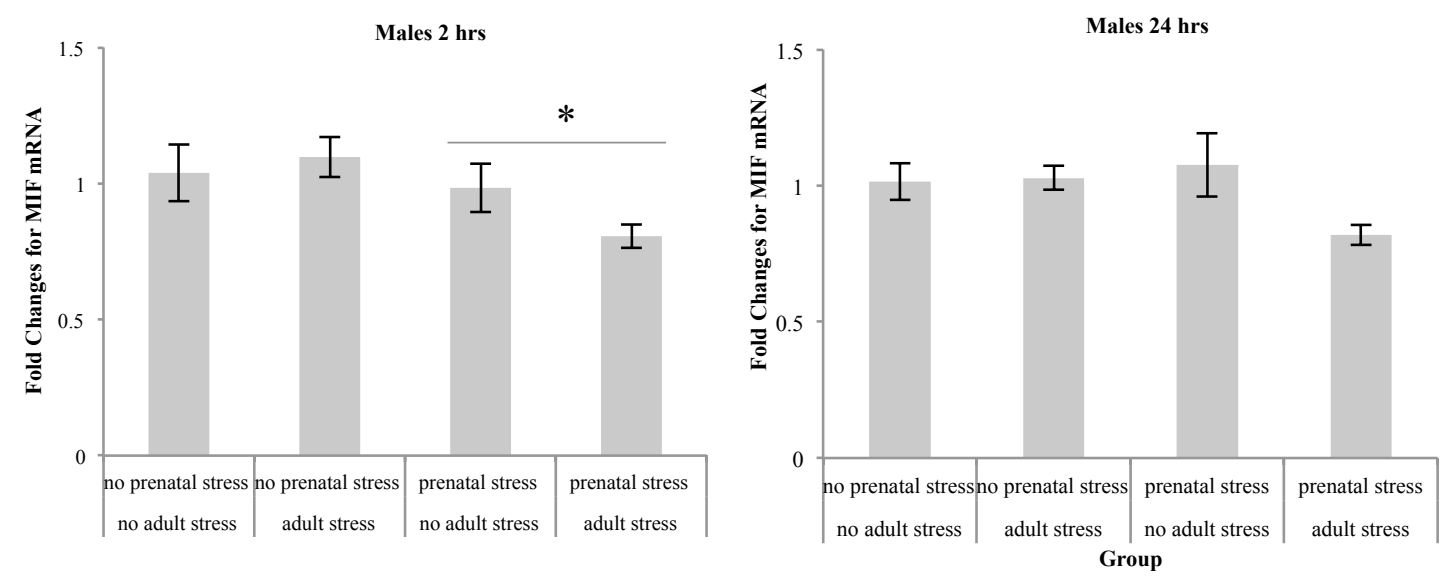

B
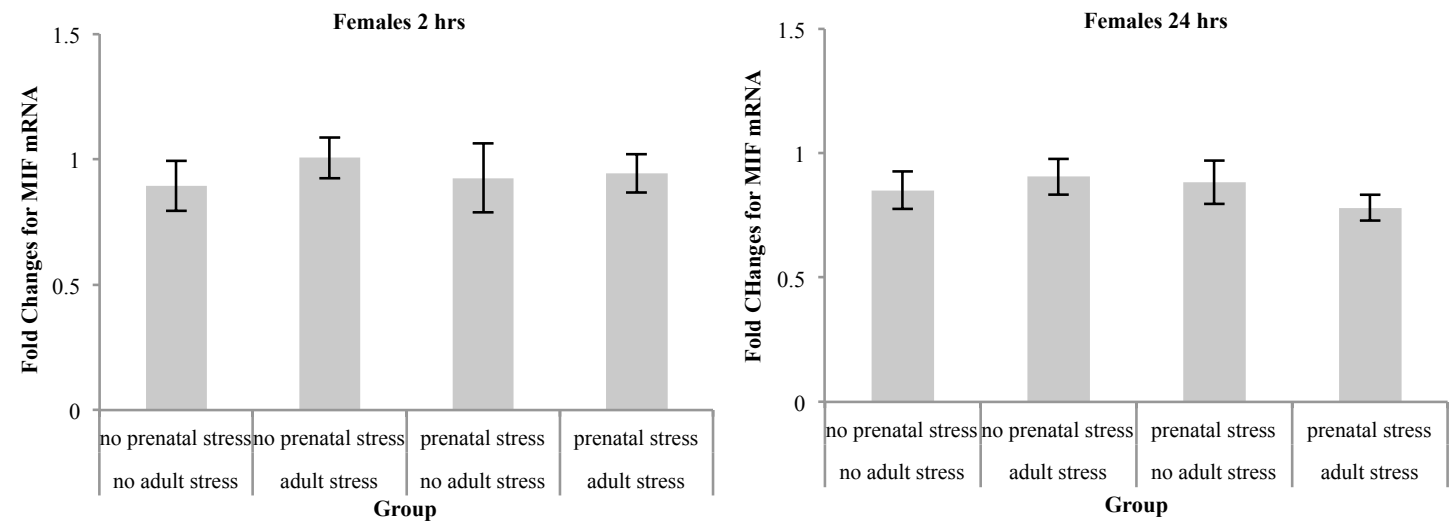

Expression of macrophage migration inhibitory factor (MIF) mRNA in the PFC of male (A) and female (B) mice as a function of the prenatal stressor treatment and 2 and 24 hours following the stressor administered during adulthood. Data are represented by mean fold changes \pm S.E.M. $* \mathrm{p}<.05$ relative to non-prenatally stressed mice. 
A
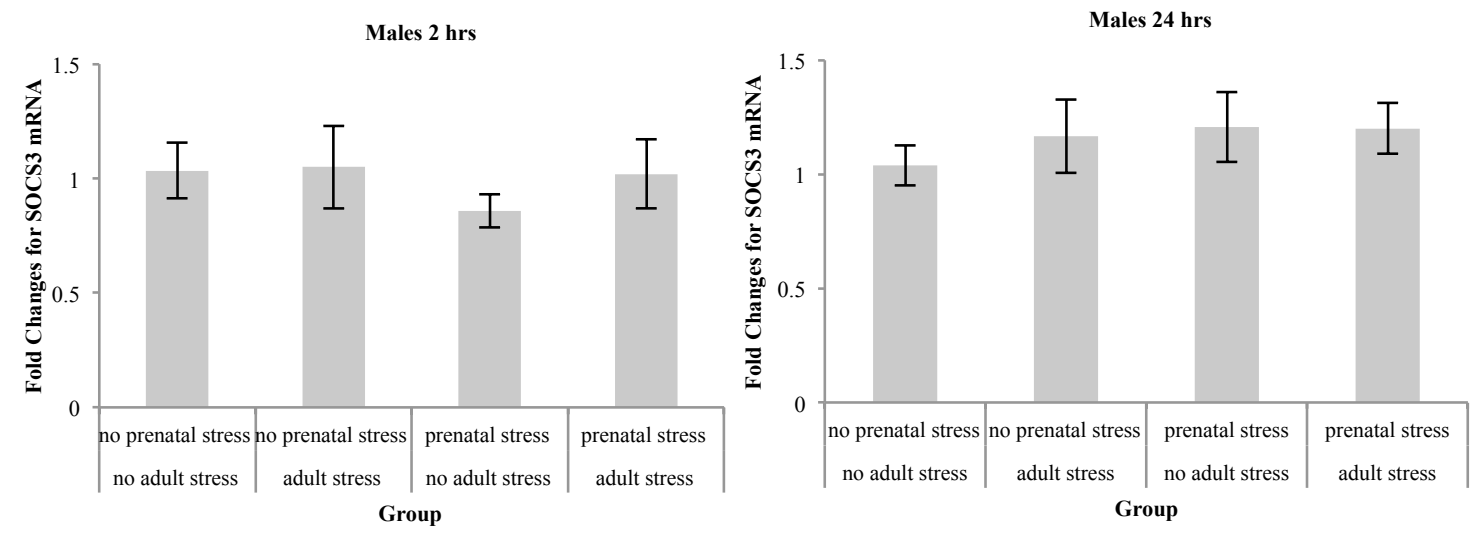

B
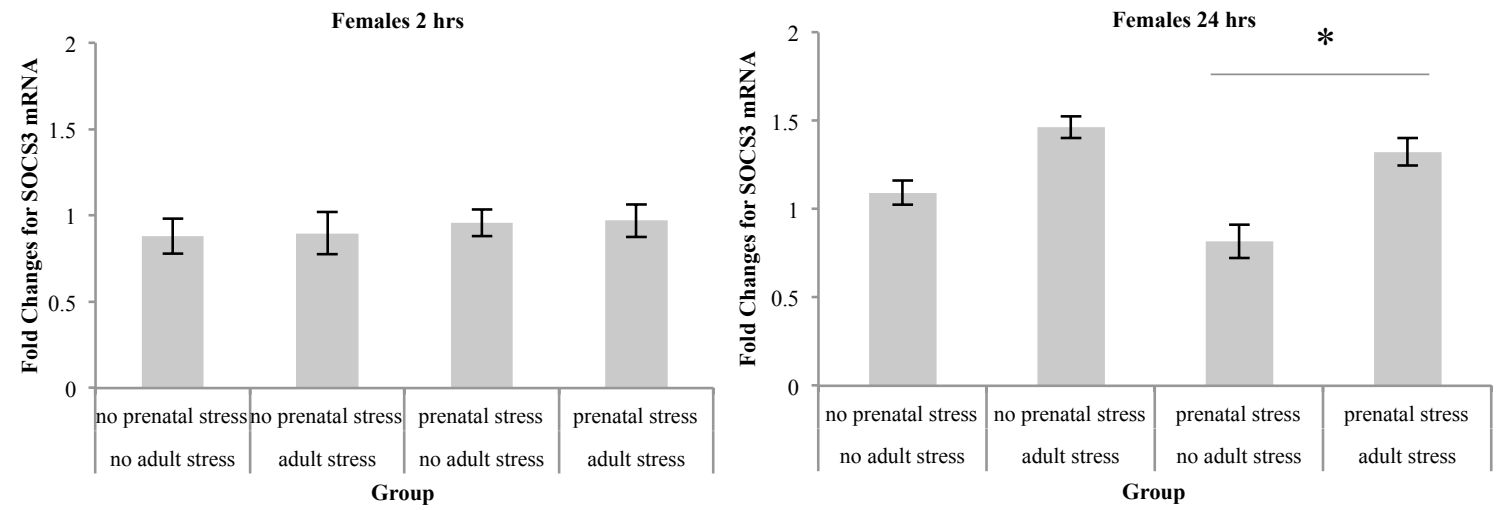

Expression of suppressor of cytokine signalling 3 (SOCS3) mRNA in the PFC of male (A) and female (B) mice as a function of the prenatal stressor treatment and 2 and 24 hours following the stressor administered during adulthood. Data are represented by mean fold changes \pm S.E.M. $* \mathrm{p}<.05$ relative to non-prenatally stressed mice. 


\section{A.2 Expression of serotonin receptor mRNA in the PFC}

A
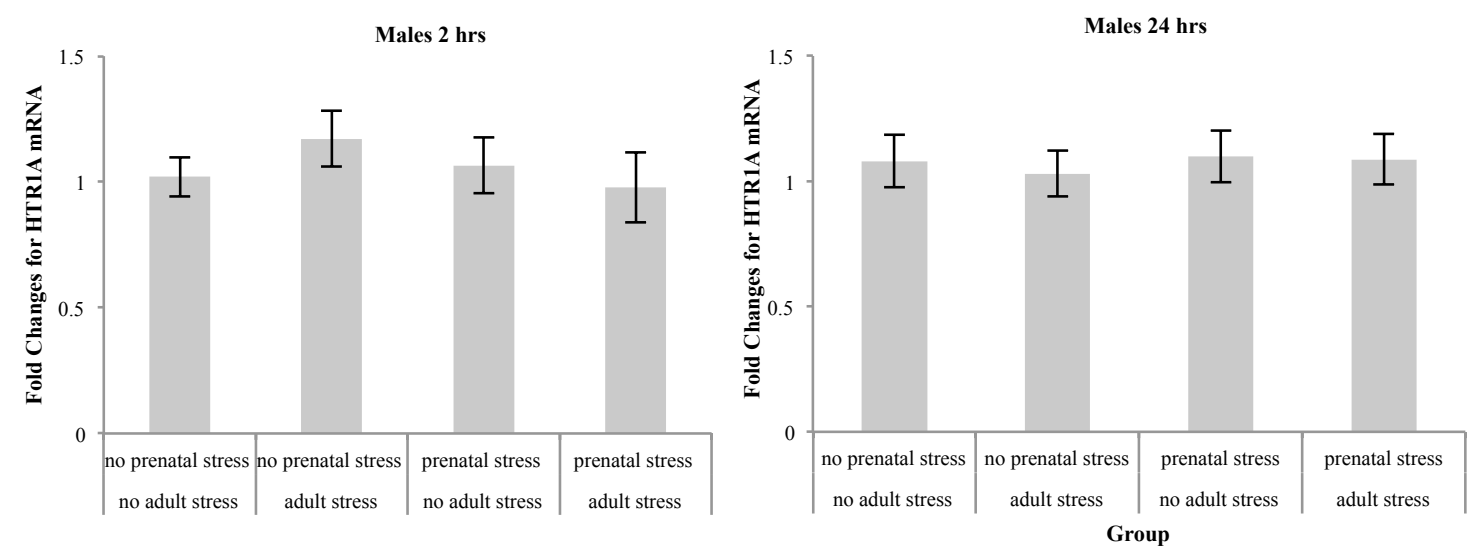

B
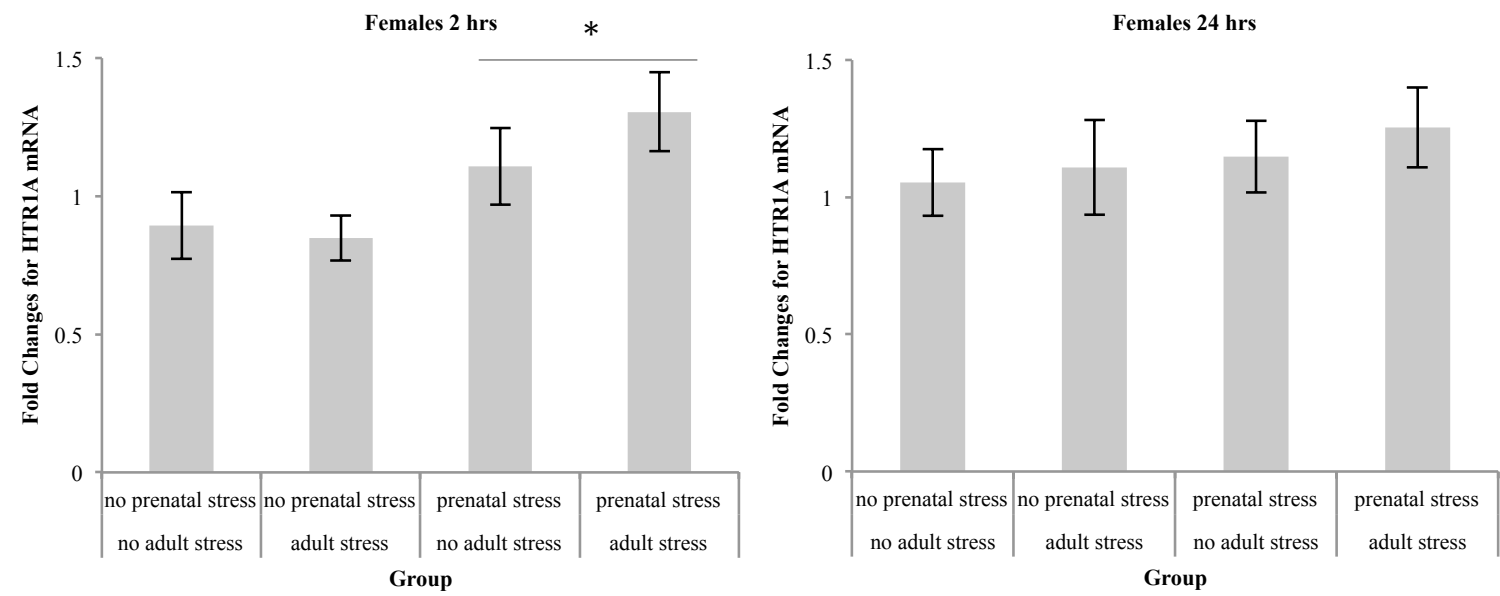

Expression of 5-hydroxytryptamine (serotonin) receptor 1A (HTR1A) mRNA in the PFC of male (A) and female (B) mice as a function of the prenatal stressor treatment and 2 and 24 hours following the stressor administered during adulthood. Data are represented by mean fold changes \pm S.E.M. $* \mathrm{p}<.05$ relative to non-prenatally stressed mice. 

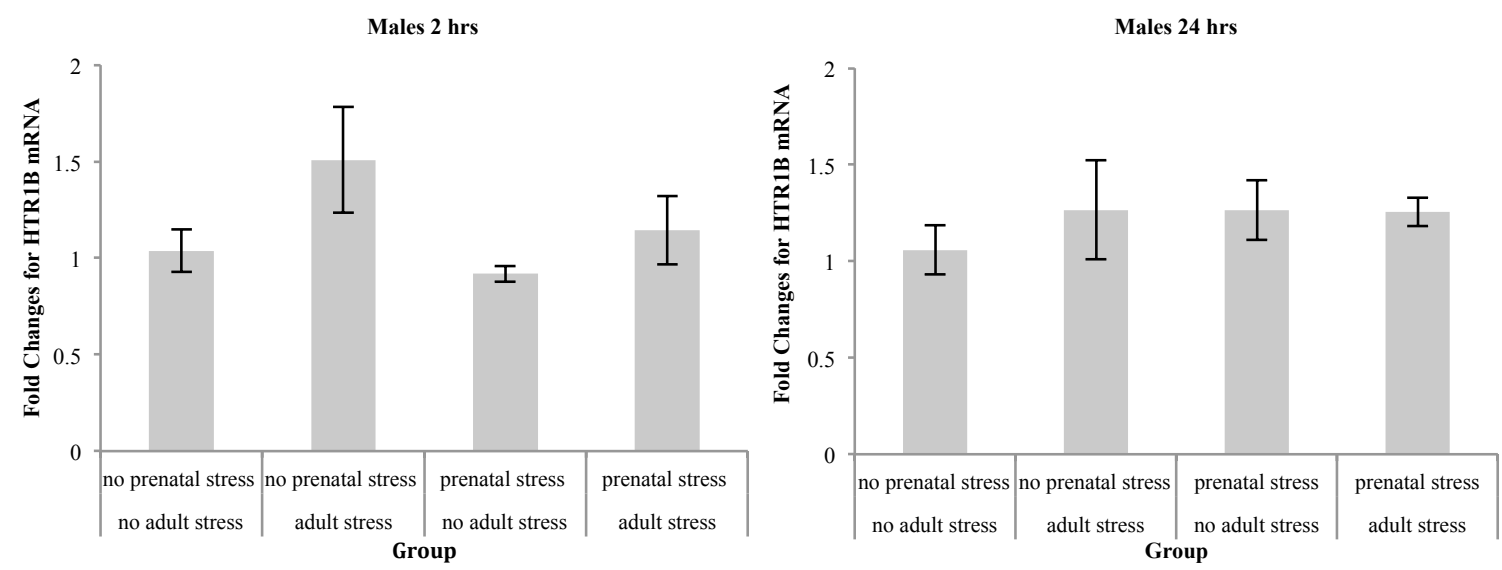

B
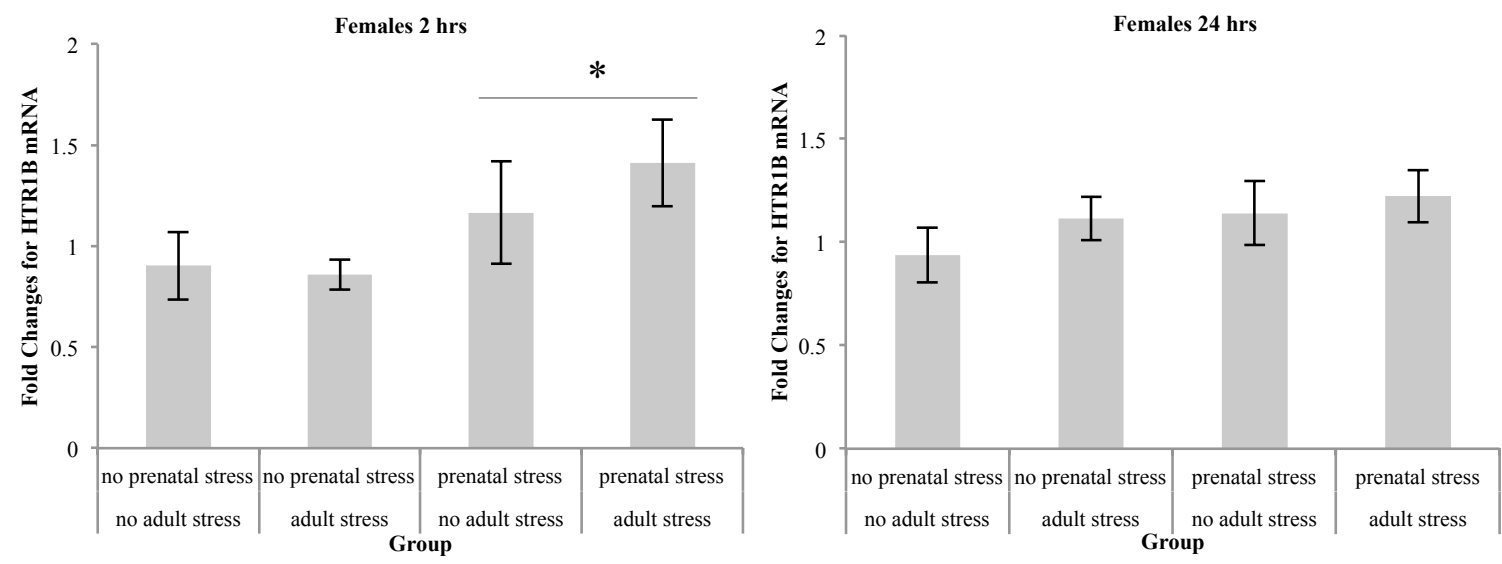

Expression of serotonin receptor 1B (HTR1B) mRNA in the PFC of male (A) and female (B) mice as a function of the prenatal stressor treatment and 2 and 24 hours following the stressor administered during adulthood. Data are represented by mean fold changes \pm S.E.M. $* \mathrm{p}<.05$ relative to non-prenatally stressed mice. 

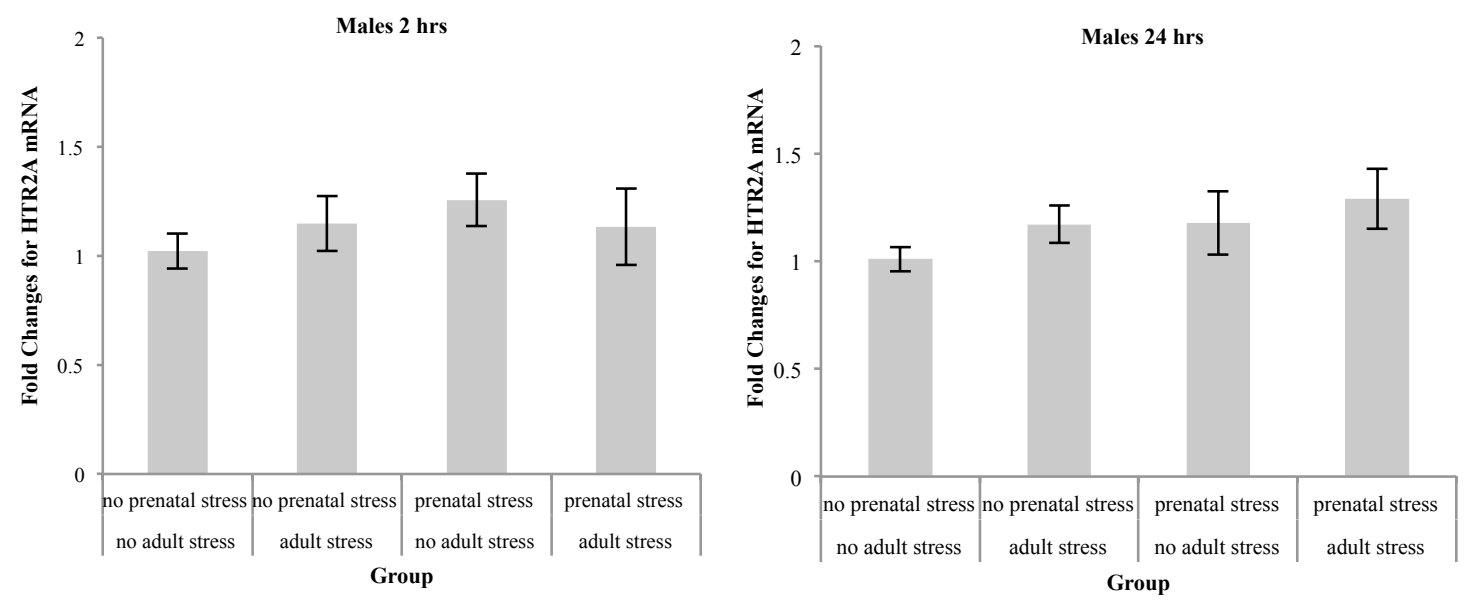

B
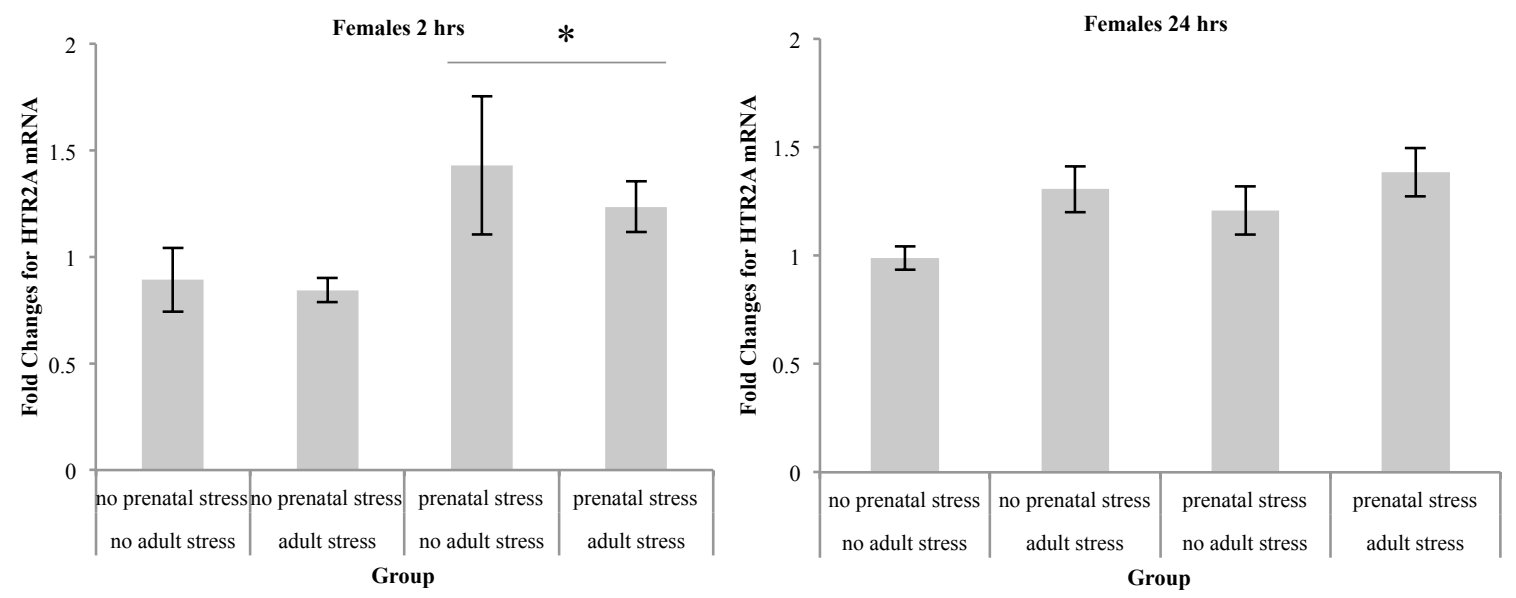

Expression of serotonin receptor 2A (HTR2A) mRNA in the PFC of male (A) and female (B) mice as a function of the prenatal stressor treatment and 2 and 24 hours following the stressor administered during adulthood. Data are represented by mean fold changes \pm S.E.M. $* \mathrm{p}<.05$ relative to non-prenatally stressed mice. 

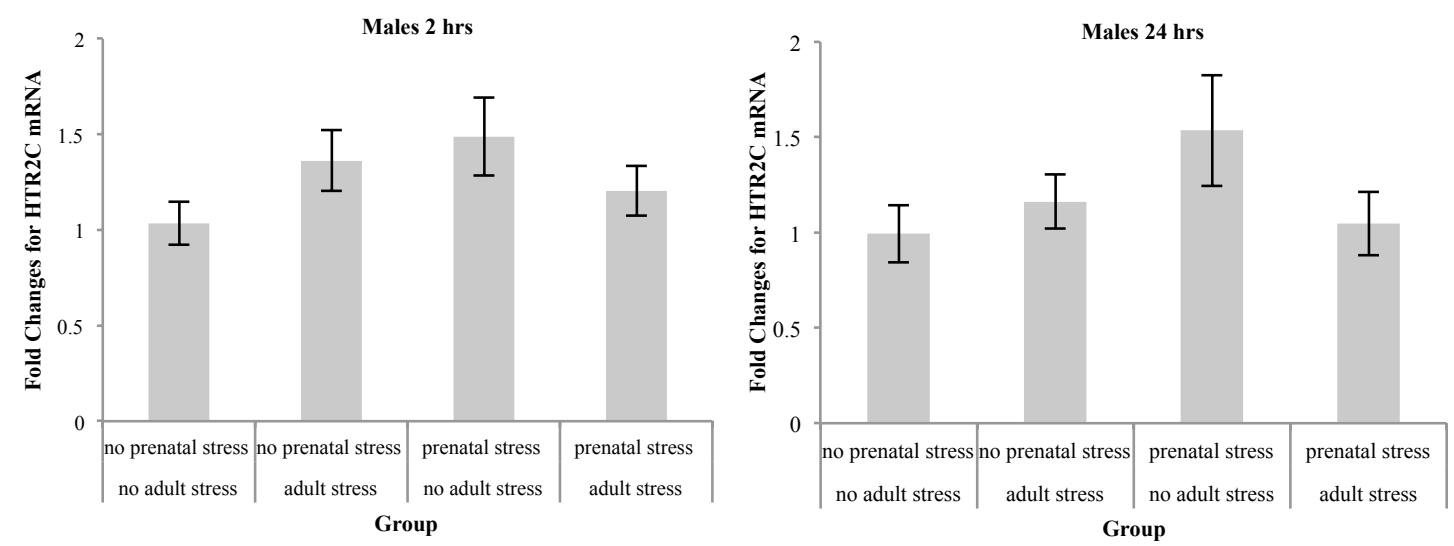

B
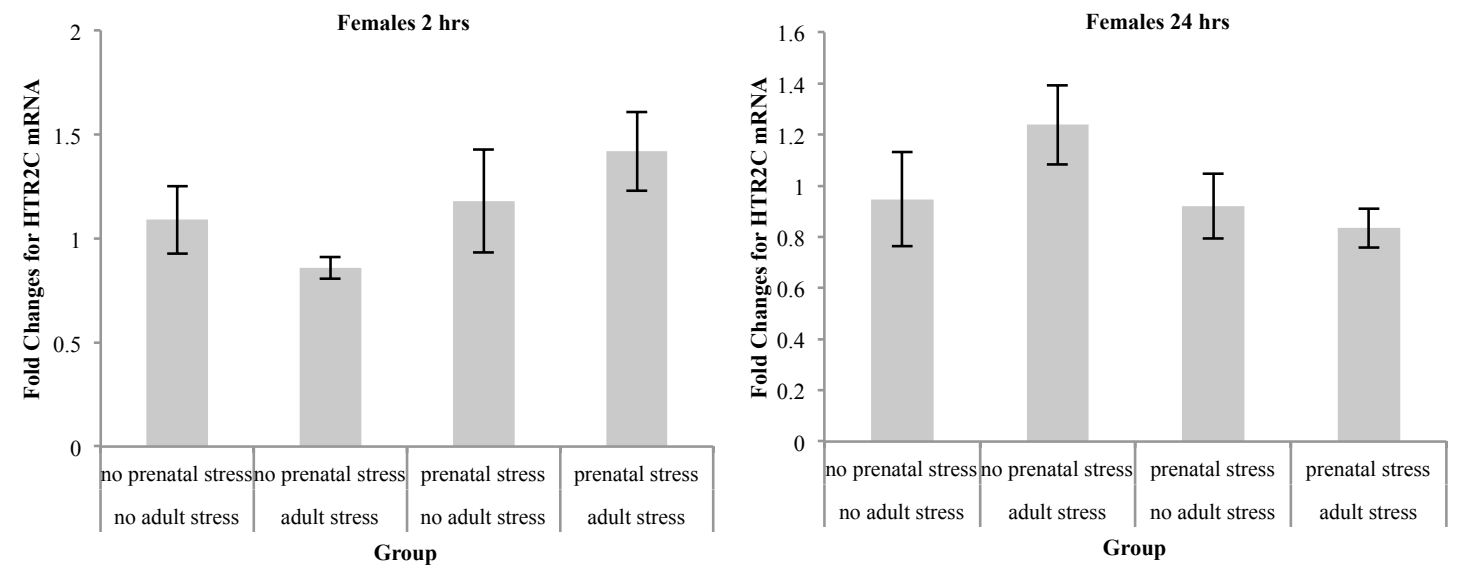

Expression of serotonin receptor 2C (HTR2C) mRNA in the PFC of male (A) and female (B) mice as a function of the prenatal stressor treatment and 2 and 24 hours following the stressor administered during adulthood. Data are represented by mean fold changes \pm S.E.M. 


\section{A.3 Expression of BDNF and NTRK2 mRNA in the PFC}

A
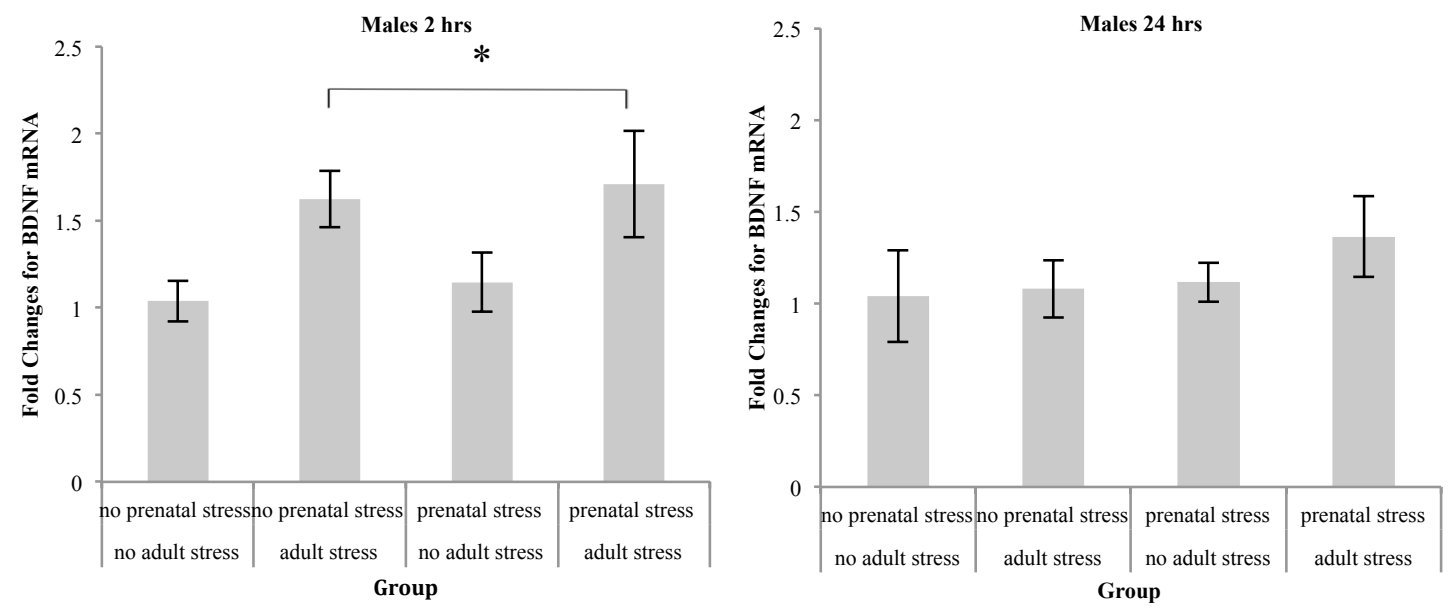

B
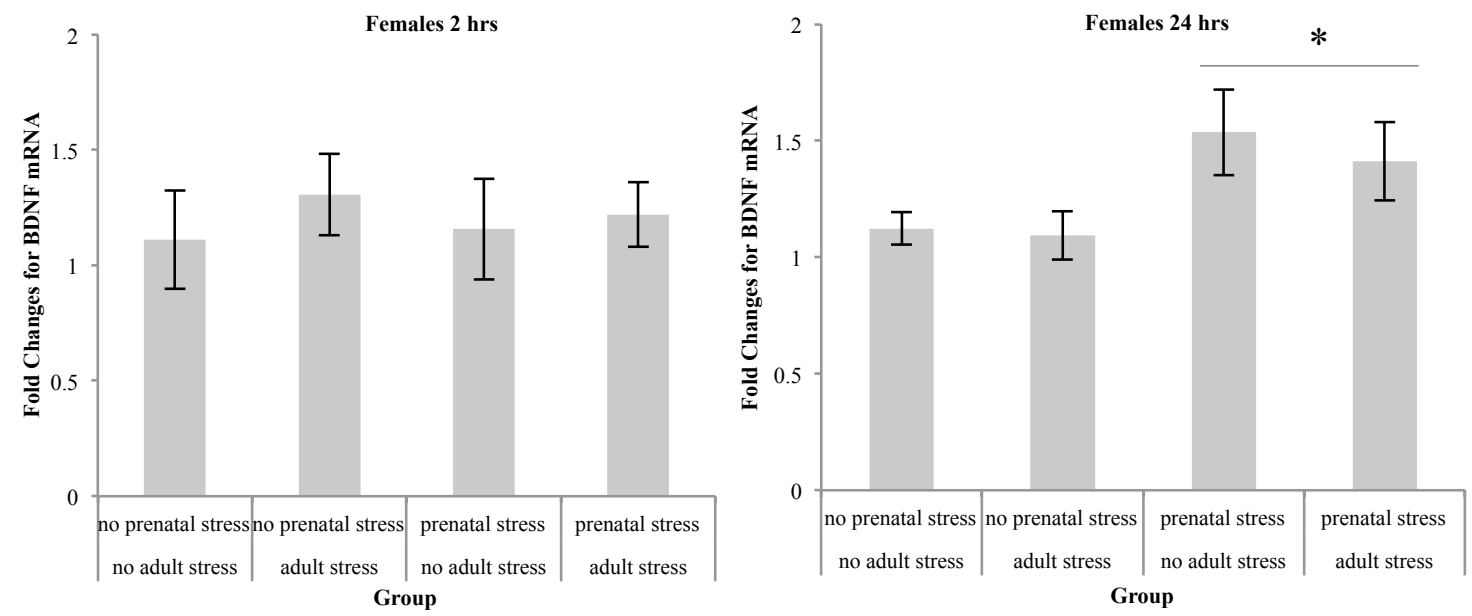

Expression of brain-derived neurotrophic factor (BDNF) mRNA in the PFC of male (A) and female (B) mice as a function of the prenatal stressor treatment and 2 and 24 hours following the stressor administered during adulthood. Data are represented by mean fold changes \pm S.E.M. ${ }^{*} \mathrm{p}<.02$ relative to mice that were not stressed in adulthood. $\# \mathrm{p}<.05$ relative to non-prenatally stressed mice. 

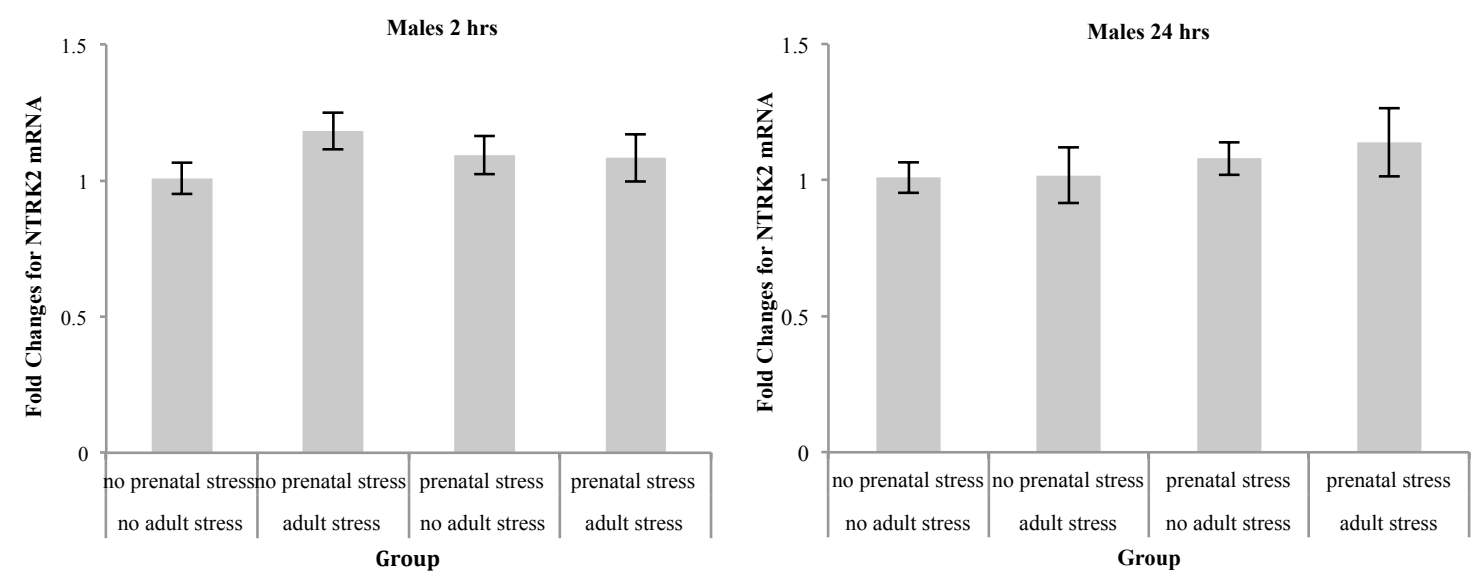

B
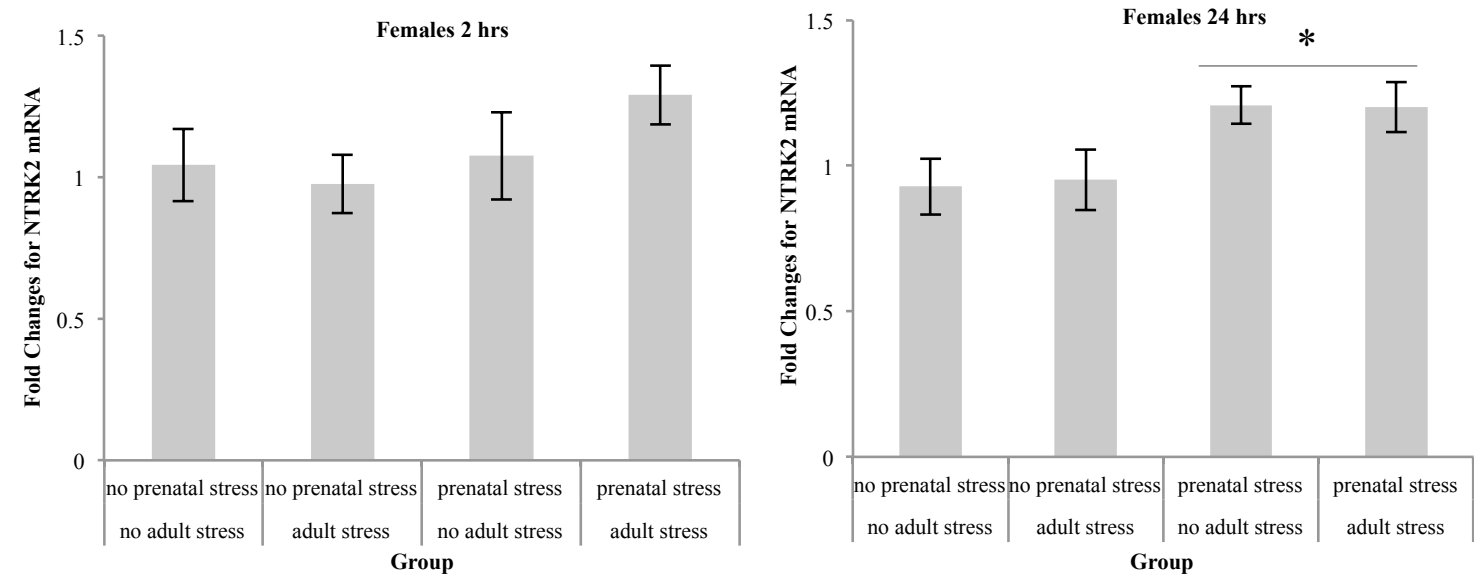

Expression of neurotrophic tyrosine kinase receptor 2 (NTRK2) mRNA in the PFC of male (A) and female (B) mice as a function of the prenatal stressor treatment and 2 and 24 hours following the stressor administered during adulthood. Data are represented by mean fold changes \pm S.E.M. ${ }^{*} \mathrm{p}<.02$ relative to prenatally stressed mice. 


\section{Appendix B}

\section{B.1 Experiment 3: Social Avoidance}
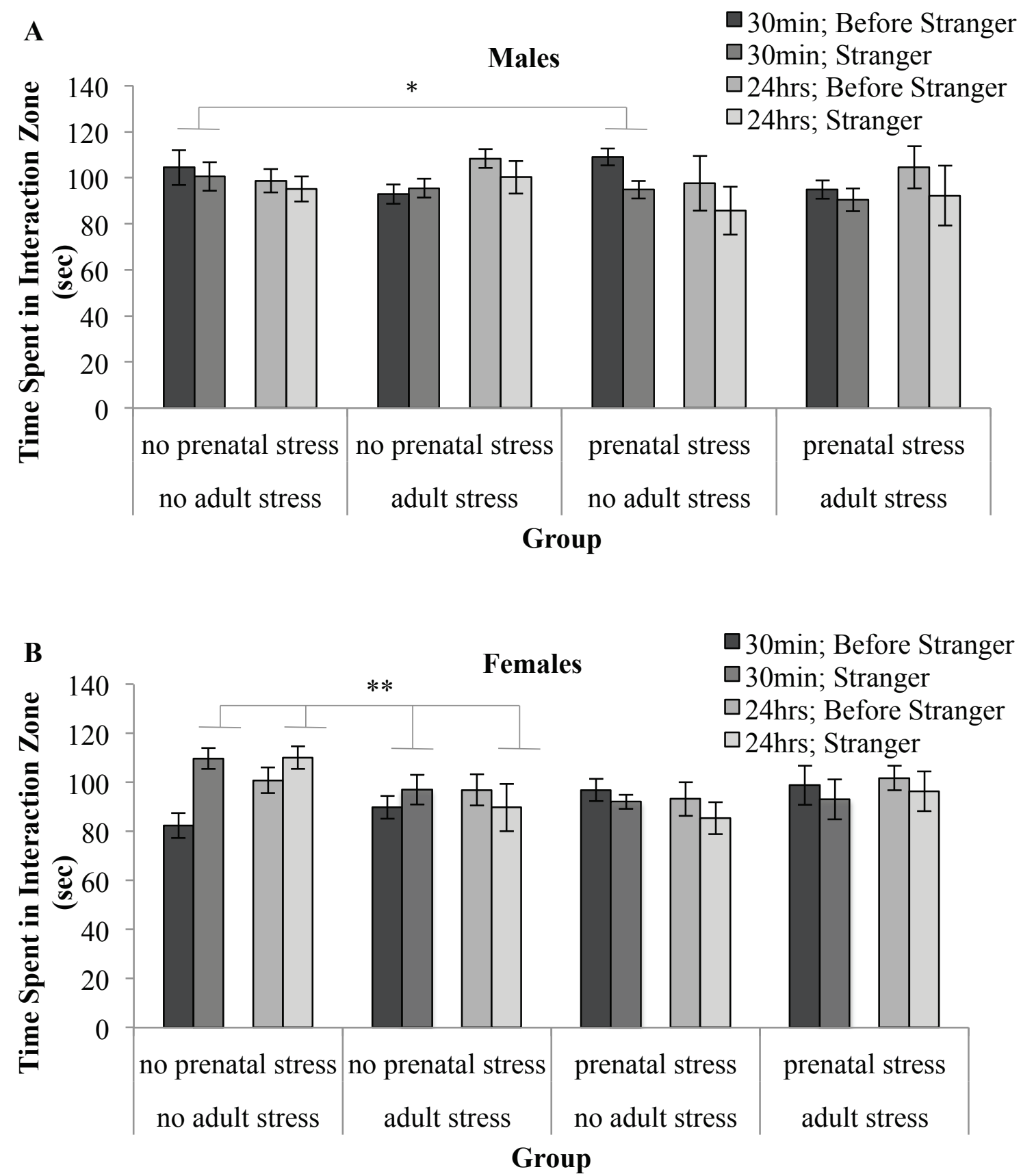

Time spent in interaction zone (seconds) of a social avoidance test among male (A) and female (B) mice tested 30 minutes and 24 hours following a stressor or control treatment in adulthood, and as a function of the prenatal stressor treatment. Data are represented by means \pm S.E.M. ${ }^{*} \mathrm{p}<.05$ relative to mice 30 minutes following adult stress. ${ }^{* *} \mathrm{p}<.05$ relative to prenatally stressed mice exposed to a novel mouse. 


\section{References}

Anisman, H., Gibb, J., \& Hayley, S. (2008). Influence of continuous infusion of interleukin-1beta on depression-related processes in mice: corticosterone, circulating cytokines, brain monoamines, and cytokine mRNA expression.

Psychopharmacology, 199(2), 231-244.

Anisman, H., \& Merali, Z. (2002). Cytokines, stress, and depressive illness. Brain, Behavior, and Immunity, 16(5), 513-524.

Arnsten, A. F. T., \& Rubia, K. (2012). Neurobiological circuits regulating attention, cognitive control, motivation, and emotion: disruptions in neurodevelopmental psychiatric disorders. Journal of the American Academy of Child and Adolescent Psychiatry, 51(4), 356-367.

Audet, M.-C., Jacobson-Pick, S., Wann, B. P., \& Anisman, H. (2011). Social defeat promotes specific cytokine variations within the prefrontal cortex upon subsequent aggressive or endotoxin challenges. Brain, Behavior, and Immunity, 25(6), 11971205.

Bakker, J., De Mees, C., Douhard, Q., Balthazart, J., Gabant, P., Szpirer, J., \& Szpirer, C. (2006). Alpha-fetoprotein protects the developing female mouse brain from masculinization and defeminization by estrogens. Nature Neuroscience, 9(2), 220226.

Baumeister, D., Lightman, S. L., \& Pariante, C. M. (2014). The Interface of Stress and the HPA Axis in Behavioural Phenotypes of Mental Illness.

Björkqvist, K. (2001). Social defeat as a stressor in humans. Physiology \& Behavior, $73(3), 435-442$. 
Bosch, O. J., Müsch, W., Bredewold, R., Slattery, D. A., \& Neumann, I. D. (2007). Prenatal stress increases HPA axis activity and impairs maternal care in lactating female offspring: implications for postpartum mood disorder.

Psychoneuroendocrinology, 32(3), 267-278.

Burke, H. M., Davis, M. C., Otte, C., \& Mohr, D. C. (2005). Depression and cortisol responses to psychological stress: a meta-analysis. Psychoneuroendocrinology, $30(9), 846-856$.

Buss, C., Davis, E. P., Shahbaba, B., Pruessner, J. C., Head, K., \& Sandman, C. A. (2012). PNAS Plus: Maternal cortisol over the course of pregnancy and subsequent child amygdala and hippocampus volumes and affective problems. Proceedings of the National Academy of Sciences, 109(20), 1312-1319.

Chaouloff, F. (2013). Social stress models in depression research: what do they tell us? Cell and Tissue Research, 354(1), 179-190.

Coe, C. L., Kramer, M., Kirschbaum, C., Netter, P., \& Fuchs, E. (2002). Prenatal stress diminishes the cytokine response of leukocytes to endotoxin stimulation in juvenile rhesus monkeys. The Journal of Clinical Endocrinology and Metabolism, 87(2), $675-681$.

Cooke, B., Hegstrom, C. D., Villeneuve, L. S., \& Breedlove, S. M. (1998). Sexual differentiation of the vertebrate brain: principles and mechanisms. Frontiers in Neuroendocrinology, 19(4), 323-362.

Corwin, E. J., Guo, Y., Pajer, K., Lowe, N., McCarthy, D., Schmiege, S., ... Stafford, B. (2013). Immune dysregulation and glucocorticoid resistance in minority and low income pregnant women. Psychoneuroendocrinology, 38(9), 1786-1796. 
Coussons-Read, M. E., Lobel, M., Carey, J. C., Kreither, M. O., D’Anna, K., Argys, L., ... Cole, S. (2012). The occurrence of preterm delivery is linked to pregnancyspecific distress and elevated inflammatory markers across gestation. Brain, Behavior, and Immunity, 26(4), 650-659.

Coussons-Read, M. E., Okun, M. L., Schmitt, M. P., \& Giese, S. (2005). Prenatal stress alters cytokine levels in a manner that may endanger human pregnancy. Psychosomatic Medicine, 67(4), 625-631.

Cratty, M. S., Ward, H. E., Johnson, E. A., Azzaro, A. J., \& Birkle, D. L. (1995). Prenatal stress increases corticotropin-releasing factor $(\mathrm{CRF})$ content and release in rat amygdala minces. Brain Research, 675(1-2), 297-302.

Dammann, O., \& Leviton, A. (1997). Maternal intrauterine infection, cytokines, and brain damage in the preterm newborn. Pediatric Research, 42(1), 1-8.

Davis, E. P., \& Sandman, C. A. (2010). The timing of prenatal exposure to maternal cortisol and psychosocial stress is associated with human infant cognitive development. Child Development, 81(1), 131-148.

DeSantis, D. T., \& Schmaltz, L. W. (1984). The mother-litter relationship in developmental rat studies: cannibalism vs caring. Developmental Psychobiology, 17(3), 255-262.

Deverman, B. E., \& Patterson, P. H. (2009). Cytokines and CNS development. Neuron, 64(1), 61-78.

Diaz, R., Brown, R. W., \& Seckl, J. R. (1998). Distinct ontogeny of glucocorticoid and mineralocorticoid receptor and 11 beta-hydroxysteroid dehydrogenase types I and II mRNAs in the fetal rat brain suggest a complex control of glucocorticoid actions. 
The Journal of Neuroscience: The Official Journal of the Society for Neuroscience, 18(7), 2570-2580.

Dunn, A. J. (2011). Cytokine Activation of the HPA axis. Annals of the New York Academy of Sciences, 917, 608-617.

Estanislau, C., \& Morato, S. (2005). Prenatal stress produces more behavioral alterations than maternal separation in the elevated plus-maze and in the elevated T-maze. Behavioural Brain Research, 163(1), 70-77.

Fortier, M.-E., Kent, S., Ashdown, H., Poole, S., Boksa, P., \& Luheshi, G. N. (2004). The viral mimic, polyinosinic:polycytidylic acid, induces fever in rats via an interleukin1-dependent mechanism. American Journal of Physiology. Regulatory, Integrative and Comparative Physiology, 287(4), 759-766.

Fujioka, A., Fujioka, T., Ishida, Y., Maekawa, T., \& Nakamura, S. (2006). Differential effects of prenatal stress on the morphological maturation of hippocampal neurons. Neuroscience, 141(2), 907-915.

Gądek-Michalska, A., Tadeusz, J., Rachwalska, P., \& Bugajski, J. (2013). Cytokines, prostaglandins and nitric oxide in the regulation of stress-response systems. Pharmacological Reports : PR, 65(6), 1655-1662.

Gangestad, S. W., Caldwell Hooper, A. E., \& Eaton, M. A. (2012). On the function of placental corticotropin-releasing hormone: a role in maternal-fetal conflicts over blood glucose concentrations. Biological Reviews of the Cambridge Philosophical Society, 87(4), 856-873. 
Glover, V., O’Connor, T. G., \& O’Donnell, K. (2010). Prenatal stress and the programming of the HPA axis. Neuroscience and Biobehavioral Reviews, 35(1), 1722.

Gluckman, P. D., Hanson, M. a, Spencer, H. G., \& Bateson, P. (2005). Environmental influences during development and their later consequences for health and disease: implications for the interpretation of empirical studies. Proceedings. Biological Sciences / The Royal Society, 272(1564), 671-677.

Grahn, R. E., Kalman, B. A., Brennan, F. X., Watkins, L. R., \& Maier, S. F. (1995). The elevated plus-maze is not sensitive to the effect of stressor controllability in rats. Pharmacology Biochemistry and Behavior, 52(3), 565-570.

Gutteling, B. M., Weerth, C., Willemsen-Swinkels, S. H. N., Huizink, A. C., Mulder, E. J. H., Visser, G. H. A., Buitelaar, J. K. (2005) The effects of prenatal stress on temperament nd problem behaviour of 27-month-old toddlers. European Child \& Adolesentc Psychiatry, 14, 41-51.

Haller, J., \& Bakos, N. (2002). Stress-induced social avoidance. Physiology \& Behavior, $77(2-3), 327-332$.

Harris, A., \& Seckl, J. (2011). Glucocorticoids, prenatal stress and the programming of disease. Hormones and Behavior, 59(3), 279-289.

Hava, G., Vered, L., Yael, M., Mordechai, H., \& Mahoud, H. (2006). Alterations in behavior in adult offspring mice following maternal inflammation during pregnancy. Developmental Psychobiology, 48(2), 162-168. 
Holladay, S. D., \& Smialowicz, R. J. (2000). Development of the murine and human immune system: differential effects of immunotoxicants depend on time of exposure. Environmental Health Perspectives, 108 Suppl, 463-473.

Howerton, C. L., \& Bale, T. L. (2012). Prenatal programing: at the intersection of maternal stress and immune activation. Hormones and Behavior, 62(3), 237-242.

Huang, H., Li, L., Wang, Y., Tang, L. Y., Wang, C. C., \& Leung, L. K. (2011). Genistein upregulates placental corticotropin-releasing hormone expression in lipopolysaccharide-sensitized mice. Placenta, 32(10), 757-762.

Jaferi, A., \& Bhatnagar, S. (2007). Corticotropin-releasing hormone receptors in the medial prefrontal cortex regulate hypothalamic-pituitary-adrenal activity and anxiety-related behavior regardless of prior stress experience. Brain Research, 1186, $212-223$.

Kaidanovich-Beilin, O., Lipina, T., Vukobradovic, I., Roder, J., \& Woodgett, J. R. (2011). Assessment of social interaction behaviors. Journal of Visualized Experiments : JoVE, (48).

Karteris, E., Grammatopoulos, D. K., Randeva, H. S., \& Hillhouse, E. W. (2001). The role of corticotropin-releasing hormone receptors in placenta and fetal membranes during human pregnancy. Molecular Genetics and Metabolism, 72(4), 287-296.

Keeney, A. J., Hogg, S., \& Marsden, C. A. (2001). Alterations in core body temperature, locomotor activity, and corticosterone following acute and repeated social defeat of male NMRI mice. Physiology \& Behavior, 74(1-2), 177-184. 
King, B. R., Smith, R., \& Nicholson, R. C. (2001). The regulation of human corticotrophin-releasing hormone gene expression in the placenta. Peptides, 22(11), $1941-1947$.

King, S., \& Laplante, D. P. (2005). The effects of prenatal maternal stress on children's cognitive development: Project Ice Storm. Stress, 8(1), 35-45.

Kinsley, C. \& Svare, B. (1987). Genotype modulates prenatal stress effects on aggression in male and female mice. Behav Neural Biol, 47(2), 138-150.

Kishimoto, T., Radulovic, J., Radulovic, M., Lin, C. R., Schrick, C., Hooshmand, F., ... Spiess, J. (2000). Deletion of crhr2 reveals an anxiolytic role for corticotropinreleasing hormone receptor-2. Nature Genetics, 24(4), 415-419.

Knackstedt, M. K., Hamelmann, E., \& Arck, P. C. (2005). Mothers in stress: consequences for the offspring. American Journal of Reproductive Immunology (New York, N.Y. : 1989), 54(2), 63-69.

Kofman, O. (2002). The role of prenatal stress in the etiology of developmental behavioural disorders. Neuroscience and Biobehavioral Reviews, 26(4), 457-470.

Lau, C., Rogers, J. M., Desai, M., \& Ross, M. G. (2011). Fetal programming of adult disease: implications for prenatal care. Obstetrics and Gynecology, 117(4), 978-985.

Madden, S. D., \& Cotter, T. G. (2008). Cell death in brain development and degeneration: control of caspase expression may be key! Molecular Neurobiology, $37(1), 1-6$.

Marcondes, F. K., Miguel, K. J., Melo, L. L., \& Spadari-Bratfisch, R. C. (2001). Estrous cycle influences the response of female rats in the elevated plus-maze test. Physiology \& Behavior, 74(4-5), 435-440. 
Marques, A. H., O’Connor, T. G., Roth, C., Susser, E., \& Bjørke-Monsen, A.-L. (2013). The influence of maternal prenatal and early childhood nutrition and maternal prenatal stress on offspring immune system development and neurodevelopmental disorders. Frontiers in Neuroscience, 7, 120.

Martini, L., \& Melcangi, R. C. (1991). Androgen metabolism in the brain. The Journal of Steroid Biochemistry and Molecular Biology, 39(5B), 819-828.

McTernan, C. L., Draper, N., Nicholson, H., Chalder, S. M., Driver, P., Hewison, M., ... Hospital, Q. E. (2001). Reduced placental 11ß-hydroxysteroid dehydrogenase type 2 mRNA levels in human pregnancies complicated by intrauterine growth Restriction: an analysis of possible mechanisms, The Journal of Clinical Endocrinology \& Metabolism, 86(10), 4979-4983.

Merlot, E., Couret, D., \& Otten, W. (2008). Prenatal stress, fetal imprinting and immunity. Brain, Behavior, and Immunity, 22(1), 42-51.

Mesquita, A. R., Correia-Neves, M., Roque, S., Castro, A. G., Vieira, P., Pedrosa, J., ... Sousa, N. (2008). IL-10 modulates depressive-like behavior. Journal of Psychiatric Research, 43(2), 89-97.

Meyer, U., Feldon, J., \& Yee, B. K. (2009). A review of the fetal brain cytokine imbalance hypothesis of schizophrenia. Schizophrenia Bulletin, 35(5), 959-972.

Meyer, U., Murray, P. J., Urwyler, A., Yee, B. K., Schedlowski, M., \& Feldon, J. (2008). Adult behavioral and pharmacological dysfunctions following disruption of the fetal brain balance between pro-inflammatory and IL-10-mediated anti-inflammatory signaling. Molecular Psychiatry, 13(2), 208-221. 
Mor, G., \& Cardenas, I. (2010). The immune system in pregnancy: a unique complexity. American Journal of Reproductive Immunology (New York, N.Y. : 1989), 63(6), $425-433$.

Müller, M. B., \& Wurst, W. (2004). Getting closer to affective disorders: the role of CRH receptor systems. Trends in Molecular Medicine, 10(8), 409-415.

Munck, A., Guyre, P. M., \& Holbrook, N. J. (1984). Physiological functions of glucocorticoids in stress and their relation to pharmacological actions. Endocrine Reviews, 5(1), 25-44.

Najjar, S., Pearlman, D. M., Alper, K., Najjar, A., \& Devinsky, O. (2013). Neuroinflammation and psychiatric illness. Journal of Neuroinflammation, 10, 43.

Nkansah-Amankra, S., Luchok, K. J., Hussey, J. R., Watkins, K., \& Liu, X. (2010). Effects of maternal stress on low birth weight and preterm birth outcomes across neighborhoods of South Carolina, 2000-2003. Maternal and Child Health Journal, $14(2), 215-226$.

Pace, T. W. W., Hu, F., \& Miller, A. H. (2007). Cytokine-effects on glucocorticoid receptor function: relevance to glucocorticoid resistance and the pathophysiology and treatment of major depression. Brain, Behavior, and Immunity, 21(1), 9-19.

Pallarés, M. E., Scacchi Bernasconi, P. A, Feleder, C., \& Cutrera, R. A. (2007). Effects of prenatal stress on motor performance and anxiety behavior in Swiss mice. Physiology \& Behavior, 92(5), 951-956.

Pariante, C. M., \& Lightman, S. L. (2008). The HPA axis in major depression: classical theories and new developments. Trends in Neurosciences, 31(9), 464-468. 
Sandman, C. A., Glynn, L. M., \& Davis, E. P. (2013). Is there a viability-vulnerability tradeoff? Sex dfferences in fetal programming. Journal of Psychosomatic Research. $75,327-335$.

Sandman, C. A, Davis, E. P., Buss, C., \& Glynn, L. M. (2011). Prenatal programming of human neurological function. International Journal of Peptides.

Saunders, N., Habgood, M., \& Dziegielewska, K. (1999). Barrier mechanisms in the brain, I. Adult brain. Clinical and Experimental Pharmacology and Physiology, $26(1), 11-19$.

Seckl, J. R. (2004). Prenatal glucocorticoids and long-term programming. European Journal of Endocrinology / European Federation of Endocrine Societies, 151 Suppl, 49-62.

Shin, L. M., Rauch, S. L., \& Pitman, R. K. (2006). Amygdala, medial prefrontal cortex, and hippocampal function in PTSD. Annals of the New York Academy of Sciences, $1071,67-79$.

Strle, K., Zhou, J.-H., Shen, W.-H., Broussard, S. R., Johnson, R. W., Freund, G. G., ... Kelley, K. W. (2001). Interleukin-10 in the Brain. Critical Reviews ${ }^{T M}$ in Immunology, 21(5), 23.

Szuran, T. F., Pliska, V., Pokorny, J., \& Welzl, H. (2000). Prenatal stress in rats: effects on plasma corticosterone, hippocampal glucocorticoid receptors, and maze performance. Physiology \& Behavior, 71(3-4), 353-362.

Talge, N. M., Neal, C., \& Glover, V. (2007). Antenatal maternal stress and long-term effects on child neurodevelopment: how and why? Journal of Child Psychology and Psychiatry, and Allied Disciplines, 48(3-4), 245-261. 
Toder, V., Fein, A., Carp, H., \& Torchinsky, A. (2003). A Symposium on Reproductive Immunology TNF- $\alpha$ in Pregnancy Loss and Embryo Maldevelopment: A Mediator of Detrimental Stimuli or a Protector of the Fetoplacental Unit?, 20(2).

Van den Hove, D. L. A., Kenis, G., Brass, A., Opstelten, R., Rutten, B. P. F., Bruschettini, M., ... Prickaerts, J. (2013). Vulnerability versus resilience to prenatal stress in male and female rats; implications from gene expression profiles in the hippocampus and frontal cortex. European Neuropsychopharmacology, 23, 12261246.

Van den Hove, D. L. A., Lauder, J. M., Scheepens, A., Prickaerts, J., Blanco, C. E., \& Steinbusch, H. W. M. (2006). Prenatal stress in the rat alters 5-HT1A receptor binding in the ventral hippocampus. Brain Research, 1090(1), 29-34.

Van den Hove, D. L. A., Steinbusch, H. W. M., Scheepens, a, Van de Berg, W. D. J., Kooiman, L. A. M., Boosten, B. J. G., ... Blanco, C. E. (2006). Prenatal stress and neonatal rat brain development. Neuroscience, 137(1), 145-155.

Wang, H., \& Dey, S. K. (2006). Roadmap to embryo implantation: clues from mouse models. Nature Reviews. Genetics, 7(3), 185-199.

Watkins, L. R., Maier, S. F., \& Goehler, L. E. (1995). Cytokine-to-brain communication: A review \& analysis of alternative mechanisms. Life Sciences, 57(11), 1011-1026.

Weinstock, M. (2001). Alterations induced by gestational stress in brain morphology and behaviour of the offspring. Progress in Neurobiology, 65(5), 427-451.

Weinstock, M. (2008). The long-term behavioural consequences of prenatal stress. Neuroscience and Biobehavioral Reviews, 32(6), 1073-1086. 
Weinstock, M. (2011). Sex-dependent changes induced by prenatal stress in cortical and hippocampal morphology and behaviour in rats: an update. Stress (Amsterdam, Netherlands), 14(6), 604-613.

Weisz, J., Brown, B. L., \& Ward, I. L. (1982). Maternal stress decreases steroid aromatase activity in brains of male and female rat fetuses. Neuroendocrinology, $35(5), 374-379$.

Xiong, F., \& Zhang, L. (2013). Role of the hypothalamic-pituitary-adrenal axis in developmental programming of health and disease. Frontiers in Neuroendocrinology, 34(1), 27-46.

Xu, L., Sun, Y., Gao, L., Cai, Y.-Y., \& Shi, S.-X. (2014). Prenatal Restraint Stress is Associated with Demethylation of Corticotrophin Releasing Hormone (CRH) Promoter and Enhances CRH Transcriptional Responses to Stress in Adolescent Rats. Neurochemical Research, 39(7), 1193-1198.

Zohar, I., \& Weinstock, M. (2011). Differential effect of prenatal stress on the expression of corticotrophin-releasing hormone and its receptors in the hypothalamus and amygdala in male and female rats. Journal of Neuroendocrinology, 23(4), 320-328.

Zubareva, O. E., \& Klimenko, V. M. (2013). Increases in Proinflammatory Cytokine Levels at Early Ages as a Risk Factor for the Development of Nervous and Mental Pathology. Neuroscience and Behavioral Physiology, 43(4), 535-541.

Zuena, A. R., Mairesse, J., Casolini, P., Cinque, C., Alemà, G. S., Morley-Fletcher, S., ... Maccari, S. (2008). Prenatal restraint stress generates two distinct behavioral and neurochemical profiles in male and female rats. PloS One, 3(5), 2170. 